\title{
Analysis of ER-12-3 \\ FY 2005 Hydrologic Testing, \\ Nevada Test Site, \\ Nye County, Nevada
}

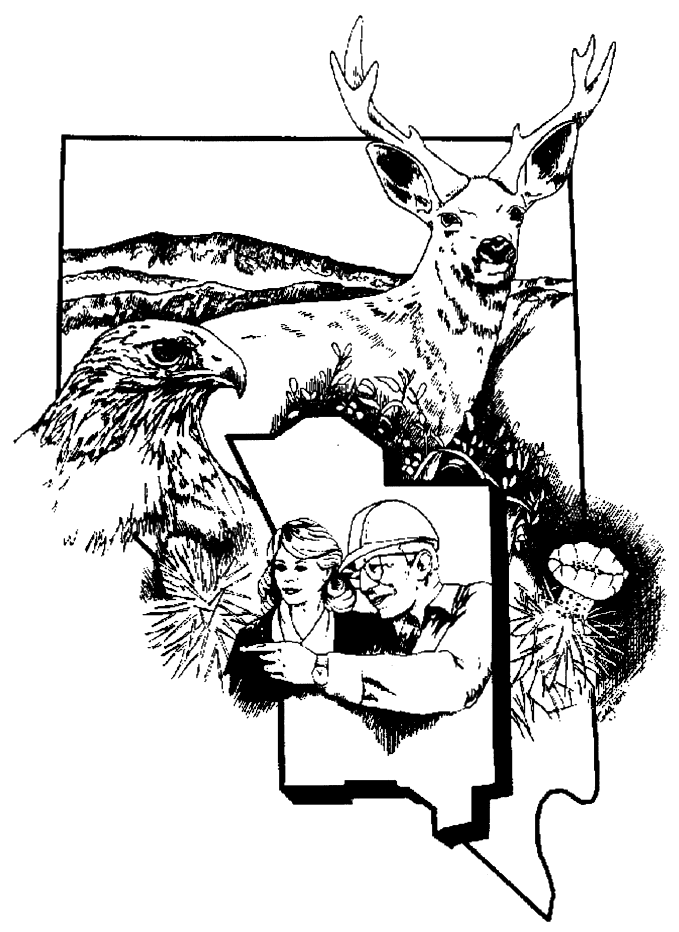

Revision No.: 0

July 2006

Prepared for U.S. Department of Energy under Contract No. DE-AC52-03NA99205

Approved for public release; further distribution is authorized. 
Available for sale to the public from:

\title{
U.S. Department of Commerce
}

National Technical Information Service

5285 Port Royal Road

Springfield, VA 22161

Phone: 800.553.6847

Fax: 703.605.6900

Email: orders@ntis.gov

Online ordering: http://www.ntis.gov/ordering.htm

Available electronically at $\underline{h t t p: / / w w w . o s t i . g o v / b r i d g e ~}$

Available for a processing fee to U.S. Department of Energy and its contractors, in paper, from:

\author{
U.S. Department of Energy \\ Office of Scientific and Technical Information \\ P.O. Box 62 \\ Oak Ridge, TN 37831-0062 \\ Phone: 865.576.8401 \\ Fax: 865.576 .5728 \\ Email: reports@adonis.osti.gov
}

Reference herein to any specific commercial product, process, or service by trade name, trademark, manufacturer, or otherwise, does not necessarily constitute or imply its endorsement, recommendation, or favoring by the United States Government or any agency thereof or its contractors or subcontractors. 


\section{ANALYSIS OF ER-12-3 FY 2005 HYDROLOGIC TESTING, NEVADA TEST SITE, NYE COUNTY, NEVADA}

Contributors:

Stoller-Navarro Joint Venture

Irene Farnham

$\underline{\text { S.M. Stoller Corporation }}$

William Fryer

Paul Domski

Revision No.: 0

July 2006

Stoller-Navarro Joint Venture

7710 W. Cheyenne, Building 3

Las Vegas, NV 89129 


\section{ANALYSIS OF ER-12-3 FY 2005 HYDROLOGIC TESTING, NEVADA TEST SITE, NYE COUNTY, NEVADA}




\section{TABLE OF CONTENTS}

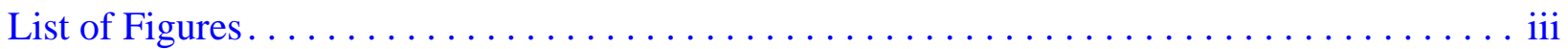

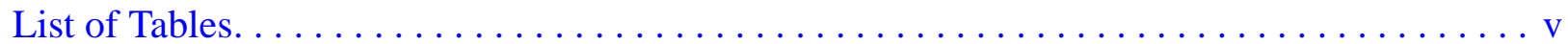

List of Acronyms and Abbreviations $\ldots \ldots \ldots \ldots \ldots \ldots \ldots \ldots \ldots \ldots \ldots \ldots \ldots \ldots$

$1.0 \quad$ Introduction. . . . . . . . . . . . . . . . . . . . . . . .

$1.1 \quad$ ER-12-3 Specifications . . . . . . . . . . . . . . . . . . . .

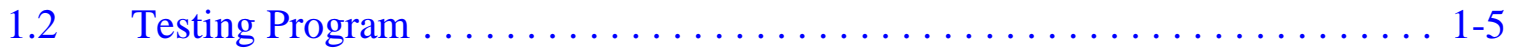

1.3 Analysis Objectives and Goals . . . . . . . . . . . . . . . . . . . . . . . . . . . . .

1.4 Report Organization . . . . . . . . . . . . . . . . . . . . . . .

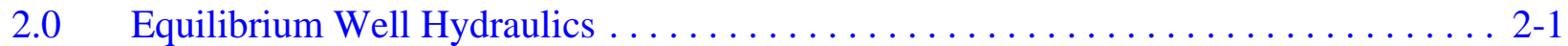

2.1 Representative Formation Head . . . . . . . . . . . . . . . . . 2-1

2.1.1 Water-Level Monitoring. ..................... 2-1

2.1.2 Continuous Water-Level Monitoring . . . . . . . . . . . . . . . 2-5

2.1.3 Vertically Discrete Water-Level Measurements . . . . . . . . . . . . . 2-6

2.2 Flow in the Well Under Natural Gradient . . . . . . . . . . . . . . . . . . . 2-7

2.2.1 Non-Pumping Temperature Profiles. . . . . . . . . . . . . . 2-7

2.2.2 Non-Pumping Flow Logs . . . . . . . . . . . . . . . . . . . . . . 2-10

2.2.3 Flow Interpretation. . . . . . . . . . . . . . . . . . . . . 2-11

2.3 Barometric Efficiency. . . . . . . . . . . . . . . . . . . . . 2-12

2.3.1 Barometric Efficiency Analysis . . . . . . . . . . . . . . . 2-12

2.3.2 Static Formation Head Versus Static Water Level. . . . . . . . . . . . . . 2-13

3.0 Pumping-Well Hydraulics $\ldots \ldots \ldots \ldots \ldots \ldots \ldots \ldots \ldots \ldots \ldots \ldots \ldots \ldots \ldots \ldots \ldots$

3.1 Processing of the Water-Level Monitoring Record . . . . . . . . . . . . 3-1

3.1.1 Background Water-Level Monitoring Record . . . . . . . . . . . . . . 3-2

3.1.2 Barometric Pressure Changes and Earth Tides . . . . . . . . . . . . . 3-2

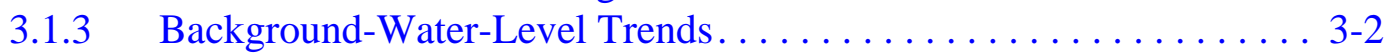

3.1 .4 Well Losses . . . . . . . . . . . . . . . . . . . . . . . . . . 3-3

3.1.5 Effects of Temperature Profile Changes . . . . . . . . . . . . . 3-3

3.2 Pumping-Test Analysis. . . . . . . . . . . . . . . . . . . . . . 3-4

3.2.1 Method of Analysis . . . . . . . . . . . . . . . . . . . 3-5

3.2.2 Conceptual Model . . . . . . . . . . . . . . . . . . 3-7

3.2.3 Hydraulic Response Analysis. . . . . . . . . . . . . . . . . . . 3-9

3.2.4 Best-Fit Parameter Estimates and Uncertainty. . . . . . . . . . . . . . . 3-10

3.3 Interpretation and Analysis of Measured Discrete Production . . . . . . . . . 3-12

3.3.1 Temperature Profiles During Pumping . . . . . . . . . . . . 3-13

3.3.2 Flow Logging During Pumping . . . . . . . . . . . . . . 3-13

3.3.3 Hydraulic Conductivity Estimates . . . . . . . . . . . . . . . . . 3-16

3.4 Summary.......................

4.0 Groundwater Chemistry . . . . . . . . . . . . . . . . .

4.1 ER-12-3 Groundwater Characterization Sample Results . . . . . . . . . . . . 4-1 


\section{TABLE of Contents (Continued)}

4.1.1 Major, Minor, and Trace Constituents and Physical Parameters . . . . 4 4-2

4.1.2 Environmental Isotopes . . . . . . . . . . . . . . . . 4-7

4.1.3 Radionuclide Contaminants ..................... 4-8

4.1 .4 Colloids. . . . . . . . . . . . . . . . . . . . . . . . . 4-8

4.2 Comparison of ER-12-3 Groundwater Chemistry to Surrounding Wells. .... . 4-9

4.3 Restoration of Natural Groundwater Quality . . . . . . . . . . . . . . . . 4-15

4.4 Source Formation(s) of Groundwater Samples . . . . . . . . . . . . . 4-16

4.5 Representativeness of Water Chemistry Results . . . . . . . . . . . 4 4-16

4.6 Use of ER-12-3 for Future Monitoring. . . . . . . . . . . . . . . . . . 4-17

5.0 Review of the Testing Program and Analysis $\ldots \ldots \ldots \ldots \ldots \ldots \ldots \ldots \ldots$ 5 1

5.1 Comments on Well Design. . . . . . . . . . . . . . . . . . . 5 -1

5.2 Comments on Well Testing Program . . . . . . . . . . . . . . . . 5-2

5.2.1 Pre-Test and Post-Test Monitoring Records . . . . . . . . . . . . . . 5-2

5.2.2 Background Well Monitoring Record . . . . . . . . . . . . . 5-3

5.2.3 Recovery Monitoring after the Constant-Rate Test . . . . . . . . . . . 5-3

$5.3 \quad$ Further Testing . . . . . . . . . . . . . . . . . . .

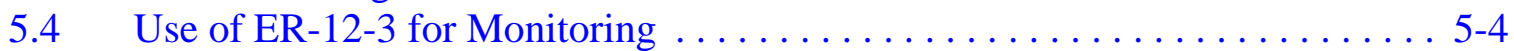

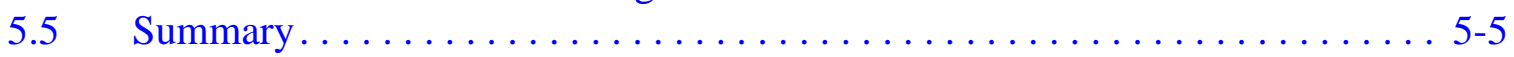

$6.0 \quad$ References................................. 6-1

A.1.0 Wellbore Deviation Surveys. . . . . . . . . . . . . . . . . . . A-1 


\section{LIST OF FIGURES}

NUMBER

TITLE

PAGE

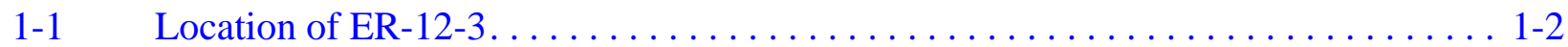

1-2 ER-12-3, Tunnels, and Selected Nearby Wells and Drillholes $\ldots \ldots \ldots \ldots \ldots \ldots$

1-3 ER-12-3 Well Completion . . . . . . . . . . . . . . . . . . . . 1-6

2-1 ER-12-3 Main Completion Water Levels. . . . . . . . . . . . . . . . . . . . 2-4

2-2 ER-12-3 Piezometer Water Levels. . . . . . . . . . . . . . . . . . . . . . . . . . . . 2-4

2-3 ER-12-1 Upper Completion Water Levels. . . . . . . . . . . . . . . . . . . . 2-5

2-4 Ambient Temperature and Flow Profiles for ER-12-3. . . . . . . . . . 2-8

3-1 ER-12-3 Complete Hydraulic Testing Stress Periods . . . . . . . . . . . . . 3-18

3-2 ER-12-3 Testing Program Observed Water-Level Response. . . . . . . . . . . . . 3-18

3-3 Stress Period F_02 Pressure Response Derivative $\ldots \ldots \ldots \ldots \ldots \ldots \ldots \ldots \ldots$. . . . . . . . .

3-4 Stress Period F_03 Pressure Response Derivative . . . . . . . . . . . . . . . . . 3-19

3-5 Stress Period F_04 Pressure Response Derivative . . . . . . . . . . . . . . 3-20

3-6 Stress Period F_05 Pressure Response Derivative . . . . . . . . . . . . . . . . . . . . 3-20

3-7 Stress Period F_06 Pressure Response Derivative . . . . . . . . . . . . . . . . 3-21

3-8 Stress Period F_07 Pressure Response Derivative . . . . . . . . . . . . . . . . . 3-21

3-9 Water-Level Response Used for Hydraulic Analysis. . . . . . . . . . . . . . . . . . 3-22

3-10 Perturbation Analysis . . . . . . . . . . . . . . . . . . . . . . . . . . . . . 3-22

3-11 Sum of Squared Errors for Static Formation Pressure Versus Transmissivity . . . . 3-23

3-12 Sum of Squared Errors for Skin Versus Specific Storage . . . . . . . . . . . . . . 3-23

3-13 Pumping Temperature and Flow Profiles for ER-12-3 . . . . . . . . . . . . 3-24

3-14 Abstracted Flow Profiles for ER-12-3 . . . . . . . . . . . . . . . . . . . . . . . . . 3-24

3-15 Schematic of Flow and Temperature Regimes in ER-12-3 . . . . . . . . . . . 3-25 


\section{LIST OF FIGURES (CONTINUED)}

NUMBER

4-1 Piper Diagram Showing Relative Major Ion Percentages for

Groundwater from ER-12-3 and Vicinity. . . . . . . . . . . . . . 4-14

4-2 Stable Isotope Composition for ER-12-3 and Vicinity . . . . . . . . . . . 4-15 


\section{LIST OF TABLES}

NUMBER

TITLE

PAGE

1-1 Summary of Work Performed at ER-12-3. . . . . . . . . .

2-1 ER-12-3 Water-Level Measurements $\ldots \ldots \ldots \ldots \ldots \ldots \ldots \ldots \ldots \ldots \ldots \ldots \ldots \ldots$

3-1 Estimated $\mathrm{T}$ Values for the Hydraulic Test Periods $\ldots \ldots \ldots \ldots \ldots \ldots \ldots \ldots$. . . . .

3-2 Estimated Parameters for the ER-12-3 Hydraulic Test . . . . . . . . . . . . . . . . . 3-10

3-3 Depth to Water. . . . . . . . . . . . . . . . . . . . . . .

3-4 Hydraulic Conductivity Estimates. . . . . . . . . . . . . . . . . . . . 3-16

4-1 Analytical Results for Groundwater Characterization Samples at ER-12-3 . . . . . 4 4-3

4-2 Additional Analyses Results for ER-12-3 Wellhead Composite Samples . . . . . . 4 4-5

4-3 Colloid Analyses for ER-12-3 Composite Wellhead Samples . . . . . . . . . . . 4-9

4-4 Groundwater Chemistry Data for ER-12-3 and Surrounding Area . . . . . . . . . . 4-10

A.1-1 EMI Logs with Borehole Deviation Information $\ldots \ldots \ldots \ldots \ldots \ldots \ldots \ldots \ldots$ A-1 


\section{LIST OF ACRONYMS AND ABBREVIATIONS}

\begin{tabular}{|c|c|}
\hline amsl & Above mean sea level \\
\hline ATCU & Argillic tuff confining unit \\
\hline atoms/g & Atoms per gram \\
\hline $\mathrm{BE}$ & Barometric efficiency \\
\hline bgs & Below ground surface \\
\hline $\mathrm{BN}$ & Bechtel Nevada \\
\hline $\mathrm{Br}^{-}$ & Bromide \\
\hline BRA & Belted Range aquifer \\
\hline${ }^{14} \mathrm{C}$ & Carbon-14 \\
\hline${ }^{\circ} \mathrm{C}$ & Degrees Celsius \\
\hline CA & Carbonate aquifer \\
\hline $\mathrm{CaCO}_{3}$ & Calcium carbonate \\
\hline CAU & Corrective Action Unit \\
\hline $\mathrm{Cl}$ & Chlorine \\
\hline $\mathrm{cm}$ & Centimeter \\
\hline CS & Carbon steel \\
\hline DOE & U.S. Department of Energy \\
\hline DRI & Desert Research Institute \\
\hline EMAX & EMAX Laboratories, Inc. \\
\hline EMI & Electric Micro-Imaging \\
\hline $\mathrm{ft}$ & Foot \\
\hline $\mathrm{ft} / \mathrm{d}$ & Feet per day \\
\hline $\mathrm{ft}^{2} / \mathrm{d}$ & Square feet per day \\
\hline $\mathrm{ft} / \mathrm{min}$ & Feet per minute \\
\hline FY & Fiscal year \\
\hline gpm & Gallons per minute \\
\hline GTFM & Graph Theoretic Field Model \\
\hline $\mathrm{HCO}_{3}$ & Bicarbonate \\
\hline $\mathrm{He}$ & Helium \\
\hline
\end{tabular}




\section{List of ACRONYMS AND ABbreVIATIONS (CONTINUED)}

HGU Hydrogeologic unit

HSU Hydrostratigraphic unit

in. Inch

K Hydraulic conductivity

kt Kiloton

LANL $\quad$ Los Alamos National Laboratory

LCA Lower carbonate aquifer

LCA3 Lower carbonate aquifer-thrust plate

$\mathrm{LiBr} \quad$ Lithium bromide

LLNL Lawrence Livermore National Laboratory

LTCU Lower tuff confining unit

$\mathrm{m} \quad$ Value of the stabilized derivative

$\mathrm{mg} / \mathrm{L} \quad$ Milligrams per liter

MGCU Mesozoic granite confining unit

N/A Not applicable

NAD North American Datum

nm Nanometer

NNSA/NSO U.S. Department of Energy, National Nuclear Security Administration Nevada Site Office

NTS Nevada Test Site

nSights n-Dimensional Statistical Inverse Graphical Hydraulic Test Simulator

OSBCU Oak Spring Butte confining unit

P Pressure

PAI Paragon Analytics, Inc.

particles/mL Particles per milliliter

pCi/L Picocuries per liter

pmc Percent modern carbon

ppb Parts per billion

psi Pounds per square inch 


\section{LIST OF ACRONYMS AND ABBREVIATIONS (CONTINUED)}

PXD Pressure transducer

S

Storativity

SNJV

Stoller-Navarro Joint Venture

SNL Sandia National Laboratories

$\mathrm{Sr}$

Strontium

Ss

Specific storage

SS

Stainless steel

SSE

Sum of squared errors

SU

Standard unit

$\mathrm{T}$

Transmissivity

TCU Tuff confining unit

TD Total depth

TFM Thermal flowmeter tool

TMVTA Timber Mountain vitric tuff aquifer

TMWTA Timber Mountain welded tuff aquifer

U Uranium

UCCU Upper clastic confining unit

UGTA Underground Test Area

USGS U.S. Geological Survey

UTM Universal Transverse Mercator

VTA Vitric tuff aquifer

WTA Welded tuff aquifer

$\delta^{13} \mathrm{C} \quad$ Delta carbon-13

$\delta \mathrm{D} \quad$ Delta deuterium

$\delta^{18} \mathrm{O} \quad$ Delta oxygen-18

$\mu \mathrm{g} / \mathrm{L} \quad$ Micrograms per liter

$\mu \mathrm{S} / \mathrm{cm} \quad$ MicroSiemens per centimeter 


\subsection{INTRODUCTION}

This report documents the analysis of data collected for ER-12-3 during the fiscal year (FY) 2005 Rainier Mesa/Shoshone Mountain well development and hydraulic testing program (herein referred to as the "testing program"). Well ER-12-3 was constructed and tested as a part of the Corrective Action Unit (CAU) 99, Rainier Mesa/Shoshone Mountain, Phase I drilling program during FY 2005. These activities were conducted on behalf of the U.S. Department of Energy (DOE), National Nuclear Security Administration Nevada Site Office (NNSA/NSO) for the Underground Test Area (UGTA) Project.

As shown on Figure 1-1, ER-12-3 is located in central Rainier Mesa, in Area 12 of the Nevada Test Site (NTS). Figure 1-2 shows the well location in relation to the tunnels under Rainier Mesa. The well was drilled to a total depth (TD) of 4,908 feet (ft) below ground surface (bgs) (surface elevation 7,390.8 $\mathrm{ft}$ above mean sea level [amsl]) in the area of several tunnels mined into Rainier Mesa that were used historically for nuclear testing (NNSA/NSO, 2006). The closest nuclear test to the well location was YUBA (U-12b.10), conducted in the U-12b Tunnel approximately 1,529 ft northeast of the well site. The YUBA test working point elevation was located at approximately 6,642 ft amsl. The YUBA test had an announced yield of 3.1 kilotons (kt) (SNJV, 2006b).

The purpose of this hydrogeologic investigation well is to evaluate the deep Tertiary volcanic section below the tunnel level, which is above the regional water table, and to provide information on the section of the lower carbonate aquifer-thrust plate (LCA3) located below the Tertiary volcanic section (SNJV, 2005b). Details on the drilling and completion program are presented in the Completion Report for Well ER-12-3 Corrective Action Unit 99: Rainier Mesa - Shoshone Mountain (NNSA/NSO, 2006).

Development and hydraulic testing of ER-12-3 took place between June 3 and July 22, 2005. The development objectives included removing residual drilling fluids and improving the hydraulic connection of the well within the lower carbonate aquifer (LCA). The hydraulic testing objectives 


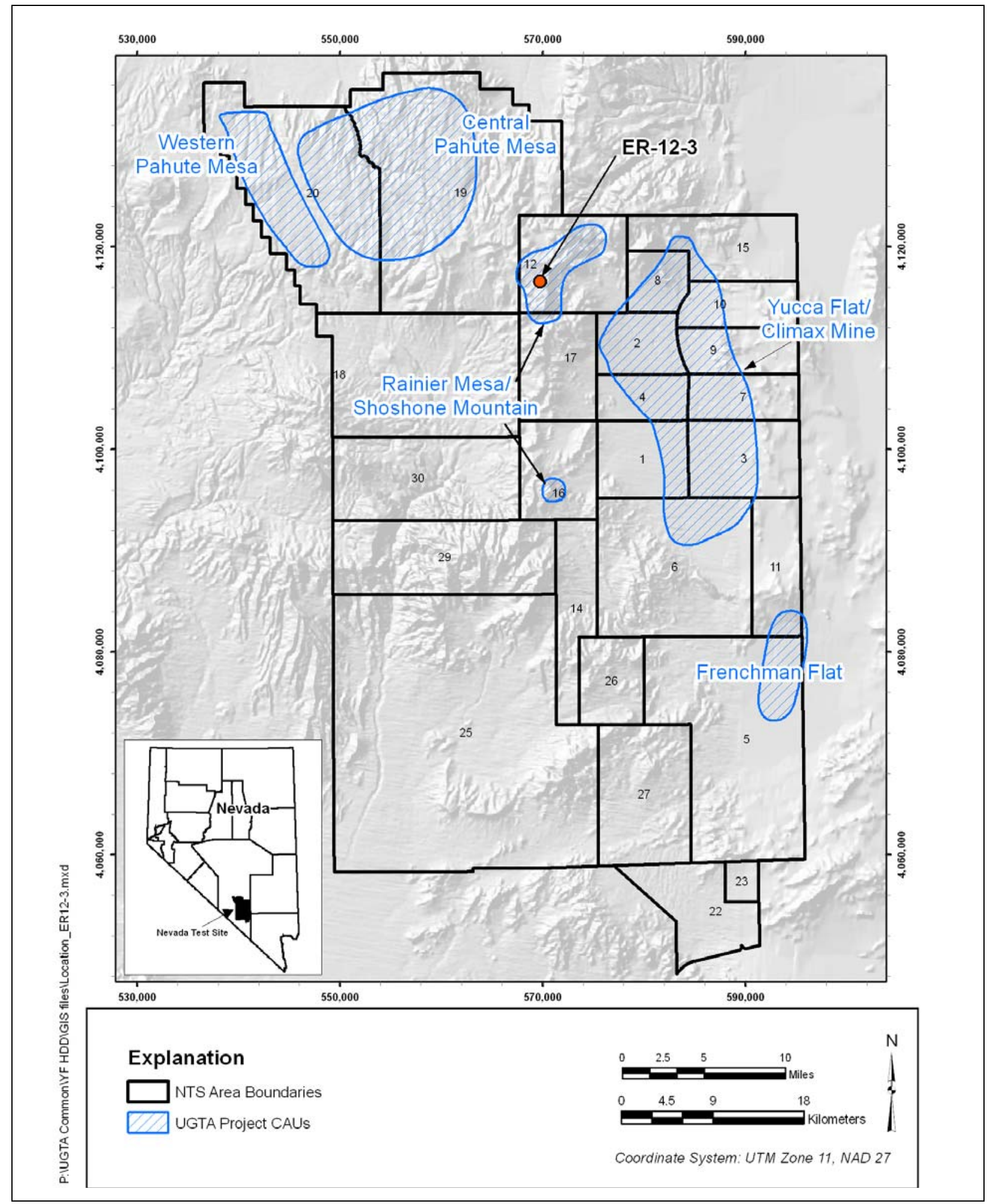

Figure 1-1

Location of ER-12-3 


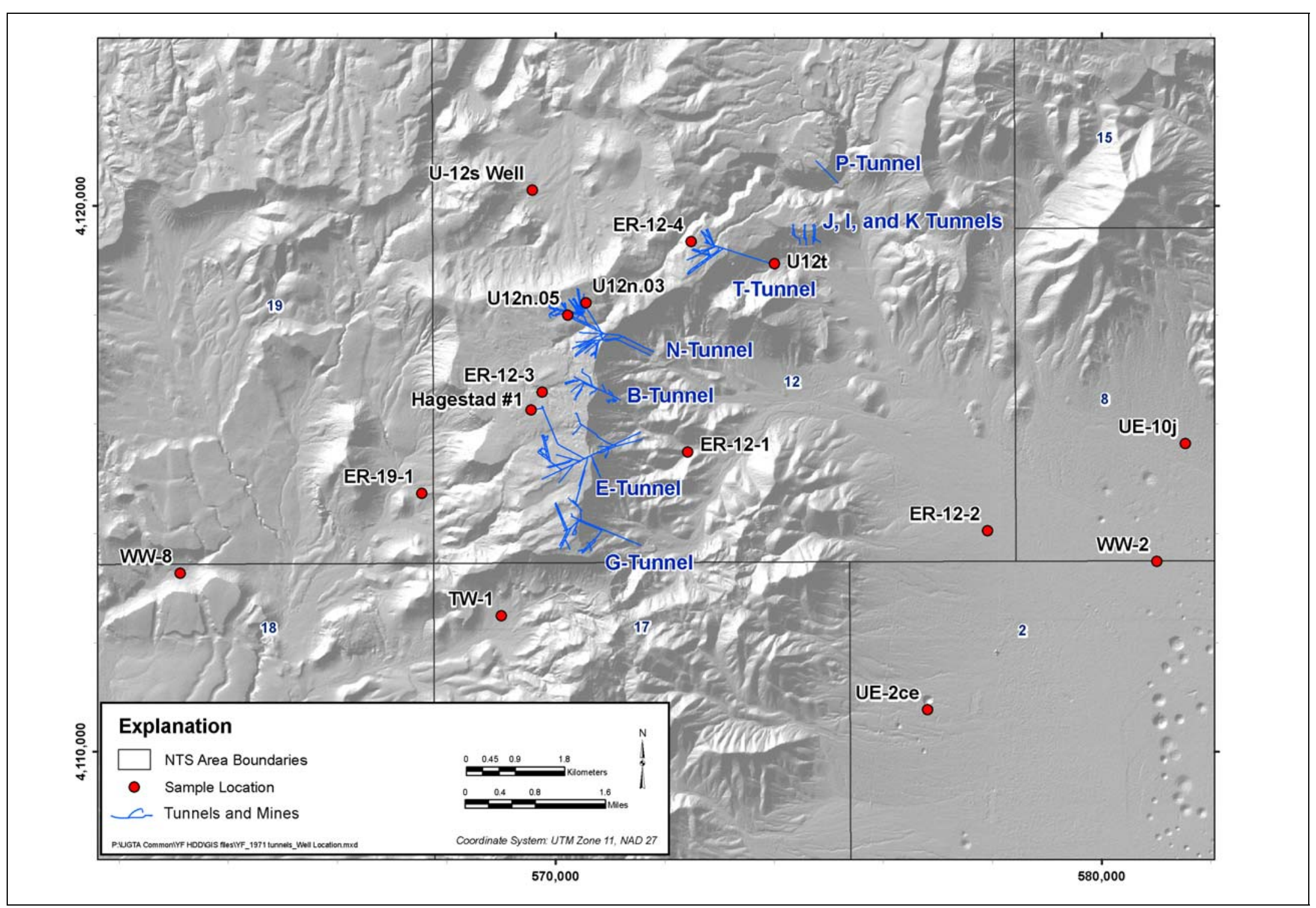

Figure 1-2

ER-12-3, Tunnels, and Selected Nearby Wells and Drill Holes 
focused on obtaining further hydrogeologic, geochemical, and radiochemical data for the site. Details on the data collected during the testing program are presented in the report Rainier Mesa Well ER-12-3 Data Report for Well Development and Hydraulic Testing (SNJV, 2006b).

Participants in ER-12-3 testing activities were: Stoller-Navarro Joint Venture (SNJV), Bechtel Nevada (BN), Desert Research Institute (DRI), Los Alamos National Laboratory (LANL), Lawrence Livermore National Laboratory (LLNL), and the U.S. Geological Survey (USGS). Stoller-Navarro Joint Venture served as the lead contractor responsible for providing site supervision, development and testing services, and waste management services; BN provided construction and engineering support services; DRI provided well logging services and participated in groundwater sampling and laboratory analyses; LANL and LLNL participated in groundwater sampling and laboratory analyses; and the USGS performed laboratory analyses. Analyses of data from the ER-12-3 testing program presented in this document were performed by SNJV except as noted.

\subsection{ER-12-3 Specifications}

Well ER-12-3 was drilled to a TD of 4,908 ft bgs between March 16 and April 28, 2005, using conventional rotary drilling equipment with direct air-foam circulation. Upon reaching an intermediate depth of 2,622 ft bgs, 13.375-inch (in.) carbon-steel (CS) surface casing was installed to a depth of 2,438 ft bgs and cemented in place at the bottom. A 2.375-in. CS piezometer was installed between the 13.375-in. CS surface casing and the borehole wall, accessing upper volcanic hydrostratigraphic units (HSUs). The piezometer was installed to a depth of 1,532.5 ft bgs, and the bottom $118 \mathrm{ft}$ of the string is slotted. Upon reaching a TD of 4,908 ft bgs, the well was completed with 7.625-in. CS production casing with internal epoxy coating from the surface to 3,502.8 $\mathrm{ft}$ bgs; a stainless-steel (SS) crossover from 3,502.8 to 3,505.1 ft bgs; blank, 5.5-in. SS production casing from 3,505.1 to 4,834.7 ft bgs; and a SS sediment sump with bullnose from 4,834.7 to 4,880 ft bgs. The 5.5-in. SS production casing was slotted in the intervals 3,591.0 to 3,805.8 and 4,191.6 to 4,834.7 ft bgs (NNSA/NSO, 2006). The completion interval accesses Paleozoic dolomite and limestone. Cement was not placed to isolate the screened intervals, nor was stemming material placed between the production casing and borehole. The static water level in the well to date has been in the depth range of 3,112 to 3,115 ft bgs, below the top of the carbonate HSU, corresponding to an elevation range of 4,270 to 4,273 ft amsl (see Table 2-1 for specific measurement information). Well 
construction is illustrated in Figure 1-3. Representative ambient water levels during the period of the testing program are indicated.

Detailed geologic information was collected during drilling (including geologic samples, cuttings, and sidewall core) for stratigraphic and lithologic interpretation. Geophysical logs, including image-type logs, were run to assist with characterization of geologic units. Detailed stratigraphic and lithologic interpretation can be found in NNSA/NSO (2006). The formations and HSUs penetrated during borehole advancement included the Timber Mountain welded tuff aquifer (TMWTA) from surface to $288 \mathrm{ft}$ bgs; the Timber Mountain vitric tuff aquifer (TMVTA), from 288 to $955 \mathrm{ft}$ bgs; the upper clastic confining unit (UCCU) from 955 to 1,085 ft bgs; the Belted Range aquifer (BRA) from 1,085 to 1,143 ft bgs; the lower tuff confining unit (LTCU) from 1,143 to 1,809 ft bgs; the Oak Spring Butte confining unit (OSBCU) from 1,809 to 2,179 ft bgs; the argillic tuff confining unit (ATCU) from 2,179 to 2,210 ft bgs; and paleozoic carbonate rocks, undivided, assigned to the LCA3, from 2,210 to 4,908 ft bgs (NNSA/NSO, 2006). Hydrogeologic unit (HGUs) delineations are included on Figure 1-3.

\subsection{Testing Program}

Development and hydraulic testing of ER-12-3 was conducted between June 3 and July 22, 2005. The development objectives included removing residual drilling fluids and improving the hydraulic connection of the well within the LCA. The hydraulic testing objectives focused on obtaining further hydrogeologic, geochemical, and radiochemical data for the site. Details on the data collected during development and testing are presented in the report Rainier Mesa Well ER-12-3 Data Report for Well Development and Hydraulic Testing (SNJV, 2006b).

The hydraulic testing program included:

- Record of the ambient water level

- Well development, including step-drawdown tests

- Flow and temperature logging under nonpumping conditions

- $\quad$ Flow and temperature logging during pumping

- $\quad$ Single-well constant-rate pumping test and recovery monitoring

A summary schedule of the completed activities is provided in Table 1-1. 


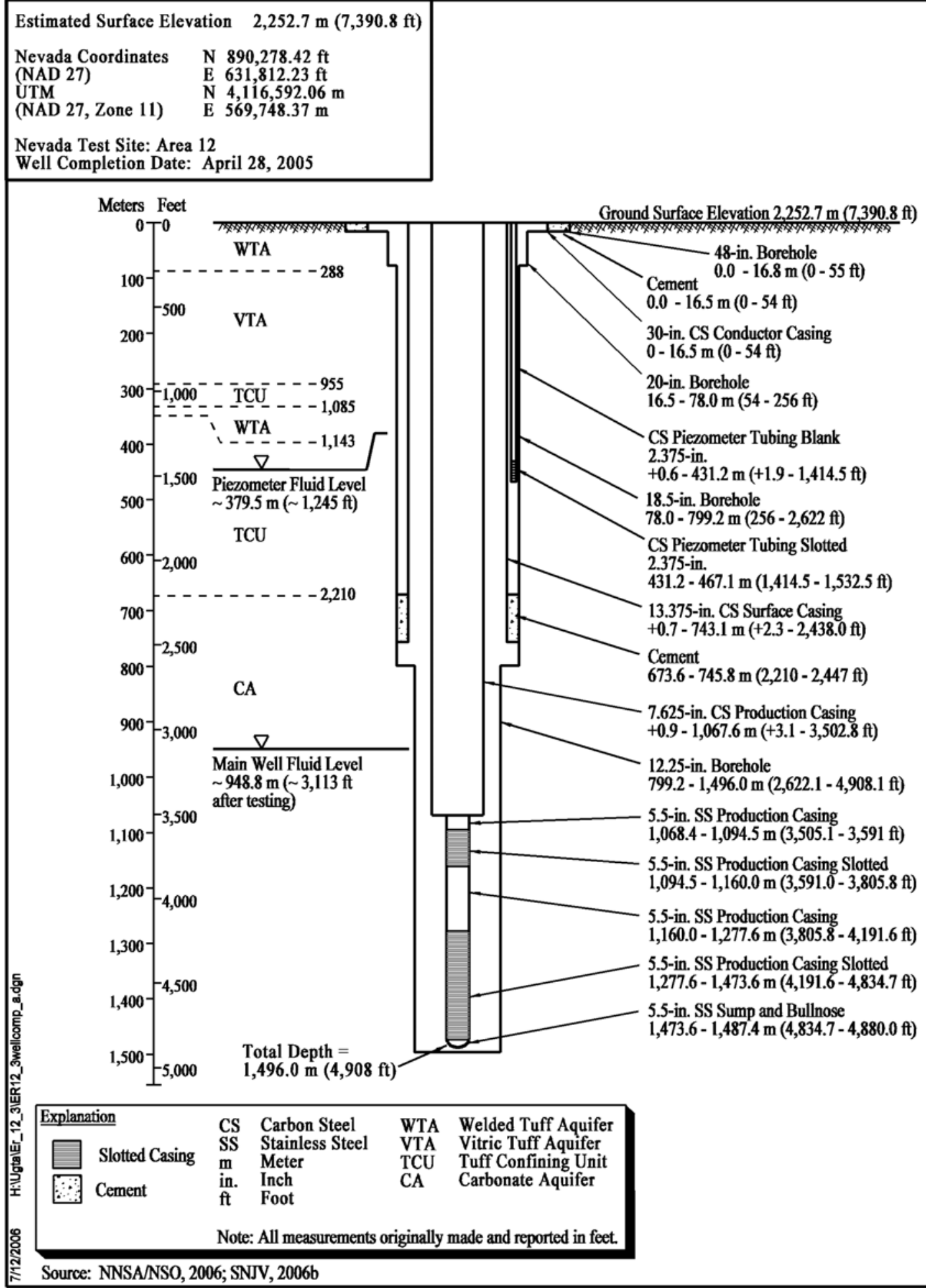

Figure 1-3

ER-12-3 Well Completion 
Table 1-1

Summary of Work Performed at ER-12-3

\begin{tabular}{|c|c|c|c|}
\hline Activity & $\begin{array}{l}\text { Start } \\
\text { Date }\end{array}$ & $\begin{array}{l}\text { Finish } \\
\text { Date }\end{array}$ & $\begin{array}{l}\text { Duration } \\
\text { in Days }\end{array}$ \\
\hline Mobilize development and testing equipment & $6 / 2 / 2005$ & $6 / 8 / 2005$ & 7 \\
\hline Predevelopment water-level measurements & $6 / 7 / 2005$ & 6/7/2005 & 1 \\
\hline Install electric submersible pump and access line & $6 / 8 / 2005$ & $6 / 11 / 2005$ & 4 \\
\hline $\begin{array}{l}\text { Check pump functionality, develop well, and conduct } \\
\text { step-drawdown testing }\end{array}$ & $6 / 12 / 5005$ & $6 / 16 / 2005$ & 5 \\
\hline $\begin{array}{l}\text { Conduct temperature and spinner flow logging, and collect } \\
\text { depth-discrete samples }\end{array}$ & $6 / 16 / 2005$ & $6 / 18 / 2005$ & 3 \\
\hline Monitor water-level recovery & $6 / 19 / 2005$ & $6 / 23 / 2005$ & 5 \\
\hline Conduct constant-rate test & $6 / 23 / 2005$ & $6 / 25 / 2005$ & 3 \\
\hline Generator fails, monitor water-level recovery & $6 / 25 / 2005$ & $6 / 27 / 2005$ & 3 \\
\hline Conduct constant-rate test and collect composite samples & $6 / 27 / 2005$ & $7 / 6 / 2005$ & 10 \\
\hline Monitor water-level recovery & $7 / 6 / 2005$ & $7 / 11 / 2005$ & 6 \\
\hline Remove pressure transducers, access line, and pump assembly & 7/11/2005 & $7 / 13 / 2005$ & 3 \\
\hline $\begin{array}{l}\text { Perform impeller flow meter, thermal flow meter (TFM), and } \\
\text { ChemTool logging }\end{array}$ & $7 / 14 / 2005$ & $7 / 15 / 2005$ & 2 \\
\hline Reinstall electric submersible pump and check pump function & $7 / 18 / 2005$ & $7 / 19 / 2005$ & 2 \\
\hline Demobilize development and testing equipment & $7 / 20 / 2005$ & $7 / 25 / 2005$ & 6 \\
\hline Clean up soil impacted from a fuel spill & $7 / 28 / 2005$ & $7 / 28 / 2005$ & 1 \\
\hline
\end{tabular}

\subsection{Analysis Objectives and Goals}

The testing program was designed to provide information on local hydrologic conditions and HSU hydraulic parameters for use in the CAU-scale flow and transport models. The objective of the analysis is to maximize the hydrogeologic information drawn from collected data. Specifically, both composite and interval-specific formation hydraulic parameters are estimated.

\subsection{Report Organization}

Section 1.0 is the introduction to this report.

Section 2.0 discusses the analysis of the nonpumping (pseudo-static) natural-gradient well hydrology. 
Section 3.0 discusses the well hydraulics during pumping and presents analyses of the constant-rate test, and flow and temperature logging.

Section 4.0 presents analysis of the geochemical information collected.

Section 5.0 contains a review of the test design and implementation, and the interpretation and analysis of the testing data.

Appendix A contains two Electric Micro-Imager (EMI) logs that contain deviation information. 


\subsection{EQUilibrium Well Hydraulics}

This section evaluates the hydrology of ER-12-3 in the static, nonpumping condition to quantify hydraulic characteristics of the well under equilibrium conditions. This provides a baseline for evaluating factors that may influence the measured response to production during hydraulic testing. The relevant characteristics include the representative head for the well completion, equilibrium borehole temperature profile, vertical gradient within the completion interval and resultant vertical circulation, and discrete-interval horizontal flow into or out of the formation.

\subsection{Representative Formation Head}

Formation head, hydraulic head expressed as equivalent elevation head, is of interest for several purposes. The head value may be used for mapping the formation head across an area of interest to determine head gradients and infer the direction of groundwater flow. It is also necessary to know whether the well is in equilibrium at the time of testing and to determine when it has recovered to an equilibrium condition. Water-level monitoring information collected periodically on schedules with different time scales allows the evaluation of different components of the natural variation of formation head such as responses to barometric pressure variation, earth tides, background trends, and responses to imposed stress during testing. Water-level information is available for ER-12-3 since the initial well completion, collected both by the Environmental Restoration contractor (SNJV) and by the USGS.

\subsubsection{Water-Level Monitoring}

Water levels have been measured by the USGS in the ER-12-3 main completion and the piezometer following the testing program. These water-level measurements are published on the Nevada USGS/DOE Cooperative Studies website (USGS/DOE, 2006). Table 2-1 lists the water-level measurements made in ER-12-3 up to the issuance of this report. 
Table 2-1

ER-12-3 Water-Level Measurements

\begin{tabular}{|c|c|c|c|c|c|c|c|}
\hline Date & Time & $\begin{array}{c}\text { Depth to Water } \\
(\mathrm{ft})\end{array}$ & Method & Accuracy & Source & $\begin{array}{c}\text { Water-Level } \\
\text { Elevation }^{\mathrm{a}} \\
\text { (ft amsl) }\end{array}$ & $\begin{array}{c}\text { Water-Level } \\
\text { Elevation } \\
\text { (m amsl) }\end{array}$ \\
\hline \multicolumn{8}{|c|}{ ER-12-3 Main Completion } \\
\hline $12 / 6 / 2005$ & 13:05 & $3,111.67$ & Electric Tape & Nearest Foot & USGS & $4,279.13$ & $1,304.28$ \\
\hline $9 / 22 / 2005$ & $11: 34$ & $3,112.56$ & Electric Tape & Nearest Foot & USGS & $4,278.24$ & $1,304.01$ \\
\hline $8 / 10 / 2005$ & $10: 48$ & $3,113.16$ & Electric Tape & Nearest Foot & USGS & $4,277.64$ & $1,303.82$ \\
\hline $7 / 27 / 2005$ & 9:04 & $3,113.37$ & Electric Tape & Nearest Foot & USGS & $4,277.43$ & $1,303.76$ \\
\hline $7 / 11 / 2005$ & $11: 20$ & $3,114.87$ & Wireline & Nearest Foot & SNJV & $4,275.93$ & $1,303.30$ \\
\hline $6 / 11 / 2005$ & $16: 20$ & $3,113.67$ & Wireline & Nearest Foot & SNJV & $4,277.13$ & $1,303.67$ \\
\hline $6 / 7 / 2005$ & 9:12 & $3,113.62$ & Wireline & Nearest Foot & SNJV & $4,277.18$ & $1,303.68$ \\
\hline $5 / 1 / 2005$ & 9:40 & $3,115.52$ & Wireline & Nearest Foot & SNJV & $4,275.28$ & $1,303.11$ \\
\hline \multicolumn{8}{|c|}{ ER-12-3 Piezometer } \\
\hline $12 / 6 / 2005$ & $13: 39$ & $1,244.80$ & Calibrated Electric Tape & Nearest Tenth Foot & USGS & $6,146.00$ & $1,873.30$ \\
\hline 9/22/2005 & $12: 05$ & $1,245.02$ & Calibrated Electric Tape & Nearest Tenth Foot & USGS & $6,145.78$ & $1,873.23$ \\
\hline 8/10/2005 & $11: 28$ & $1,245.28$ & Calibrated Electric Tape & Nearest Tenth Foot & USGS & $6,145.52$ & $1,873.15$ \\
\hline $7 / 26 / 2005$ & $8: 58$ & $1,245.41$ & Calibrated Electric Tape & Nearest Tenth Foot & USGS & $6,145.39$ & $1,873.11$ \\
\hline $7 / 11 / 2005$ & 9:15 & $1,245.75$ & Calibrated Electric Tape & Nearest Tenth Foot & SNJV & $6,145.05$ & $1,873.01$ \\
\hline $6 / 11 / 2005$ & $15: 57$ & $1,246.32$ & Calibrated Electric Tape & Nearest Tenth Foot & SNJV & $6,144.48$ & $1,872.84$ \\
\hline $6 / 7 / 2005$ & $10: 03$ & $1,246.88$ & Calibrated Electric Tape & Nearest Tenth Foot & SNJV & $6,143.92$ & $1,872.67$ \\
\hline $5 / 10 / 2005$ & $10: 40$ & $1,248.58$ & Calibrated Electric Tape & Nearest Tenth Foot & USGS & $6,142.22$ & $1,872.15$ \\
\hline $5 / 1 / 2005$ & $10: 30$ & $1,250.08$ & Electric Tape & Nearest Foot & SNJV & $6,140.72$ & $1,871.69$ \\
\hline
\end{tabular}

Source: SNJV, 2006; USGS/DOE, 2006

aSurface elevation: 7,390.8 ft amsl 
Note the varying accuracy specified for the different measurements. Measurements are made to the nearest $0.01 \mathrm{ft}$, but the uncertainty is $+/$ - the listed accuracy. The depth-to-water for the main completion is greater than the length of the electric tapes generally used for measurement, and the equipment available with a sufficient depth capability is not calibrated to the normal standard of $0.10 \mathrm{ft}$.

The water-level elevations are calculated assuming an undeviated borehole. A full-depth deviation survey has not been run in this well. Partial-depth deviation information recorded with the EMI logs (see Appendix B) below 2,400 ft indicates that the borehole deviates a fraction of a degree from vertical at 2,400 ft bgs, and that the deviation increases up to 21 degrees at TD. The known deviation between 2,400 ft and the water level at about 3,113 ft bgs requires a correction of $-1.05 \mathrm{ft}$ for true vertical depth for water-level measurements. A full-depth deviation log would be required to determine the total correction from the ground surface for deviation. The estimated correction above is not included in the reported water-level information.

Figure 2-1 shows the USGS graph of the ER-12-3 main completion water-level measurements, and Figure 2-2 shows the ER-12-3 piezometer measurements. The water levels shown are rounded per the specified accuracy in Table 2-1. The water level for the ER-12-3 main completion has trended upward following completion and testing, and it is not clear that it is in equilibrium as of the last measurement. The first data point was measured shortly after completion, when the well may not have been in equilibrium. Disturbance in the well due to the testing program began June 8, following pre-testing measurements. The data point on July 11 immediately followed the testing program, and the well may not have been fully recovered. At this time, a representative, equilibrium head has not been determined. The ER-12-3 piezometer has also trended upwards over the same time period, but this record appears to show an equilibration-type curve that is consistent with the low permeability of the formation in which the piezometer is completed.

Figure 2-3 shows the long-term water-level measurements for the ER-12-1 upper completion, completed in a section of the LCA3 nominally. This record shows a rise of about $3.5 \mathrm{ft}$ in the latter half of 2005, which is similar to the overall rise for ER-12-3 main completion record over this same time period. Other wells in Yucca Flat completed in the LCA also exhibited a water-level rise in the 


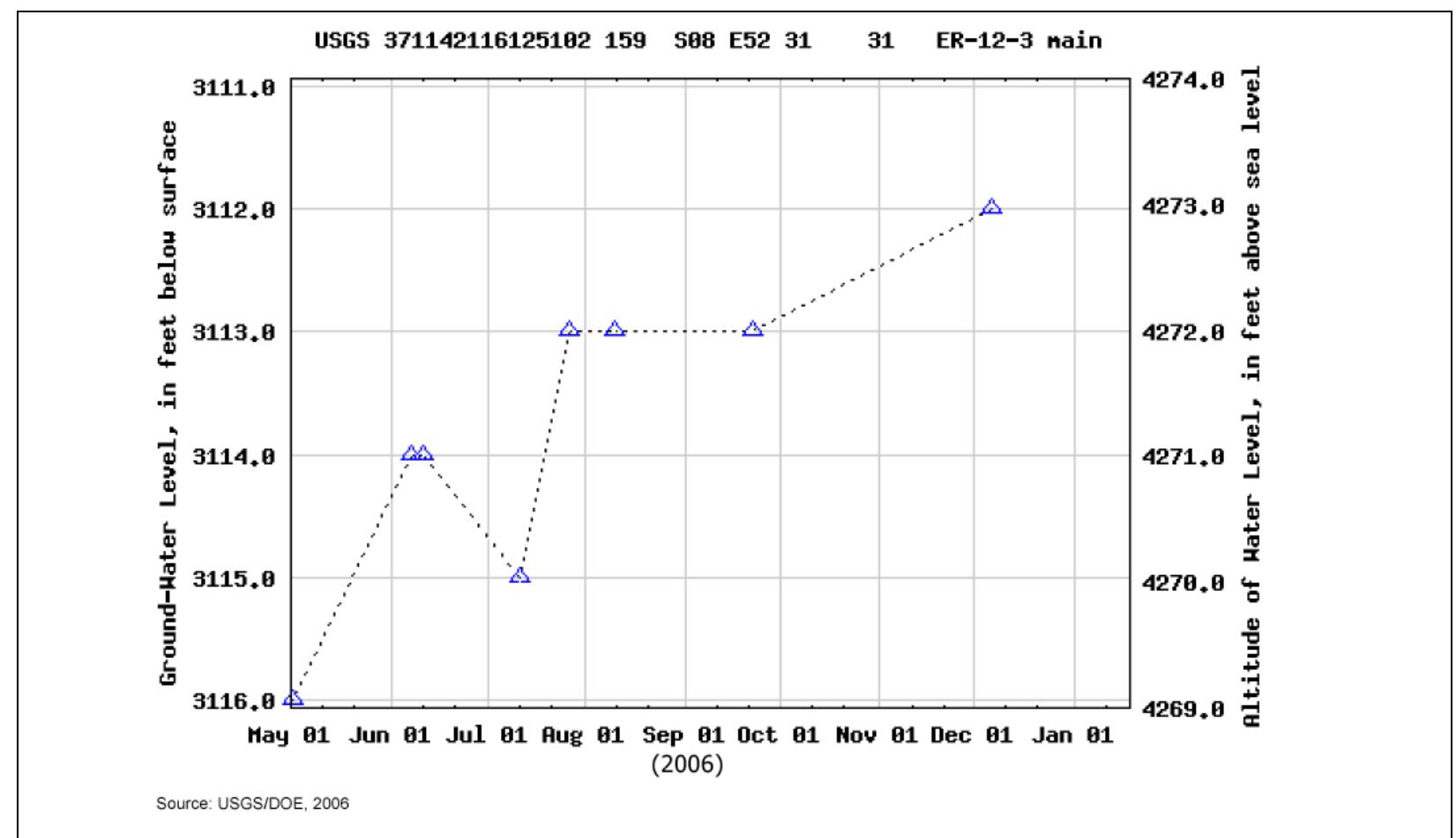

Figure 2-1

ER-12-3 Main Completion Water Levels

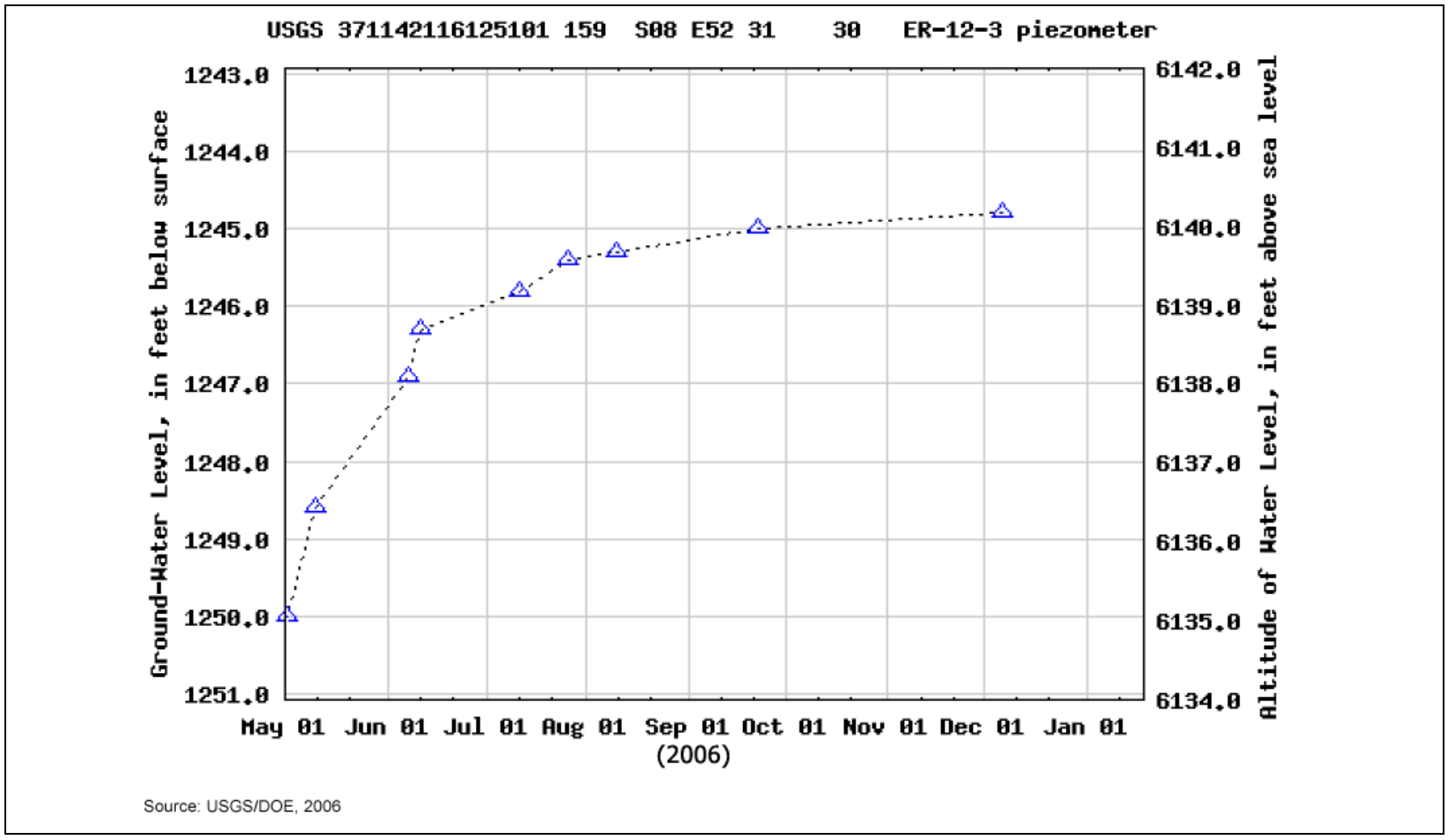

Figure 2-2

ER-12-3 Piezometer Water Levels 


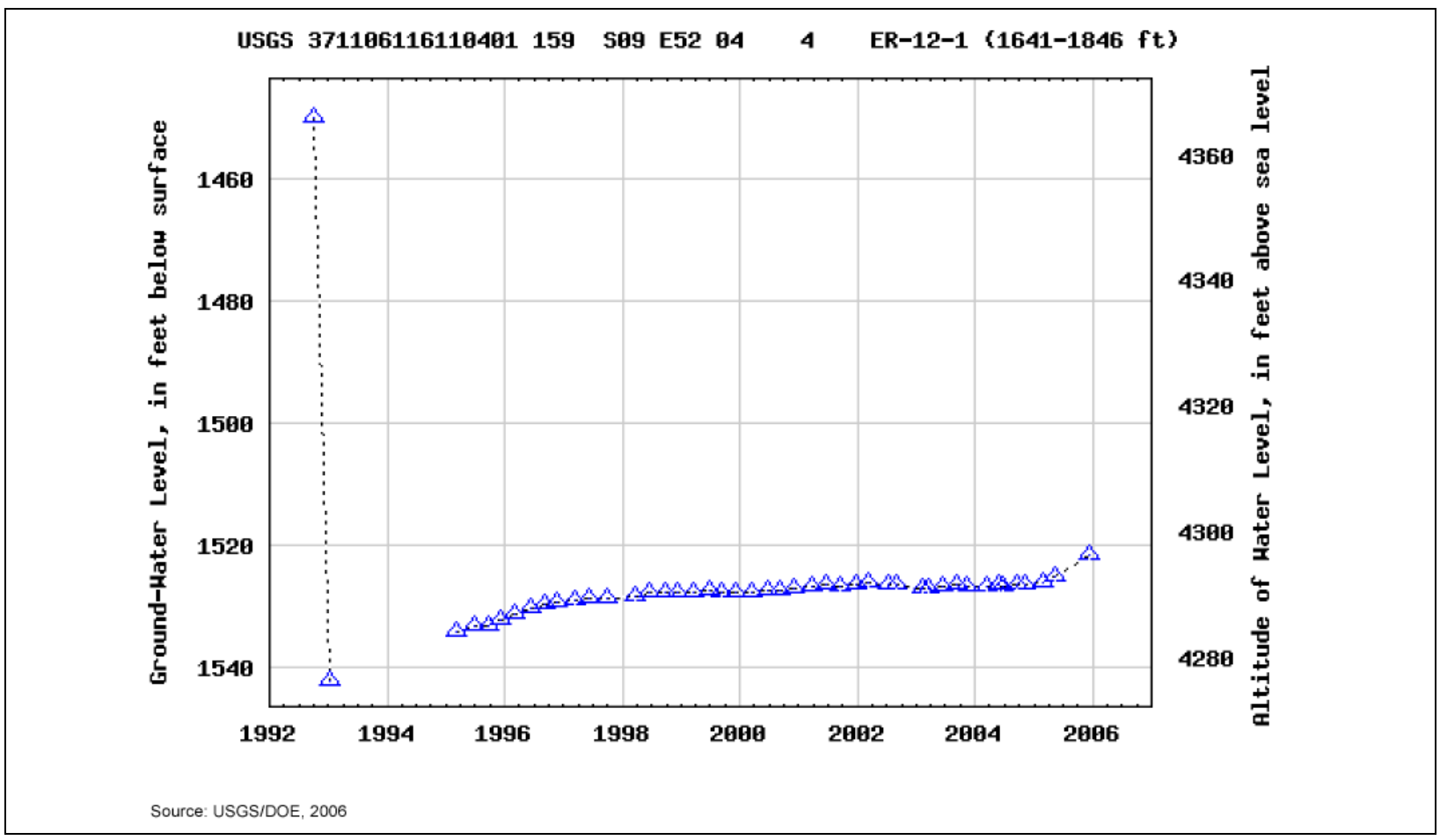

Figure 2-3

ER-12-1 Upper Completion Water Levels

second half of 2005, so the rise in the later part of the year may reflect a trend. This trend should be considered when using the formation head measurements reported in this document.

\subsubsection{Continuous Water-Level Monitoring}

Continuous water-level monitoring records were recorded during the testing program. However, the periods of record before various pumping periods in the main completion were too short to evaluate the records relative to either equilibration or background trends to determine a representative formation head. It appears that the well was not in equilibrium when the constant-rate test was begun, and the post-pumping record was terminated before recovery to equilibrium was achieved.

No effects of pumping are observed in the continuous water-level monitoring record for the piezometer (see Figure 2-4 of SNJV, 2005c), which may be expected because the piezometer appears to monitor a perched water table. The continuous records appear to show relatively stable water levels, but the long-term discrete water-level measurements indicate that a slow trend of apparent 
equilibration was taking place during the entire record period. The continuous records are too short to provide the basis for evaluating stability.

\subsubsection{Vertically Discrete Water-Level Measurements}

Water-level measurements representing equilibrium were not made during drilling of ER-12-3 due to the slow equilibration of the water level. Such measurements would have provided information on the vertical head distribution in the upper volcanic units and for the gradient within the LCA3 section. There is a very substantial head difference between the piezometer completion and the main completion. The water level is about 1,870 ft higher in the overlying volcanic units than in the LCA3. The two completions are separated by a cement seal, $245 \mathrm{ft}$ long (Figure 1-3), mostly located in the LCA3. The piezometer completion (open annulus) is open across all three upper volcanic units (welded tuff aquifer [WTA], vitric tuff aquifer [VTA], and tuff confining unit [TCU]), and the bottom of the open annulus (top of cement) is at the same elevation as the top of the LCA3. The water level in the piezometer is within the upper part of the TCU. Because the water level represents an average of the individual heads for each unit weighted by the transmissivity of the unit, location of the water level in the TCU suggests that only the TCU below the water level is saturated. Units identified as aquifer HGUs would be expected to be more transmissive, and the water level (weighted average head) would be within those units if they were saturated. The large head difference between the piezometer and main completion indicates that the TCU has very low vertical hydraulic conductivity and that vertical flow from the TCU to the LCA3 is probably very low. This is also reflected in the LCA3 water level (main completion) below the top of the LCA3. The fact that the large head difference is maintained even though the bottom of the piezometer open borehole is close to the top of the LCA3 suggests that the LCA3 also has very low vertical hydraulic conductivity, presumable when not fractured.

The main completion in the LCA3 is also open for almost the full depth of the LCA3 penetration, and the water level within the completion is below the top of the LCA3, resulting in an unsaturated condition in the top of the unit. Consequently, the piezometer head is interpreted to reflect "perched" water in the TCU and does not indicate a continuous vertical gradient with the LCA3. To some extent, vertical gradient in the LCA3 may be interpreted based on natural flow in the borehole or well completion, which is discussed in Section 2.2. 


\subsection{Flow in the Well Under Natural Gradient}

The interpretation of temperature logs can be used in conjunction with borehole flow measurements for identification of flow patterns in the well. This applies both to the ambient, equilibrium condition and during pumping. The downhole flow and temperature data will be evaluated in this section to interpret natural-gradient flow and identify implications for conditions in the formation. The data for the pumping condition will be evaluated in Section 3.3. The natural-gradient condition provides the baseline for interpretation of the pumping condition data. The flow and temperature data are interpreted at face value without discounting information that is unusual or confusing, but without necessarily accounting for all features. The interpretation is not definitive, but is offered as a framework for understanding the hydrology at this location based on the data collected. Further data collection may be required to confirm or discount implications of this interpretation.

\subsubsection{Non-Pumping Temperature Profiles}

Figure 2-4 shows the overlay of three temperature profiles and two flow profiles that will be discussed in this section, superimposed on a schematic indication of the vertical extent of the slotted casing intervals in the production casing. The two slotted intervals will be referred to as the "upper" interval (3,591 to 3,806 ft amsl) and the "lower" interval (4,192 to 4,835 ft amsl) in the discussion. Along the left side of the diagram is a schematic indication of the occurrence of open fractures in the borehole as determined by Fronterra Integrated Geosciences (Leavitt, 2005) from interpretation of the EMI log that was run after drilling was completed. These fracture picks are preliminary and have not been confirmed by UGTA staff. However, the primary objective here is to indicate the vertical density of fracturing, which appears qualitatively representative in review, and identify that there appear to be three distinct groupings of fractures. These will be referred to as the "upper" fracture interval (about 3,100 to 3,450 ft amsl), the "middle" fracture interval (about 3,780 to 4,160 ft amsl) and the "lower" fracture interval (below 4,650 ft amsl).

Temperature increases with depth, and the geothermal gradient in formations is approximately linear in formations with homogeneous thermal conductivity not affected by advective heat transport or significant localized heat sources (e.g., intrusives). Temperature profiles measured in water-filled boreholes mimic the geothermal gradient, but can be modified by vertical movement of water in the borehole due to various factors such as temperature differences, hydraulic gradients, and hydraulic 


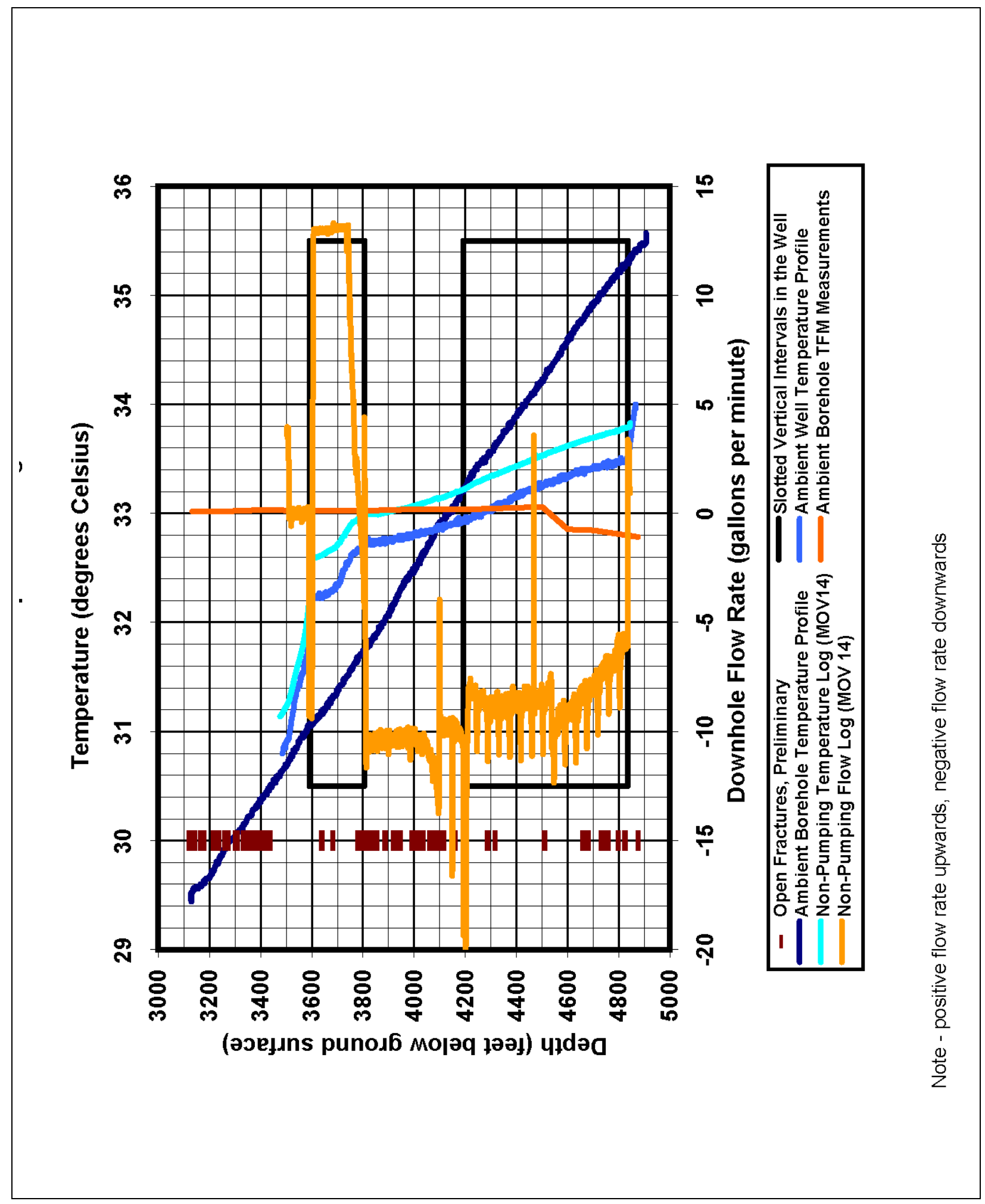

Figure 2-4

Ambient Temperature and Flow Profiles for ER-12-3 
conductivity variations. Temperature profiles can be evaluated based on changes in gradient with depth and with respect to changes between profiles logged under differing borehole conditions such as ambient borehole circulation versus during pumping.

Figure 2-4 shows the ambient borehole temperature profile, which was the observed temperature profile in the open borehole after drilling. The temperature in the borehole at the time of this logging may not have been in complete equilibrium with the formation to yield an "ambient" temperature profile. However, the profile is used as representative of the formation temperature profile relative to later temperature profiles that appear to be very affected by natural flow in the borehole. More typically, a borehole temperature profile affected by drilling would have been closer to isothermal. This “ambient” temperature profile indicates an almost linear thermal gradient from the water level in the borehole to the TD. The actual ambient temperature profile may be warmer than this log indicates because drilling at this time of year typically results in cooling of the borehole with drilling fluids colder than subsurface temperatures. The various temperature logs that are compared in this analysis were run with two different tools, the DRI ChemTool and the DRI flow logging tool. Comparison of the temperature logs from the two tools must allow for some uncertainty in the absolute calibration of the tools and differences in the effects the two tools may have on the recorded temperature profiles. Also shown is the Ambient Borehole TFM log, which indicates very low natural flow rate in the borehole, apparently upwards from about 4,500 ft bgs, and downwards below that depth. The lack of substantial flow in the borehole suggests that the temperature measured profile was not significantly affected by borehole circulation.

The well completion was then installed (see Figure 1-3), which placed casing within the borehole that was slotted through two vertical intervals, indicated on Figure 2-4 as slotted vertical intervals. Subsequent temperature logs were run within this completion, and it can be seen that the measured flow in the borehole was substantially changed. It must be kept in mind that logs run in the well completion reflect changing relationships of the logged water column with conditions in the annulus, depending upon whether the logging tool is within a slotted interval or within blank casing. Water interchange with the annulus can occur within the slotted intervals, but only flow between the two slotted intervals occurs within the blank completion casing. Temperature in the annulus may have an effect on the temperature profile in the blank casing through heat conduction across the casing. 
A development program was conducted before the subsequent temperature logs, during which the well was pumped extensively. Pumping may have substantially changed borehole conditions, cleaning the fractures of residual drilling fluid, which affected the natural circulation in the well by opening the fracture hydraulic conductivity. An interpretation of the nature of the change between the open borehole temperature log and the ambient temperature log in the well completion is that the fractures were initially plugged with residual drilling fluid/cuttings, and there was little flow in the well because of the consequent low hydraulic conductivity of the fractures. After development, increased hydraulic conductivity of the fracture intervals would allow substantial circulation in the well driven by the natural head differences between the fracture intervals, modifying the temperature profile. The Non-Pumping Temperature Profile was recorded with a flow log run shortly after development pumping ceased. The profile shown is the MOV14 log, which was recorded at a line speed of about 20 feet per minute ( $\mathrm{ft} / \mathrm{min}$ ) upwards. The well construction appears to substantially affect the measurement of temperature and flow profiles.

Following development, the well was pumped for 10 days at an average (constant) rate of 29.55 gallons per minute (gpm). The ambient well temperature profile was logged after a recovery period of about nine days following the constant-rate pumping test. At this point, the well may have been in approximate equilibrium, although there is no way to ascertain how close it was to equilibrium. The ambient temperature profile is slightly cooler, about 0.2 degrees Celsius $\left({ }^{\circ} \mathrm{C}\right)$, than the temperature profile logged shortly after pumping ceased. This may indicate further cooling with longer-term equilibration after pumping or may be a calibration discrepancy between the logging tools - different tools were used to log these two profiles. However, the two profiles are almost identical in form, and will be referred to as the non-pumping temperature profile. Temperature profiles will be discussed within the context of natural flow in the well in Section 2.2.3.

\subsubsection{Non-Pumping Flow Logs}

As mentioned in the previous section, a TFM flow profile was logged before well completion, identified as the ambient borehole TFM. This log indicated very low upward flow from a depth of about 4,550 ft bgs (midpoint depth between two measurements showing the increase in flow), and more substantial downward flow below that depth. Impeller flow logging was conducted at the end of the development period at several different pumping rates (see Section 3.3.2). After pumping for 
development ceased, two impeller flow logs were run to determine non-pumping flow distribution. The impeller flow meter was used because the flow rates were above the upper limit of the TFM. The MOV14 log was selected for Figure 2-4 because the logging rate of $20 \mathrm{ft} / \mathrm{min}$ upward produced the $\log$ with the least noise.

\subsubsection{Flow Interpretation}

There is a great difference in form between the ambient well temperature profile after well completion and development/testing, and the ambient borehole temperature profile. The borehole temperature profile does not indicate significant vertical flow in the borehole, which agrees well with the TFM flow profile in the borehole, also shown on Figure 2-4. The temperature gradient is linear with only minor inflections. There appears to be a low-rate inflow to the borehole in the interval 4,500 to 4,600 ft bgs (interval between measurements), based on the TFM measurements, with both slight upward flow and greater downward flow.

The difference between the ambient borehole temperature profile and the non-pumping-well temperature profile indicates inflow to the borehole approximately where the temperature profiles cross (between depths of 3,800 to 4,200 ft bgs) allowing for uncertainty in the absolute temperature of the ambient borehole temperature profile), and both upward and downward flow from that interval of inflow. Inflow of water at this depth would raise the temperature above and decrease the temperature below the inflow interval, relative to the ambient borehole temperature profile. This inflow interval approximately coincides with greater density of fracturing in the borehole, shown on the left side in Figure 2-4. Additional inflow in the interval 3,700 to 3,800 ft bgs is also indicated by the cooling inflection of the temperature profile across that depth interval.

The non-pumping flow log reflects this flow pattern, recognizing that the flow log only indicates flow within the well completion casing and the interchange with the annulus. There is flow into the upper slotted interval at the bottom of the slotted interval, which increases upwards before stopping at the top of the interval where the flow re-enters the annulus, as it must because there is no discharge from the well. This flow is presumed to enter the formation in the upper interval of heavy fracturing, above 3,450 ft bgs, where the temperature log indicates the temperature becomes asymptotic to the ambient borehole temperature profile. Some of the inflow to the upper slotted interval from the lower annulus also was measured going down the well casing from the upper interval to the lower interval. This 
flow re-enters the formation in the lower slotted interval as downward flow decreases downward in the lower slotted interval.

The observed flow rates are much higher in the cased well than in the uncased borehole, which may be due to improved connection of the borehole with the formation as a result of the development program. The hydraulic divide between upward and downward flow in the well completion is a function of the dynamics of the well completion and does not directly reflect the flow from the formation. This flow pattern is probably substantially controlled by the hydraulic conductivity distribution, which is assumed to closely reflect the fracturing density. The flow is driven primarily by head differences between the different intervals of dense fracturing, and possibly also by convection driven by temperature difference.

\subsection{Barometric Efficiency}

The barometric efficiency (BE) of the well is used to remove head variation in the water-level monitoring records - particularly for the constant-rate test, produced by barometric pressure variation - which are unrelated to the test. The importance of determining the correct value for BE is somewhat dependent on the magnitude of the drawdown of the well during testing; the greater the drawdown, the less influence the barometric correction has on the measured formation response. For ER-12-3, the water-level changes that occurred during pumping were large compared to the small-scale changes resulting from barometric pressure variation, and the removal of barometric pressure variation is not critical to an accurate analysis of the response to pumping. Barometric efficiency is determined from analysis of the correlation of head variations in continuous water-level monitoring records and barometric pressure variation. Because the primary use of BE is for removing the effect of barometric pressure variation, it is treated as a fitting parameter for maximum smoothing of records.

\subsubsection{Barometric Efficiency Analysis}

The methodology used for determining BE, as a fitting parameter, consists of overlaying the water-level record with the barometric pressure record after converting barometric data to consistent units and inverting the trace. The processed barometric trace is trended and scaled until a best-fit match to the water-level record is determined. The trending represents water-level trends not related 
to barometric response allowing the barometric component of the water-level record to overlay the barometric record; the scaling factor is equal to the BE. This method assumes that the water level in the well is in equilibrium with the groundwater head, and that trends are linear. Good results from this method require that the record includes changes in barometric pressure that are longer term than semidiurnal fluctuations, with magnitude substantially greater than those fluctuations. These conditions are necessary to separate the barometric response of the well from earth-tide-related fluctuations and to avoid phase-shift uncertainty of short-term barometric responses.

The determination of BE was reported in Section 3.1 of the data report for hydraulic testing (SNJV, 2006b) for monitoring records. The short monitoring records and inability to separate earth-tide effects result in substantial uncertainty in the derived BE values, and the trend may be non-linear. The best fit for the ER-12-3 main completion was obtained with BE greater than 1.0, which is theoretically inappropriate. As a fitting parameter for use to smooth barometric pressure variation effects from the water-level records, the maximum theoretical BE of 1.0 provides the best result. However, an accurate value for BE was not determined for use in direct analysis of formation hydraulic properties. A value specifically attributable only to the effect of barometric pressure variation would require a water-level monitoring record meeting the requirements stated above.

\subsubsection{Static Formation Head Versus Static Water Level}

Static formation pressure measured as the head of the water column surface within the well is equivalent to the composite equilibrium pressure of the formation(s) accessed by the well completion. The well completion effectively connects varying pressure within the formation, resulting in formation static pressure that is the integrated average of the varying pressure weighted by the associated hydraulic conductivity. The static formation pressure represents the starting head for the pressure response to hydraulic stress, and the head that recovering formation pressure approaches with time.

In practice, the static formation pressure is difficult to characterize for several reasons. First, head measurements are made at the water surface in the well rather than within the production interval. Second, variable density along the water column with depth due to temperature variation and water-quality variation results in uncertain estimation of the formation head at the completion interval. Third, natural ambient flow driven by pressure gradients within the well alters the pressure 
distribution. In the case of ER-12-3, these factors are not well known due to the inability to make continuous measurements of flow and temperature in the annulus where these measurements would reflect the formation directly. The discontinuous nature of the completion within the long, open annulus and the complex interaction of the production from the formation with the completion make interpretation difficult. The uncertainty resulting from these factors often cannot be resolved because sufficient information is not available. These factors during pumping and the associated uncertainties are discussed in Section 3.0. 


\subsection{Pumping-Well Hydraulics}

This section evaluates pumping-well hydraulics and presents an analysis of the constant-rate pumping test. The recorded well response to pumping can be affected by barometric pressure changes during the test, earth tides, and background-water-level trends. These factors are evaluated to determine whether corrections to the record are required. Also evaluated are well losses and effects of temperature changes in the well during pumping. Pumping hydraulics are assessed to determine whether the magnitude of well losses requires corrections to attribute the correct proportion of the drawdown to the formation response. In cases where there are substantial temperature profile changes in the water column resulting from pumping, the magnitude of the temperature change effect on the observed water-level change must be considered in analysis. After analysis of the pumping test to determine the composite transmissivity $(\mathrm{T})$ of the formation tested, the discrete production distribution measured from the flow logs is used to determine the hydraulic conductivities of distinct flow intervals of the formation.

\subsection{Processing of the Water-Level Monitoring Record}

The raw pumping response record may be processed in several ways to render a more accurate record of the actual formation response to pumping. This may entail removing effects of barometric pressure changes during the test, both short-term for smoothing the record, and long-term for gross changes in barometric pressure during the test. Additional processing may be employed to remove earth tides, background-water-level trends, well losses, and temperature profile change effects. Commonly, the response is recorded as pressure changes (of the water pressure of the water column above a pressure transducer [PXD]) and is converted to water-level changes by multiplying the pressure changes by a conversion factor for water density derived from pressure versus depth measurements made during PXD installation. However, the ER-12-3 analysis was conducted using recorded pressure changes directly. 


\subsubsection{Background Water-Level Monitoring Record}

A background monitoring record was not recorded during the ER-12-3 testing program. This record may be used for removal of background-water-level trends and/or earth tides. It is not clear that there is a well which could necessarily be expected to exhibit an appropriate, similar response to background conditions. Well ER-12-4 would have been the most likely candidate; however, this well was drilled and constructed just before testing operations began at ER-12-3 and had not yet reached equilibrium.

\subsubsection{Barometric Pressure Changes and Earth Tides}

Barometric pressure changes during the constant-rate test were not great enough with respect to the drawdown observed to require that the record be processed to remove the effects. The record of barometric pressure changes during the test is shown in Figure 2-19 of the Rainier Mesa Well ER-12-3 Data Report for Well Development and Hydraulic Testing (SNJV, 2006b). Earth tides were not significant with respect to the drawdown response, and also were not smoothed or removed.

\subsubsection{Background-Water-Level Trends}

Background-water-level trends were not removed from the record. Clear definition of any such trend was not available from data collected. A sufficient background-water-level record was not collected, and the pre- and post-test records were also insufficient to ascertain trends. The well was not recovered from development pumping at the time the constant-rate test was begun, and the pre-test record primarily reflects the continuing recovery. The post-test monitoring was terminated before complete recovery, and any background trend superimposed on the recovery is not separable. A qualitative evaluation of the available records does not suggest that any substantial trend, relative to the magnitude of the drawdown response, was occurring.

The incomplete recovery from development pumping was incorporated in the analysis of the constant-rate test by way of incorporating the development pumping in antecedent conditions. 


\subsubsection{Well Losses}

Well losses due to friction losses in the well, entrance losses for the slotted intervals, and losses for upward flow to the pump in the production casing may be accounted for using analysis of step-drawdown tests or other means to estimate such losses. The importance of accounting for such losses depends on the magnitude of such losses relative to the measured response. The magnitude of friction losses is proportional to the square of the flow velocity and the length of the flow path. For ER-12-3, the low pumping rate relative to the slotted-interval length and production casing diameter results in fairly low flow velocities within the well, and the distance of flow from the entrance into the slotted casing to the pump was, on average, a little over $300 \mathrm{ft}$. These factors would result in fairly low well-friction losses.

The step-drawdown tests did not produce consistent results, probably due to the inequilibrium starting point of each test sequence and the slow equilibration of the well to changes in production rate relative to the length of pumping at each step. The results in general indicate that the non-linear part of the losses is probably quite low, which was expected, and correction of the pumping response data for well losses was not considered necessary.

\subsubsection{Effects of Temperature Profile Changes}

Formation pressure is commonly monitored with a PXD located near the water surface rather than in the completion interval for practical reasons. The water-surface elevation reflects the formation pressure as a function of the water density in the water column. The water-column density may vary as a result of temperature and water-quality variation. When the density profile is constant, the water-surface elevation varies linearly, with respect to the formation pressure, after accounting for secondary components of the responses, such as barometric pressure variation and earth tides. However, pumping the well can alter the temperature profile as a result of moving water from the completion interval to the surface replacing both water in the water column below the pump intake and conduction of heat above the pump intake. After pumping has begun, the temperature profile will approach a new equilibrium, and after pumping ceases, the profile will equilibrate back to the ambient profile. The volume expansion (or contraction) as temperatures increase (or decrease) affects the water-surface elevation independent of the formation pressure changes, and the effect can be significant when temperature changes are large and/or the water-column length long. Borehole 
temperature profiles were logged intermittently during development, both under ambient conditions and at multiple pumping rates, and then again following recovery and the testing program. The temperature shift from the ambient to the pumping condition was not great (compare produced water temperatures as shown in Figure 3-15). The temperature effect on the pumping response was not considered great enough to warrant correction of the record before analysis.

Water-quality variation affecting the water-column density may result from suspended sediment in the water column and/or gas entrainment in the water, due to air removal from the formation from drilling production and to exsolving gas from depressurizing the water. However, no information was collected to provide understanding of these factors, and they are assumed to have a negligible effect.

Density variation that occurs in the water column above the PXD does not affect the PXD pressure measurement used to measure the well response to stress. If formation pressure were measured at the depth of the completion interval, changes in water-column density would not affect measurement of formation pressure changes, and these effects of temperature change would not be a problem in analysis.

\subsection{Pumping-Test Analysis}

The hydraulic testing of the ER-12-3 well was analyzed under transient conditions to provide both the composite and discrete-interval hydraulic properties of the ER-12-3 LCA3 completion. The analyses are based on interpretation of a succession of three pump and recovery sequences, and on spinner-tool flow logging. The following sections describe the method, conceptual model, analysis, and results for the ER-12-3 single-well pumping test drawdown and recovery responses.

The nSights (formally, n-Dimensional Statistical Inverse Graphical Hydraulic Test Simulator) well-test interpretation program was used to generate log-log diagnostic plots and estimate the formation properties. The nSights program was developed by INTERA for Sandia National Laboratories (SNL) based on the Graph Theoretic Field Model (GTFM) well-test analysis code, the precursor to nSights. Field use for GTFM has a long history including the Swiss, Swedish, and French nuclear waste programs, as well as at the DOE Waste Isolation Pilot Plant in New Mexico (Roberts et al., 1999). A description of the governing equations used in both codes is found in Pickens et al. (1987). Following the SNL Nuclear Waste Management Program Procedure NP19-1, 
“Software Requirements," Rev. 4, nSights was verified to meet NQA-2 requirements (ASME, 1990). Verification was documented through comparison to the analytical solutions for constant-rate pumping tests (Theis, 1935), constant drawdown tests (Lohman, 1972), slug tests (Cooper et al., 1967), and pulse tests (Bredehoeft and Papadopulos, 1980). The nSights program is complete with a suite of statistical routines that support the identification and quantification of parameter sensitivity and uncertainty.

The nSights program uses a numerical approach to simulate radial/nonradial groundwater flow through a confined, single-phase, single-porosity or dual-porosity, one-dimensional (for this analysis) flow domain in response to boundary conditions (i.e., pumping rate changes) applied at the production well. The flow domain is discretized into a system of concentric rings centered on the borehole that uses a multiplicative factor to increase the spacing between rings with increasing distance from the borehole. Each ring is represented by a node; hence, the radial symmetry.

The nSights program can simulate transient flow and pressure responses, which vary in accordance to the imposed boundary condition at the well. Because nSights is a numerical simulator, all combinations of inner boundary conditions (constant rate, constant pressure, and non-constant rate and pressure) may be sequentially simulated without the need for restarts. This feature allows simultaneous simulation of complex hydraulic test sequences that otherwise, using conventional analytic analysis techniques, would need to be split into individual events. The advantage of this approach is that the set of estimated parameters are consistent for an entire test sequence.

\subsubsection{Method of Analysis}

The analysis of pressure/head transient data takes a step-wise approach:

1. Identify the conceptual flow model.

2. Estimate initial parameter.

3. Execute inverse process.

4. Evaluate uncertainty.

The conceptual flow model is evaluated by the use of log-log diagnostic plots (Horne, 1995). The pressure data and pressure derivative diagnostic plot aids in identifying characteristic responses of flow regimes, and identifies how changes through time define characteristics of the well/reservoir or aquifer system (Horne, 1995). For example, a typical log-log diagnostic plot of a constant-rate 
drawdown test will exhibit an early time response characteristic of the well (wellbore storage and skin), a middle-time response characteristic of the aquifer (stable derivative for a homogeneous aquifer), and a late-time response characteristic of outer boundaries (upturned derivative for no-flow and downturned derivative for constant head boundaries). Likewise, fractured, dual-porosity, closed boundaries all have characteristic shapes when displayed in the log-log diagnostic plot format. In actual hydraulic testing, it is possible that not all of the three flow regimes (early, middle and late time) will be observed in the measured data due to the specific formation and test parameters (e.g., T, and rate and duration of pumping). Therefore, it may not be possible, for example, to identify the wellbore storage period or outer boundary condition from the diagnostic plot. Diagnosis of the conceptual model defines the parameters that must be estimated in the analysis. In the case where no definitive model can be identified, the simplest model that represents the measured the data is always chosen.

To provide a starting point for the nSights inverse modeling, it is useful to "rough in" a fit to the measured data. This is accomplished by estimating the $\mathrm{T}$ from the diagnostic plot if possible; otherwise, nSights is run in the forward mode, and the T and storativity (S) (or other model parameters) are adjusted by the analyst until an approximate fit to the measured data is achieved. These "ballpark" simulations function to provide a reasonable initial guess at the fitting parameters. Otherwise, in the absence of a good initial guess, the parameter optimization procedure in nSights may not be able to converge to a solution. From the diagnostic plot the T may be estimated from the radial flow portion of the data via the expression:

$$
T=Q / 4 \pi m
$$

where $Q$ is the flow rate during the drawdown period and $m$ is the value of the stabilized derivative during radial flow.

The inverse model for the ER-12-3 test was set up in nSights by inputting all of the test-specific information. This information includes the well completion information; the test interval length; the fluid data; and the formation data (i.e., the conceptual model specific parameters [initial parameter estimates, T, S, etc.] and the numerical parameters [outer boundary radius and number of nodes]). 
Also input into nSights are the measured pressure data and flow rate data; the durations or starting times of the pumping and recovery periods; and finally, the specific data, termed “data constraint," to which nSights will compare the simulated response and minimize the difference of the measured and simulated data.

With the inverse model properly set up, test runs are executed to ensure that nSights can converge to solution, and that the solution makes sense with regard to the measured data. These troubleshooting simulations are necessary because they establish a set of base case parameters from which the perturbation analysis originates. The perturbation analysis is a large set $(>100)$ of inverse runs that are consecutively executed where the starting values of the fitting parameters are randomly perturbed from their base-case values and nSights estimates a new set of parameters for each perturbation. The purpose for such an analysis is to gain an understanding of the uncertainty in the fitting parameters. When post-processed, a series of plots and descriptive statistics are developed that facilitate evaluation of the goodness of fit, and hence the uncertainty in the parameter estimates.

\subsubsection{Conceptual Model}

Figure 3-1 shows the pumping rate changes during the hydraulic testing program and the assigned stress periods. (Note: All figures are found at the end of Section 3.4.) Figure 3-2 shows the water level response, also identified with the stress periods. Diagnostic plots of ER-12-3 pumping and recovery periods designated F_02 through F_07 were created in nSights to facilitate model identification and are shown in Figures 3-3 through 3-8. Diagnostic plots are sensitive to borehole events that occurred before pumping began. This superposition effect can have an adverse impact on flow model diagnosis because of the influence on the derivative; this effect is particularly evident in the late-time data. The ER-12-3 hydraulic test was preceded with 10 days of well development where the pump was surged on and off a minimum of 10 times, and following the final period of surging, the water level in ER-12-3 had not recovered to a static level before hydraulic testing commenced. Thus, there were a number of pressure transients propagating through the system during hydraulic testing that complicated making a definitive conceptual model diagnosis.

Examination of Figures 3-3 through 3-8 reveals that the early time responses show a brief period of wellbore storage followed by a "hump" in the derivative, which is characteristic of a skin effect. The middle-time data for each period show a relatively well-defined stabilization in the derivative, which 
is characteristic of radial flow to the well. The late-time derivatives, in turn, tend to exhibit inconsistent behavior from period to period. For periods F_02 through F_05, the late-time derivatives increase, while for period F_06, the derivative has a slightly declining trend, and for F_07, the derivative increases and then decreases. The variability in the behaviors of the late-time derivative data is probably caused by the effect of the complex pressure history in the well during surging and is not a true physical feature of the formation. Therefore, the conceptual model will not consider an outer boundary, and for the analysis, the conceptual model will consist of wellbore storage and skin in a confined homogeneous aquifer of unlimited lateral extent.

Also included on Figures 3-3 through 3-8 are estimates of the formation T, which were calculated based on the stabilized values of the derivative and average flow rate during the pumping periods. The same rate is used for the recovery periods as for the pumping periods because it is the last effective rate before pumping ceases that is used in analysis of recovery data. Table 3-1 summarizes the estimates of $\mathrm{T}$ for the different flow periods. Hydraulic conductivity $(\mathrm{K})$ values may be calculated using an aquifer thickness determined appropriate, which will be addressed later. A nominal thickness of $858 \mathrm{ft}$, the combined length of the two screened intervals, was used during the analysis. However, this length is only used to calculate specific storage (Ss); nSights determines T.

Table 3-1

Estimated T Values for the Hydraulic Test Periods

\begin{tabular}{|c|c|c|c|}
\hline Stress Period & $\begin{array}{c}\text { Flow Rate } \\
\text { (gpm) }\end{array}$ & $\begin{array}{c}\mathbf{m}^{\mathbf{a}} \\
\mathbf{( p s i )}\end{array}$ & $\begin{array}{c}\mathbf{T} \\
\mathbf{( \mathbf { f t } ^ { 2 }} \mathbf{\text { d}} \mathbf{)}\end{array}$ \\
\hline \hline F02 & 29.5 & 0.25 & 785 \\
\hline F03 & 29.5 & 0.17 & 1,153 \\
\hline F04 & 29.5 & 0.22 & 891 \\
\hline F05 & 29.5 & 0.18 & 1,089 \\
\hline F06 & 29.5 & 0.22 & 933 \\
\hline F06 & 29.5 & 0.21 & 933 \\
\hline
\end{tabular}

avalue of the stabilized derivative

$\mathrm{ft} / \mathrm{d}=$ Feet per day

$\mathrm{ft}^{2} / \mathrm{d}=$ Square feet per day

gpm $=$ Gallons per minute

psi - Pounds per square inch 
Based on the values reported in Table 3-1, a formation $\mathrm{K}$ value of $1 \mathrm{ft} / \mathrm{d}$ was used as the initial value for the nSights inverse modeling. The other fitting parameters included formation Ss, the skin radius, and K. The formation initial pressure was also set as a fitting parameter in the analysis; this was necessary because the water level did not recover to static conditions before the hydraulic test was started, making it necessary to fit this parameter.

\subsubsection{Hydraulic Response Analysis}

The pump and recovery periods were defined in nSights based on the measured pressure (P) and flow rate data as reported in the Rainier Mesa Well ER-12-3 Data Report for Well Development and Hydraulic Testing (SNJV, 2006b) (data files on the data CD). Well development activities commenced on June 12, 2005 (Julian day 163), with surging and pumping cycles at 30 gpm. These activities continued for six days until June 18, 2005 (Julian day 169). Following well development activities, the water level was allowed to partially recover for about five days before hydraulic testing began. During this period, while the water level was recovering, the PXD used during development was replaced with a higher-resolution PXD. These pre-testing activities are important because they set up the P history in the formation surrounding the well and influenced the hydraulic response during testing. The variable flow rate history during well development and up until the first constant-rate test was used as input to nSights to set up the proper antecedent $\mathrm{P}$ conditions in the model grid. Figures 3-1 and 3-2 show the measured flow rate and P during development and testing. The flow rates used in the nSights analysis are also plotted in Figure 3-1 as the interpolated line between the measured data points. There are no P measurements displayed for the development period in Figure 3-9 because the PXD placement during development was at a greater depth, and P measurements during the development period were much greater than those measured during testing and displayed on the same scale the two datasets do not provide adequate detail. Attempts to normalize the $\mathrm{P}$ data from the development period to the pumping data were not successful. Figure 3-9 shows the sequence grid lines used in the nSights simulations to distinguish between pumping and recovery periods.

The nSights program uses nonlinear regression to minimize the difference between the simulated test response and the measured test data by adjusting the initial values of the fitting parameters up or down until a set of convergence criteria are met. The nSights program defines a set of formation 
hydraulic parameters that provide a best-fit simulated response to the measured data. The K, Ss, initial pressure, and skin parameters were defined as the fitting parameters in the ER-12-3 analysis. Note that K and Ss are calculated based on the input interval length, and that internally, nSights works with the $\mathrm{T}$ and $\mathrm{S}$. The data constraint used in the analysis was the measured Cartesian P history starting with F_02 up to and including F_07.

To gain an understanding of the uncertainty in the fitting parameters, a perturbation analysis was set up, and the results are discussed in Section 3.2.4.

\subsubsection{Best-Fit Parameter Estimates and Uncertainty}

The results of a 500-run perturbation analysis were evaluated based on the value of the objective function (i.e., the sum of squared errors [SSE]). The SSE term ranged from 84 to 375, with the fit of the simulated data to the measured data degrading at SSE values greater than 100 . Therefore, the results of the perturbation analysis are based on those runs for which the SSE was less than 100, which included 107 of the 500 perturbations. Table 3-2 provides the minimum and maximum values of the fitting parameters for the conceptual model. Figure 3-10 shows the SSE plotted as a function of $\mathrm{T}$ for all 500 perturbations; those used to define the $\mathrm{T}$ range are plotted in blue and those excluded are in red. Also of interest in Figure 3-10 is the appearance of a local minimum where the simulator repeatedly converged to a solution but for which the SSE values were much greater than for the global minimum. Figure 3-11 is a Cartesian plot of the measured $\mathrm{P}$ and the nSights simulations that correspond to the fits where the SSE was less than 100 (red values in Figure 3-10).

Table 3-2

Estimated Parameters for the ER-12-3 Hydraulic Test

\begin{tabular}{|c|c|c|c|c|c|c|c|}
\hline \multicolumn{2}{|c|}{$\begin{array}{c}\text { T } \\
\left(\mathrm{ft}^{2} / \mathbf{d}\right)\end{array}$} & \multicolumn{2}{c|}{$\begin{array}{c}\text { Ss } \\
(\mathbf{1} / \mathrm{ft})^{\mathrm{a}}\end{array}$} & \multicolumn{2}{c|}{$\begin{array}{c}\text { P } \\
(\mathbf{p s i})\end{array}$} & \multicolumn{2}{c|}{ Skin } \\
\hline Minimum & Maximum & Minimum & Maximum & Minimum & Maximum & Minimum & Maximum \\
\hline \hline 548 & 697 & $3.1 \mathrm{E}-10$ & $3.1 \mathrm{E}-05$ & 23.14 & 23.35 & -1.8 & 5.6 \\
\hline
\end{tabular}

a Inverse feet

The range of estimated $\mathrm{T}$ is small and agrees reasonably well with the values estimated from the diagnostic plots (Table 3-1). The initial pressure (head) was also a fitting parameter, reported as $\mathrm{P}$ in Table 3-3. The estimated initial pressure covers a small range, which corresponds to $0.5 \mathrm{ft}$ of head. 
Table 3-3 shows the depth-to-water values calculated based on the P values (Table 3-2) and the calculated PXD depth values provided in Table 2-4 of the ER-12-3 data report. There was no compensation made for changes in fluid density due to temperature effects at depth. This table provides the conversion of the $\mathrm{P}$ response to hydraulic property values as units of length/time through equating head change (in feet) to $\mathrm{P}$ change.

Table 3-3

Depth to Water

\begin{tabular}{|c|c|c|c|c||}
\hline \multirow{2}{*}{$\begin{array}{c}\text { Measured Pressure } \\
\text { (psi) }\end{array}$} & \multirow{2}{*}{$\begin{array}{c}\text { Head } \\
\text { (ft) }\end{array}$} & \multicolumn{2}{|c|}{$\begin{array}{c}\text { Depth to Water } \\
\text { (ft bgs) }\end{array}$} \\
\cline { 4 - 5 } & & & Initial & Final \\
\hline \hline Minimum & 23.14 & 53.3 & $3,114.9$ & $3,115.2$ \\
\hline Maximum & 23.35 & 53.8 & $3,114.5$ & $3,114.7$ \\
\hline
\end{tabular}

As reported in Table 2-4 of the ER-12-3 data report, the calculated depth to the PXD was 3,168.26 ft bgs at the start of hydraulic testing and 3,168.52 feet bgs at the completion of testing. The difference in these values may be attributed to temperature changes during testing and the great depth of the borehole. The values for depth to water in Table 3-3 agree well with those reported in Table 2-2 of the ER-12-3 data report, lending confidence to the nSights estimated P values.

Figure 3-11 shows the fit values of $\mathrm{P}$ versus $\mathrm{T}$ as a color map of SSE, and reveals a negative correlation between initial P and T. The dark-blue points on Figure 3-11 represent those fits with the smallest SSE (i.e., those where the simulation most closely matched the measured data). Even though Figure 3-11 displays a strong correlation between $\mathrm{P}$ and $\mathrm{T}$, this correlation does not have a great influence on the uncertainty of either parameter for two reasons: 1) the range of both parameters is very small; and 2) the best-fit values are clustered over an even smaller range than the maximum and minimum of either parameter, as denoted on Figure 3-11 by the cluster of blue points near $\mathrm{T}=650$ $\mathrm{ft}^{2} / \mathrm{d}$. For the conceptual model, the perturbation analysis provided high-confidence estimates of $\mathrm{T}$ and initial formation P.

Contrary to the T estimate, the estimated Ss spans five orders of magnitude and was unconstrained by the fitting procedure. For single-well tests, where a well skin is present, obtaining a reliable estimate of formation storage is not possible. The reason is that the time segment of the measured $\mathrm{P}$ that contains storage information is coincident with the time period that contains skin information. This 
results in these parameters being correlated, and the correlation makes it impossible to discern unique values for either parameter. Figure 3-12 displays an SSE color-mapped plot of the skin factor versus Ss. The skin factor and Ss show high positive correlation, and the best-fit values (blue points) do not form a well-defined cluster as they did for static formation P versus T in Figure 3-11. Thus, it is not possible to obtain a high-confidence estimate of storage or skin from the analysis of the ER-12-3 test.

For the conceptual model (wellbore storage and skin in a homogeneous aquifer of infinite lateral extent) used in the ER-12-3 hydraulic test analysis, high-confidence estimates of T and initial P were obtained. The estimates for Ss and skin, on the other hand, are low confidence because of the correlation discussed above. An additional model that included fitting on the flow dimension was attempted with similar results in terms of skin and storage. This model was discarded because it unnecessarily complicated the analysis without increasing the parameter confidence.

\subsection{Interpretation and Analysis of Measured Discrete Production}

The production profile in the well can be evaluated using both flow logging and temperature logging during pumping. Flow logging may be interpreted quantitatively, while temperature logging is qualitative. Neither of these logs directly reflects the production distribution in the formation because the configuration of the ER-12-3 completion does not provide continuous access to the formation. The flow logs indicate the flow profile within the well completion string of slotted and blank casing, which localizes the observed production to the intervals of slotted casing and shows flow between the slotted intervals. The distribution of production in the annulus behind blank casing cannot be directly observed, but may be inferred from the temperature profiles. The temperature logs directly measure temperature in the water column within the well completion. The temperature profile within the well completion reflects the flow in the well modified by the temperature distribution in the annulus behind the completion casing through heat conduction, which reflects flow in the annulus.

Production behind the unslotted casing is evident from the substantial inflows at the upper and lower ends of the slotted interval shown the flow logs and the temperature profiles. Production intervals in the borehole were identified and flow rates specific to those intervals determined. Inferences about the relative $\mathrm{T}$ of production intervals behind the unslotted casing and head differences were made from the changes in production between the ambient and the pumping condition, relative to the drawdown. 


\subsubsection{Temperature Profiles During Pumping}

Figure 3-13 shows the pumping temperature profile as well as ambient borehole and for the ambient well temperature profiles, for reference. It was noted in the DRI report on flow and temperature logging (Oberlander and Russell, 2005) that the temperature profiles for both pumping rates (20 and $30 \mathrm{gpm}$ ) were virtually the same, and one log has been selected for illustration in the figures.

Figure 3-13 shows the temperature and flow profile for the MOV_02 logging run, while the well was pumping at $30 \mathrm{gpm}$. The pumping temperature profile in the well, in comparison to the ambient borehole temperature profile (where the TFM logging indicated virtually no flow, see Figure 2-4), indicates inflow to the annulus above about 4,150 ft bgs, similar to that indicated by the ambient well temperature profile. Also, inflow from above the upper slotted interval (at the lower temperature of the borehole temperature profile) is indicated by the large inflection of the temperature log to lower temperature at about 3,640 ft bgs. The flow log indicates about $14 \mathrm{gpm}$ coming from below the upper slotted interval and about $16 \mathrm{gpm}$ inflowing from above the upper slotted interval into the completion above 3,640 ft bgs. This indicates that the $16 \mathrm{ft}$ of drawdown produced at a pumping rate of $30 \mathrm{gpm}$ reduced the head in the completion below the head in the upper fractured interval.

\subsubsection{Flow Logging During Pumping}

Flow logging during pumping was conducted at two different pumping rates and then for the ambient (no-pumping) condition, and at several different logging rates for each pumping rate. The $20 \mathrm{ft} / \mathrm{min}$ upwards logging run at the $30 \mathrm{gpm}$ pumping rate was selected for illustration because this logging configuration has a low noise level. Figure 3-13 shows the flow and temperature profiles for the pumping condition, which can be compared to Figure 2-4 for the uncased borehole and the ambient well condition. Figure 3-14 shows an overlay of ambient, 20 gpm, and 30 gpm abstracted flow logs. These are representative flow profiles derived by DRI (Oberlander and Russell, 2005) after cleaning, calibrating, and combining all of the flow logs at each pumping rate to produce one consistent result. The representative flow profiles are similar to the individual flow logs presented in Figures 2-4 and 3-13, but show the flow distribution with less noise. Figure 3-15 shows the flow and temperature regimes labeled for both the ambient and pumping condition.

The three flow profiles in Figure 3-14 show the change in configuration of flow in the well due to pumping. The logs for the two different pumping rates have similar profiles. Consistent features of 
flow for all three wells is upward flow in the upper screened interval, downward flow in the production casing between the upper slotted interval and the lower slotted interval, and decline in downward flow in the lower slotted interval for all three profiles. The flow profiles for 20 gpm and for 30 gpm pumping rates are similar in the upper slotted interval, with an additional 10 gpm coming from above the screened interval at the 30 gpm pumping rate. There appears to be about 4 gpm less downward flow in the lower interval at the 30 gpm pumping rate. This is consistent with the increased drawdown at the higher pumping rate.

Figure 3-15 shows a schematic of flow and temperature regimes in the well for both the ambient borehole, ambient well and for pumping at $30 \mathrm{gpm}$. The labels are color coded (using the flow log color coding) according to whether they refer to ambient or pumping flows. Labels referring to both conditions display both colors. The temperature logs indicate inflow from the formation into the annulus above about 4,100 ft bgs, and both upward flow and downward flow from that interval, which is consistent with the flow log interpretation. These flows under ambient conditions indicate that head in both the upper and lower fracturing intervals is lower than in the middle interval.

During pumping, flow comes down the annulus from above the upper slotted interval to the slotted interval, as opposed to flow to the annulus above the upper slotted interval (presumably to the fractures above the upper slotted interval) under ambient conditions. This inflow of cooler water (source evident on the ambient borehole temperature profile) from above can be seen as a steep temperature gradient above about 3,640 ft bgs during pumping. Note that the temperature above the top of the slotted interval is not the annulus temperature but the temperature of the mixed flow up the casing to the pump. The temperature logs through the upper slotted interval suggest that flows of different temperature from the two contributing fracture intervals mix in the annulus outside of the casing, and the mixing interval is evident in the temperature log within the slotted casing. The DRI indicated in their report on the flow logging (Oberlander and Russell, 2005) that it appeared that trolling the impeller meter resulted in eddying through the slotted casing, which may have promoted such mixing. Flow down the casing from the upper slotted interval to the lower interval decreases suddenly at the top of the lower slotted interval, and then gradually along the casing with depth until a sudden drop to zero at the bottom of the slotted casing. This probably reflects flow from the casing into the annulus through the slotted casing, recognizing also that the borehole extends below the 
casing TD. The downward flow in the annulus of the lower slotted casing may be greater than the flow observed in the casing.

The flow reversal for the annulus above the upper slotted interval indicates that the head of the upper fracturing interval is less than the head in the middle fracturing interval, but greater than the in-well head during pumping (16 ft of drawdown). If the head distribution in the formation is considered in terms of heads assigned to the three discrete fracture intervals, the composite head in the well is a T-weighted average of the head in each interval. The relative $\mathrm{T}$ of each interval can be determined from the specific capacity for each (production/drawdown) observed during testing. For the fracturing interval above the upper slotted interval, the ambient flow upwards was $12 \mathrm{gpm}$ and production during pumping at $30 \mathrm{gpm}$ was about $16 \mathrm{gpm}$, for a total change of $28 \mathrm{gpm}$ resulting from a head decrease of $16 \mathrm{ft}$. The head difference between the composite ambient head and the upper fracturing interval, based on an assumption of equivalent $\mathrm{T}$ for production versus inflow to the formation, is about $7 \mathrm{ft}$. The calculation uses specific capacity: $-12 \mathrm{gpm} / \Delta \mathrm{H}$ (head difference, in feet, between the upper fracturing interval and the composite head $)=+16 \mathrm{gpm} /(\Delta \mathrm{H}-16 \mathrm{ft}$ [drawdown from composite head]). The small change in upward flow in the annulus from the middle fracturing interval between the ambient condition and the pumping condition, 26 gpm to 31 gpm, indicates that the 16-ft head change is small relative to the head difference between the middle fracture interval and the ambient, composite head. Based on an assumption of constant $\mathrm{T}$ (and specific capacity), the head in the middle fracturing interval would be about $80 \mathrm{ft}$ higher than the composite head ([26 gpm / 5 gpm] x 16 ft drawdown). The head in the bottom of the borehole would be $>16 \mathrm{ft}$ less than the ambient wellbore head because flow was still downward from the upper to the middle slotted interval during pumping at $30 \mathrm{gpm}$, which imposed about $16 \mathrm{ft}$ of drawdown. The small increase in downward flow during pumping, 14 gpm to $17 \mathrm{gpm}$, is inconsistent and not explained.

The relationship between the fracturing intervals appears to be that the middle fracturing interval is at much higher head than the upper fracturing interval, but less transmissive. This is interpreted from the production versus drawdown data (specific capacity); $28 \mathrm{gpm}$ / (16 - $7 \mathrm{ft}$ )-drawdown for the upper fracturing interval and $5 \mathrm{gpm} /$ 16-ft drawdown for the middle fracturing interval. The lower fracturing interval is at an undetermined lower head than the other fracturing intervals. Based on the similar flow to the lower fracturing under ambient and pumping conditions, the head in the lower 
fracturing appears to be substantially lower than the 16-ft drawdown from the composite head during pumping.

\subsubsection{Hydraulic Conductivity Estimates}

Hydraulic conductivity can be calculated from the T by dividing by aquifer thickness; that is, the thickness of the formation that the test response is deemed to represent. This can be considered in several ways depending upon the nature of the representation of hydraulic properties required. Several types of aquifer thicknesses can be defined, and the resultant estimates of $\mathrm{K}$ are listed in Table 3-4. A general value for the formation can be calculated using the entire formation thickness open to the pumping stress, listed as Type 1. Due to the open annulus behind the completion casing, pumping stress is applied the entire length of the borehole from the static water level to the bottom of the borehole.

Table 3-4

Hydraulic Conductivity Estimates

\begin{tabular}{|c|c|c|c|c|c|}
\hline Parameter & Type & Description & Thickness (ft) & Minimum & Maximum \\
\hline$T\left(\mathrm{ft}^{2} / \mathrm{d}\right)$ & $\bar{N} / \mathrm{A}$ & Test analysis result & $\bar{N} / \mathrm{A}$ & 548 & 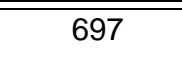 \\
\hline$K(f t / d)$ & 1 & $\begin{array}{l}\text { Entire open annulus, static water } \\
\text { level to bottom of borehole }\end{array}$ & 1,793 & 0.31 & 0.39 \\
\hline$K(f t / d)$ & 2 & $\begin{array}{l}\text { Top of upper fracture interval to } \\
\text { bottom of middle fracture interval }\end{array}$ & 1,060 & 0.52 & 0.66 \\
\hline T Upper (ft²/d) & 3 & Apportioned by specific capacity & N/A & 498 & 633 \\
\hline K Upper (ft/d) & 3 & Upper fracture interval & 350 & 1.42 & 1.81 \\
\hline T Middle (ft $2 / \mathrm{d})$ & 3 & Apportioned by specific capacity & N/A & 50 & 64 \\
\hline K Middle (ft/d) & 3 & Middle fracture interval & 380 & 0.13 & 0.17 \\
\hline
\end{tabular}

N/A = Not applicable

However, flow and temperature logging (discussed in Section 3.3) indicate the part of the borehole from which water was produced as a result of pumping, which was less than the total length of the borehole. Reflecting the flow logging information, a more representative $\mathrm{K}$ can be defined as the interval from the top of the upper fracture interval to the bottom of the middle fracture interval, which defines the overall thickness contributing to production from the well during pumping (listed as Type 2). The fracturing intervals were generally defined in Section 2.2.1. 
Finally, the thickness of the fractured intervals only, identified as the producing intervals during the test (see Section 3.3), can be used to determine K values for the fractured intervals alone, listed as Type 3. There is some uncertainty that all production came from these two fractured intervals, and it also is apparent that the intervals probably have very different hydraulic conductivities. The T determined from the test analysis can be divided between the two intervals according to the specific capacity attributed to each based on the analysis of the flow distribution and relative drawdown for each interval. Table 3-4 lists estimates of the $\mathrm{K}$ for these different interval types based on the $\mathrm{T}$ estimates from the nSights analysis listed in Table 3-2. The results show the range of K values possible resulting from the uncertainty in the test analysis and different assumptions for aquifer thickness.

\subsection{Summary}

This well was not very productive compared to other wells producing from the LCA; the production rate was low relative to the drawdown induced by pumping. However, flow observed in the well under non-pumping conditions was comparatively large, of similar magnitude to production during pumping, indicating that there are large natural head gradients across the formation. Drawdown during pumping did not exceed the natural downward gradient, and natural gradient flow downward continued during pumping. The temperature and flow logs generally indicate that groundwater inflows and outflows from the borehole are associated with the three discrete fracturing intervals: above the upper slotted interval, between the upper and the lower slotted intervals, and near the bottom of the lower slotted interval. Considering the density of fracturing, the fractures are not very permeable. The hydraulic test was interpreted in terms of T. Conversion of $\mathrm{T}$ to $\mathrm{K}$ requires that the formation thickness be identified. For this well, selection of an appropriate formation thickness depends upon the type of representativeness for the $\mathrm{K}$ value that is desired and the assumptions that are made about production from the formation. An interpretation is offered in Section 3.3.2 for the production from the different fracturing intervals and the associated head gradients in the well. However, other interpretations are possible. The T can be assigned to formation intervals according to the particular needs of the analysis, and $\mathrm{K}$ determined as a variable for different intervals or as an average for the entire completion interval. 


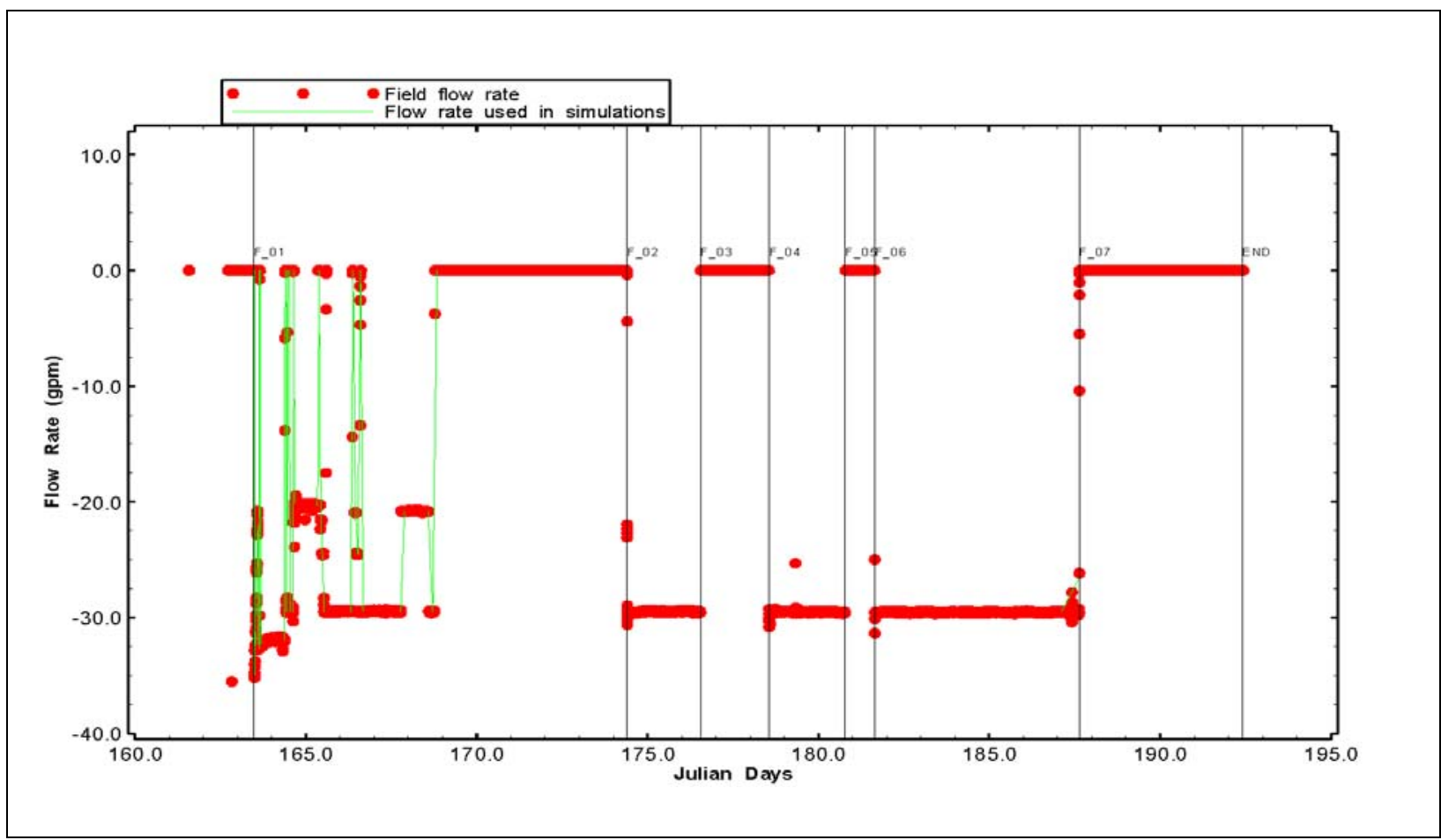

Figure 3-1

ER-12-3 Complete Hydraulic Testing Stress Periods

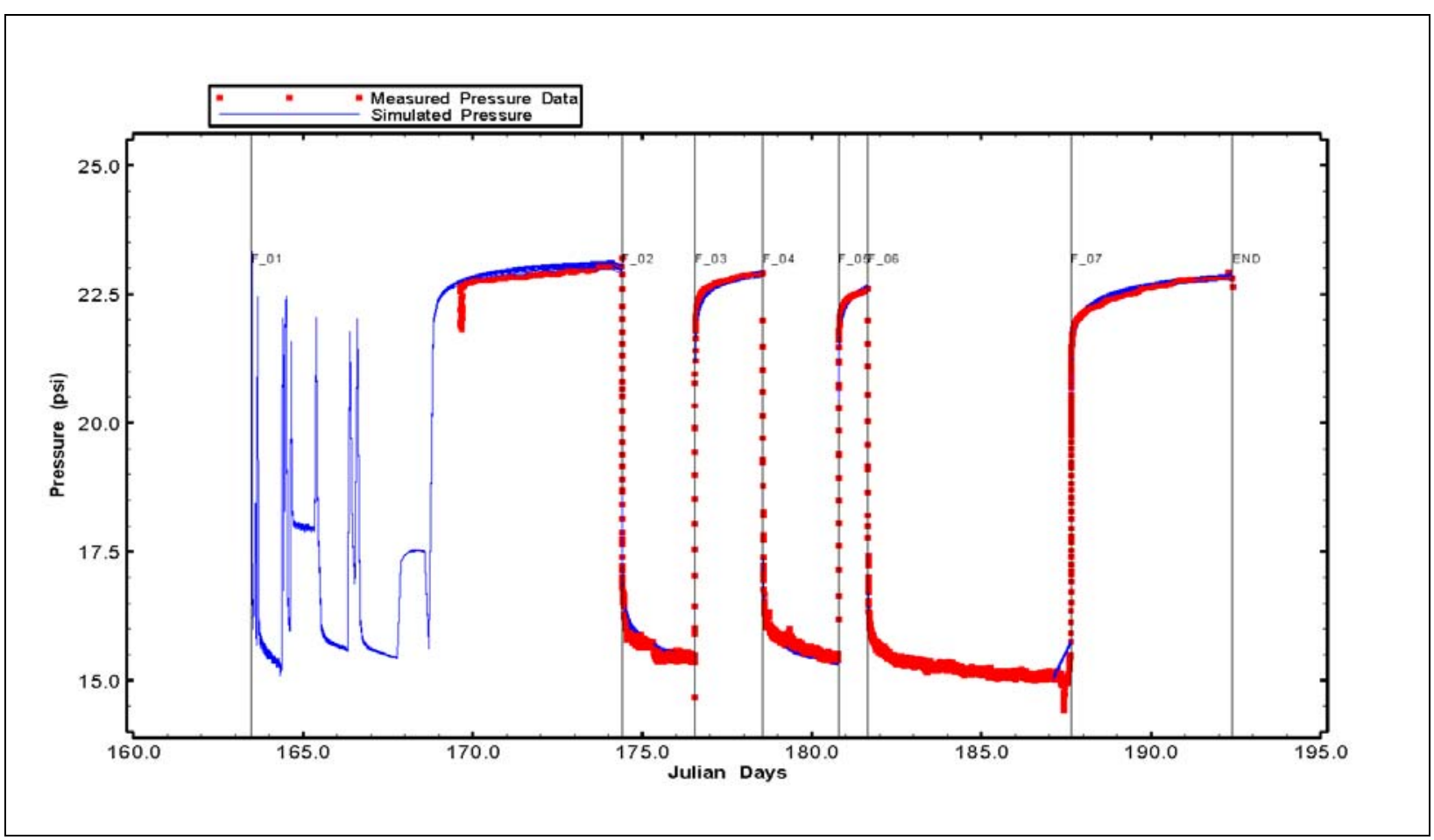

Figure 3-2

ER-12-3 Testing Program Observed Water-Level Response 


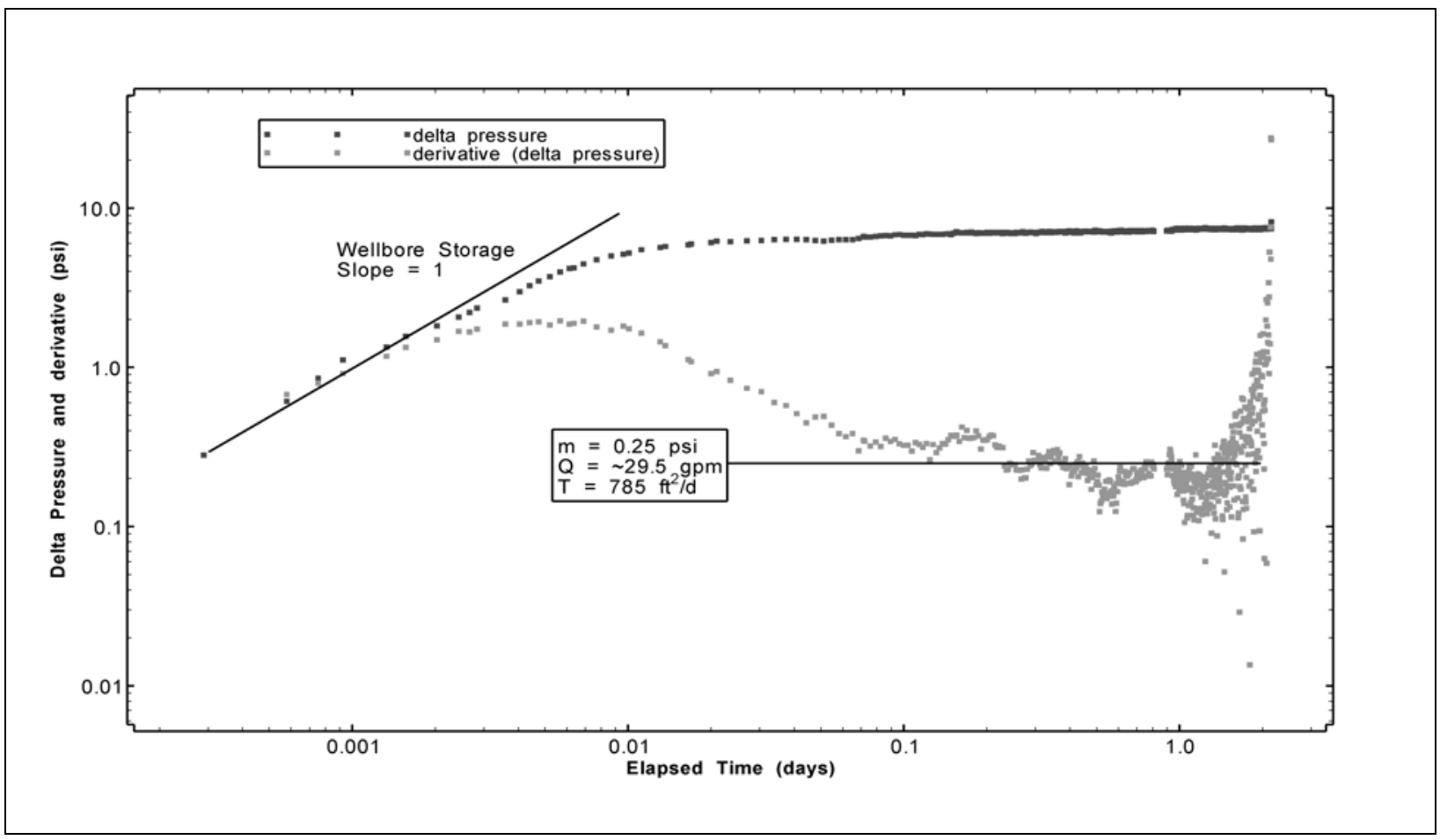

Figure 3-3

Stress Period F_02 Pressure Response Derivative

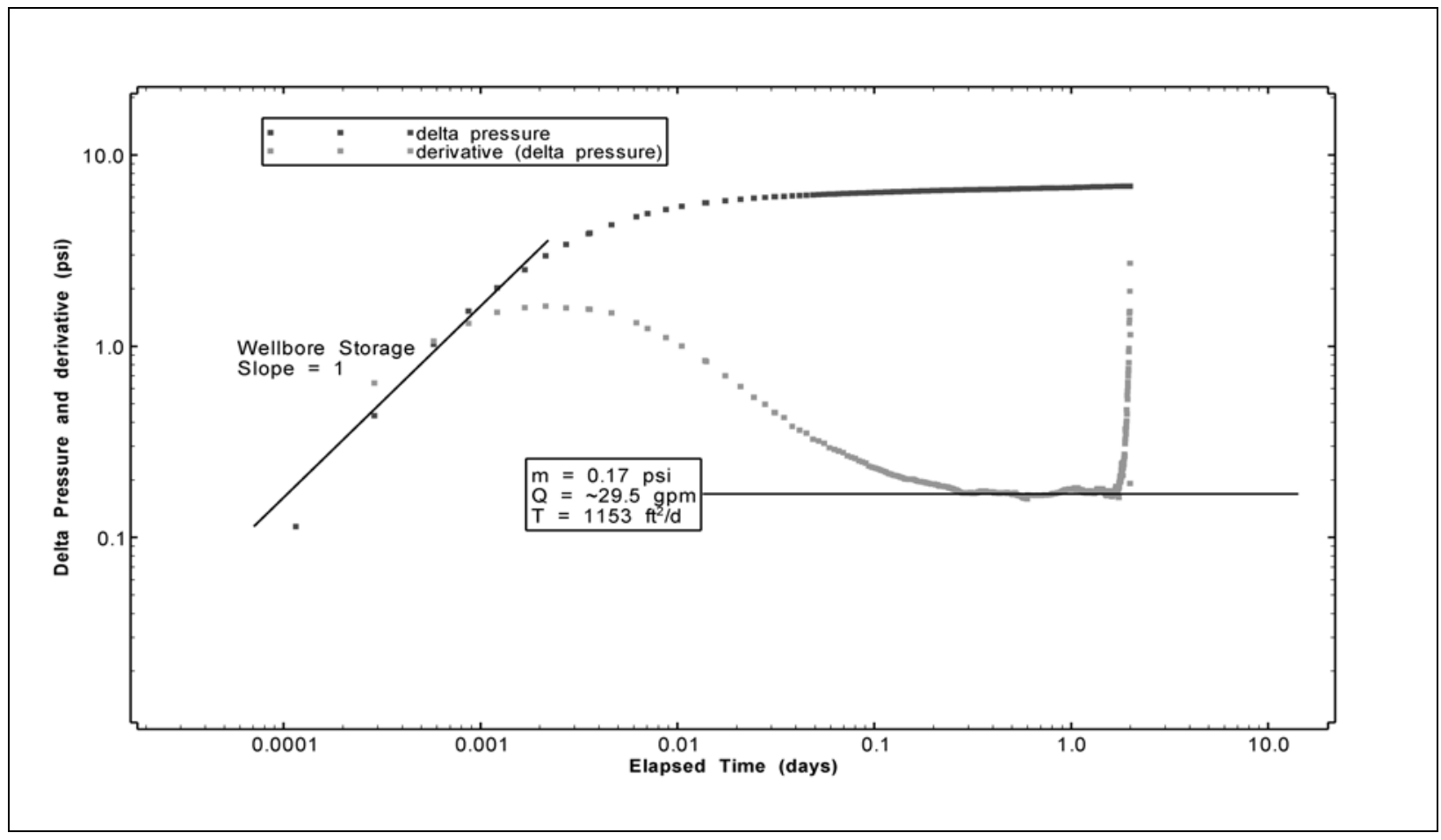

Figure 3-4

Stress Period F_03 Pressure Response Derivative 


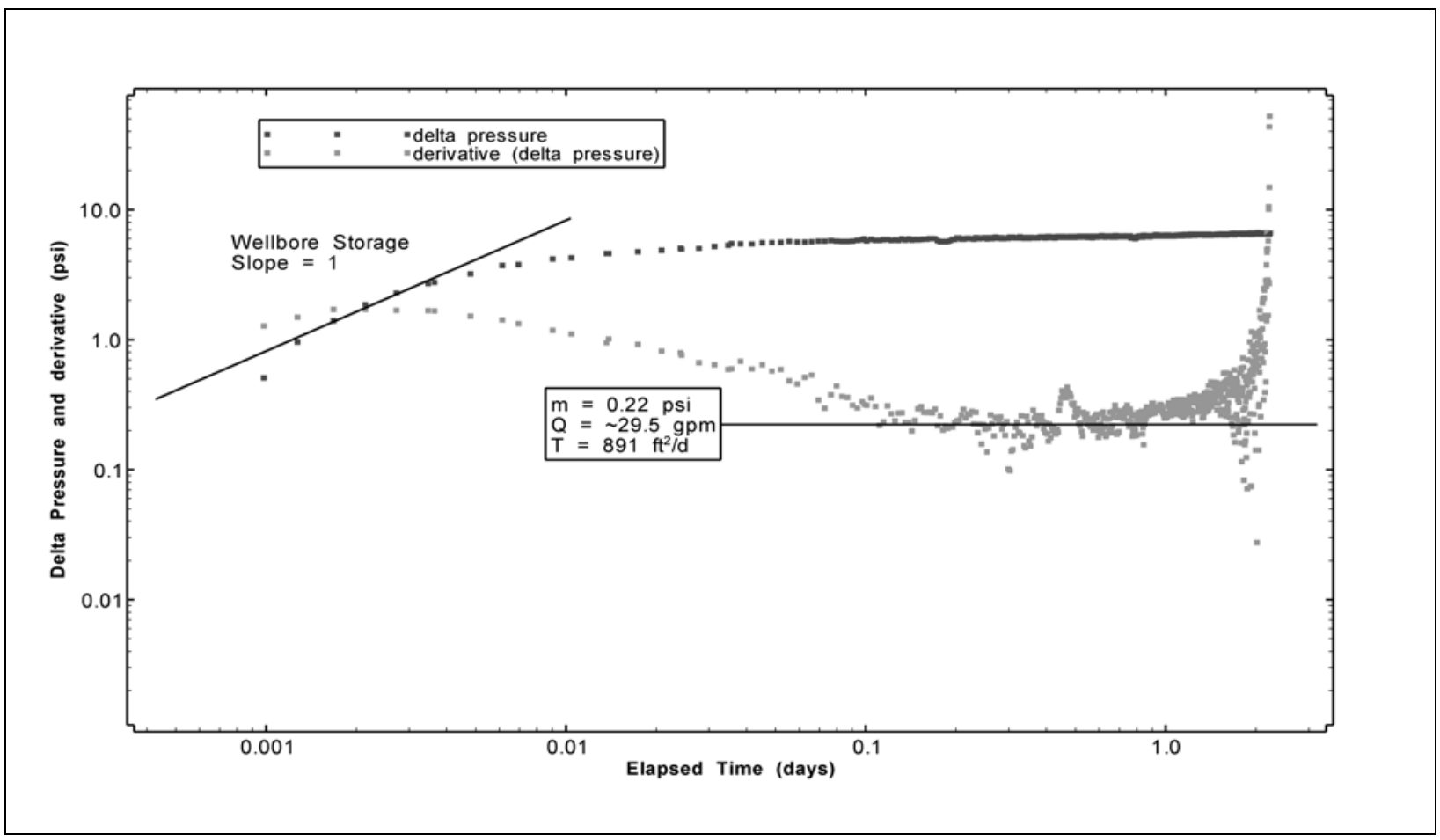

Figure 3-5

Stress Period F_04 Pressure Response Derivative

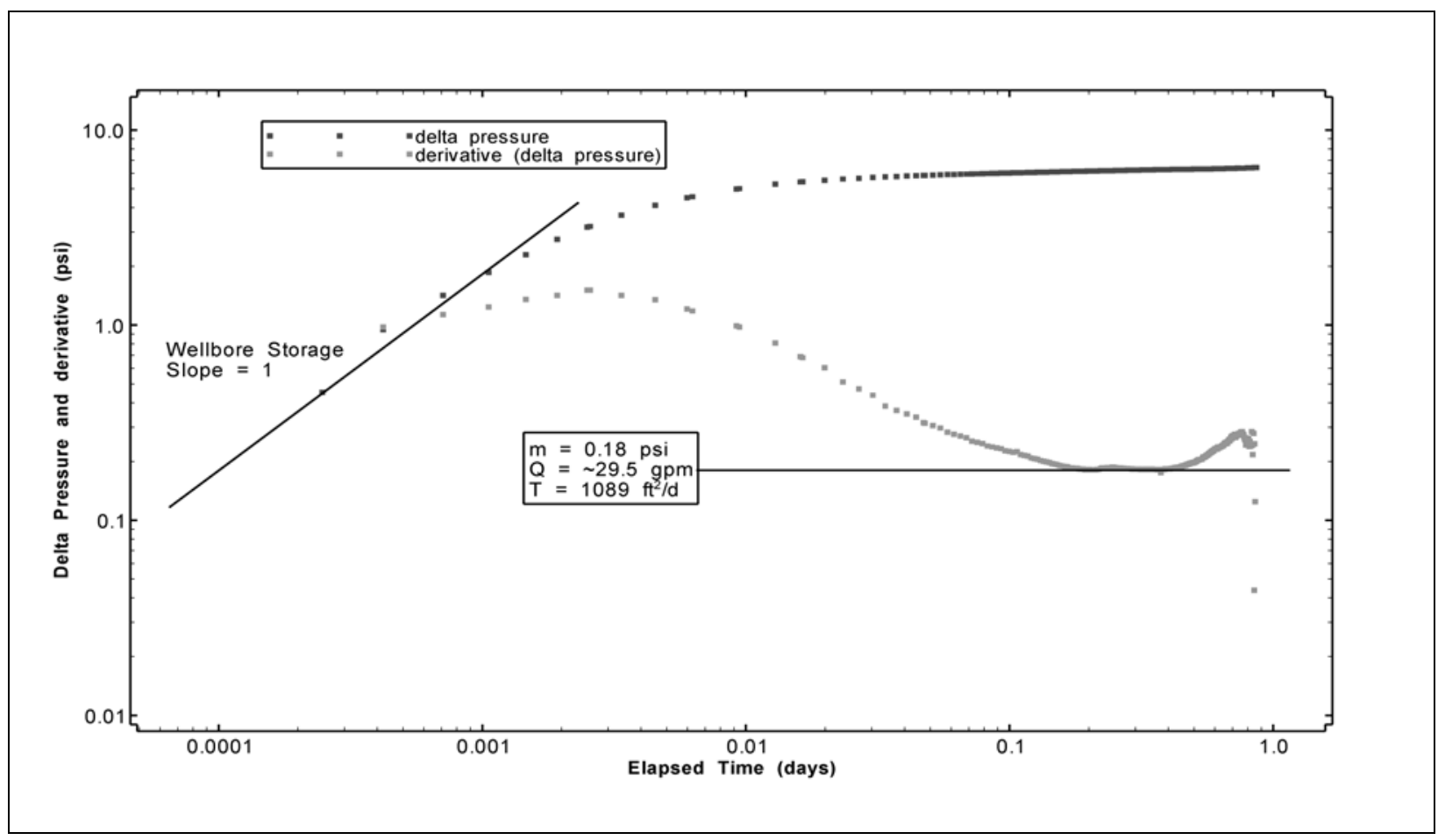

Figure 3-6

Stress Period F_05 Pressure Response Derivative 


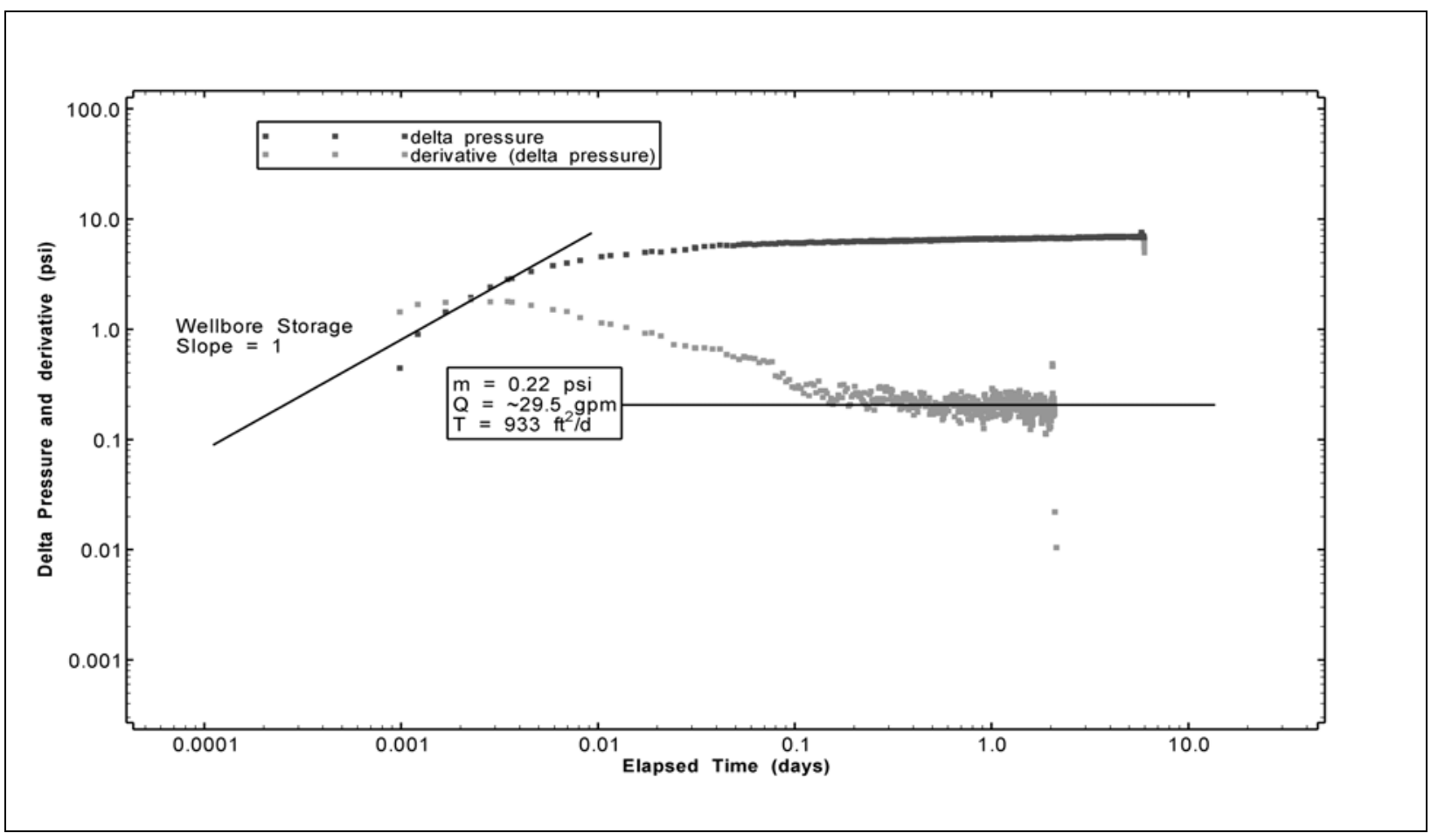

Figure 3-7

Stress Period F_06 Pressure Response Derivative

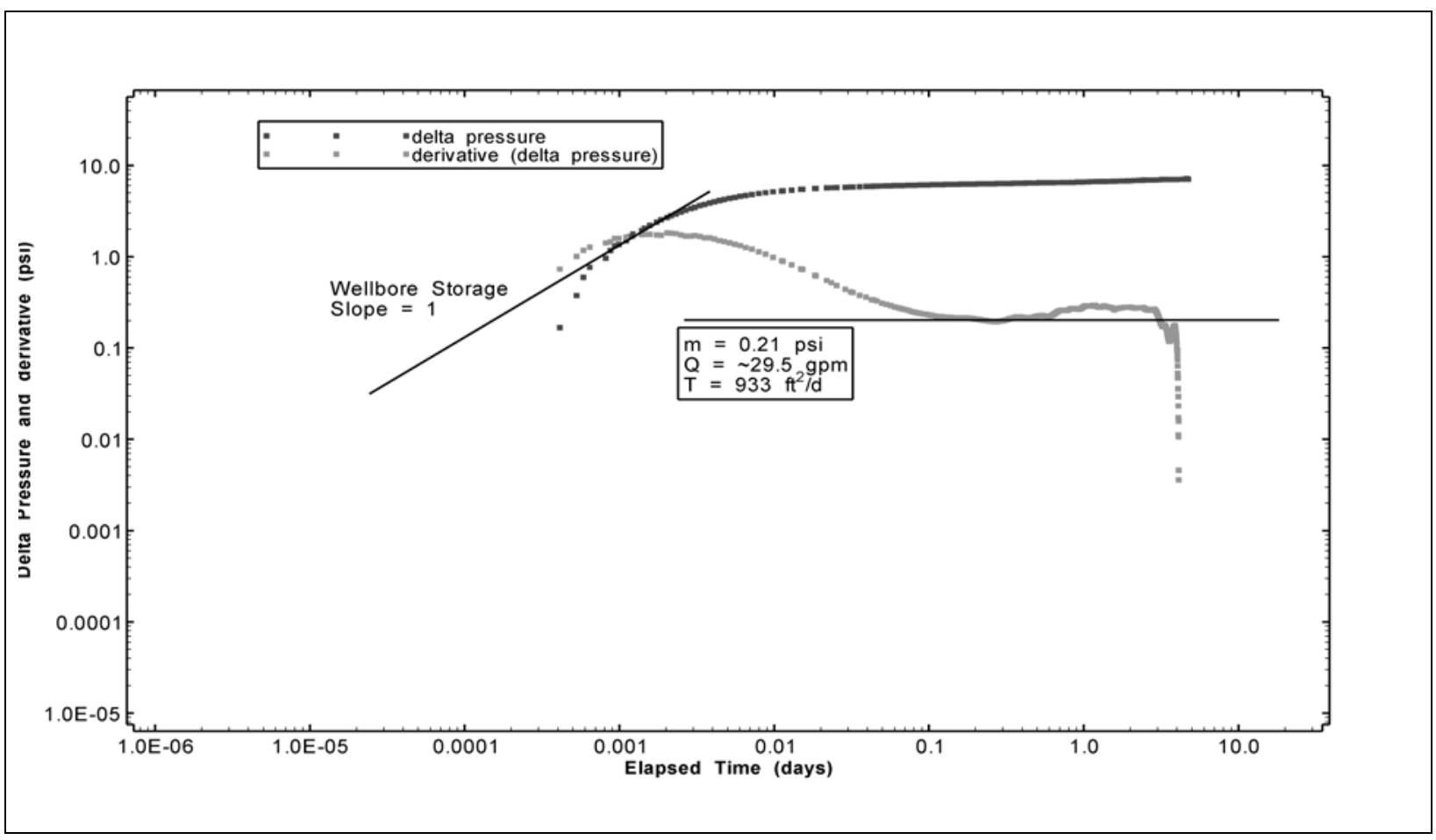

Figure 3-8

Stress Period F_07 Pressure Response Derivative 


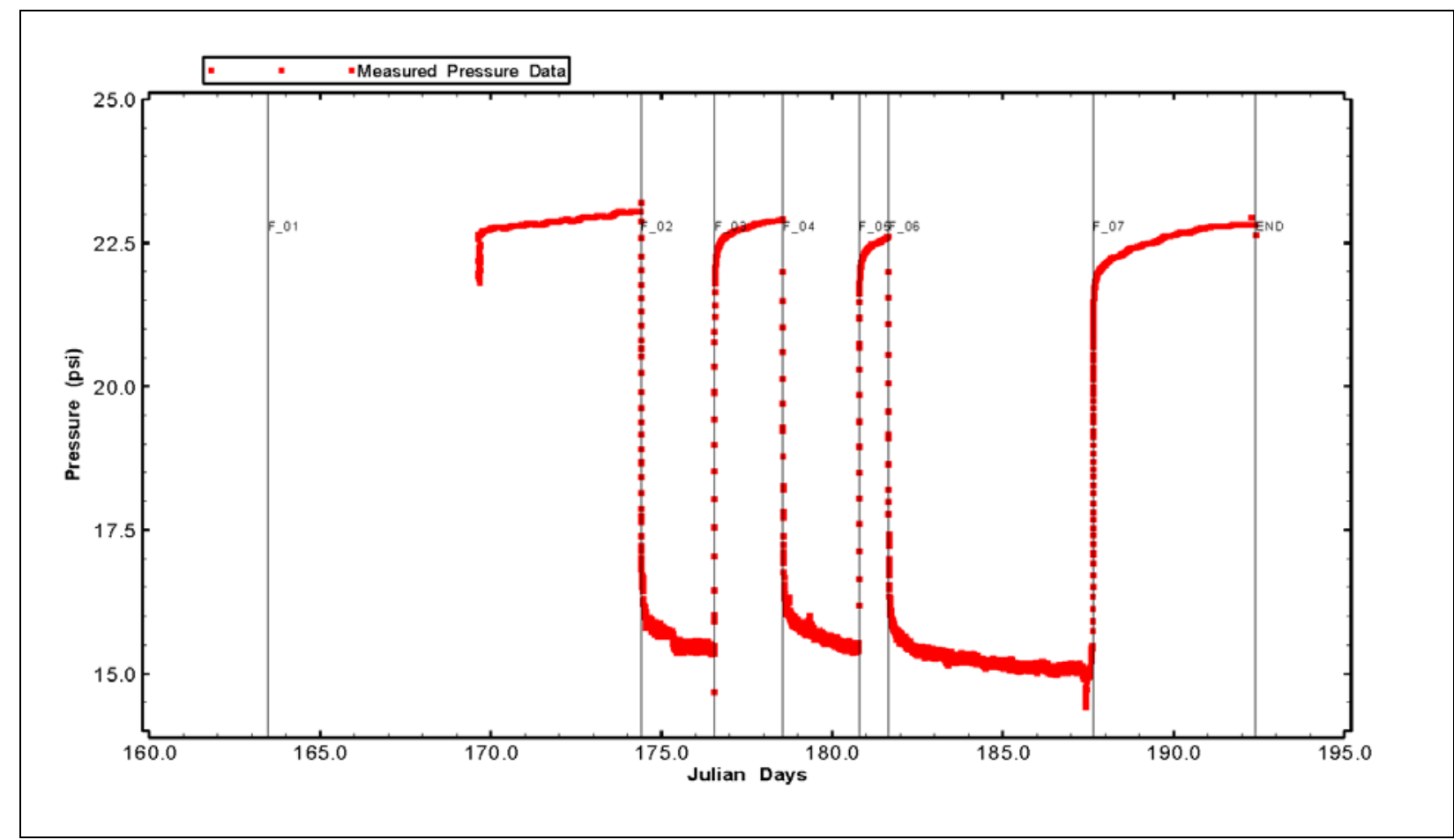

Figure 3-9

Water-Level Response Used for Hydraulic Analysis

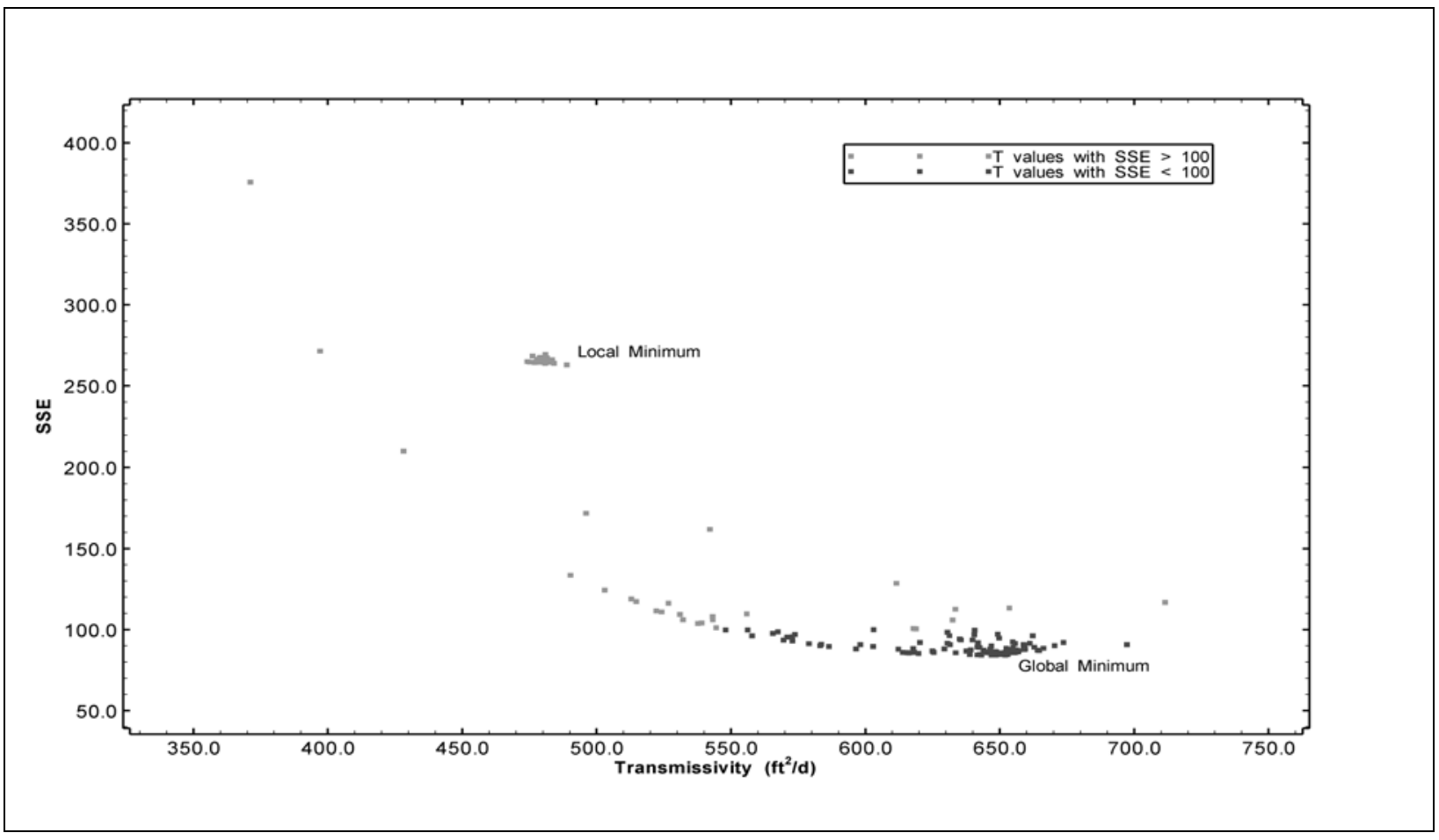

Figure 3-10

Perturbation Analysis 


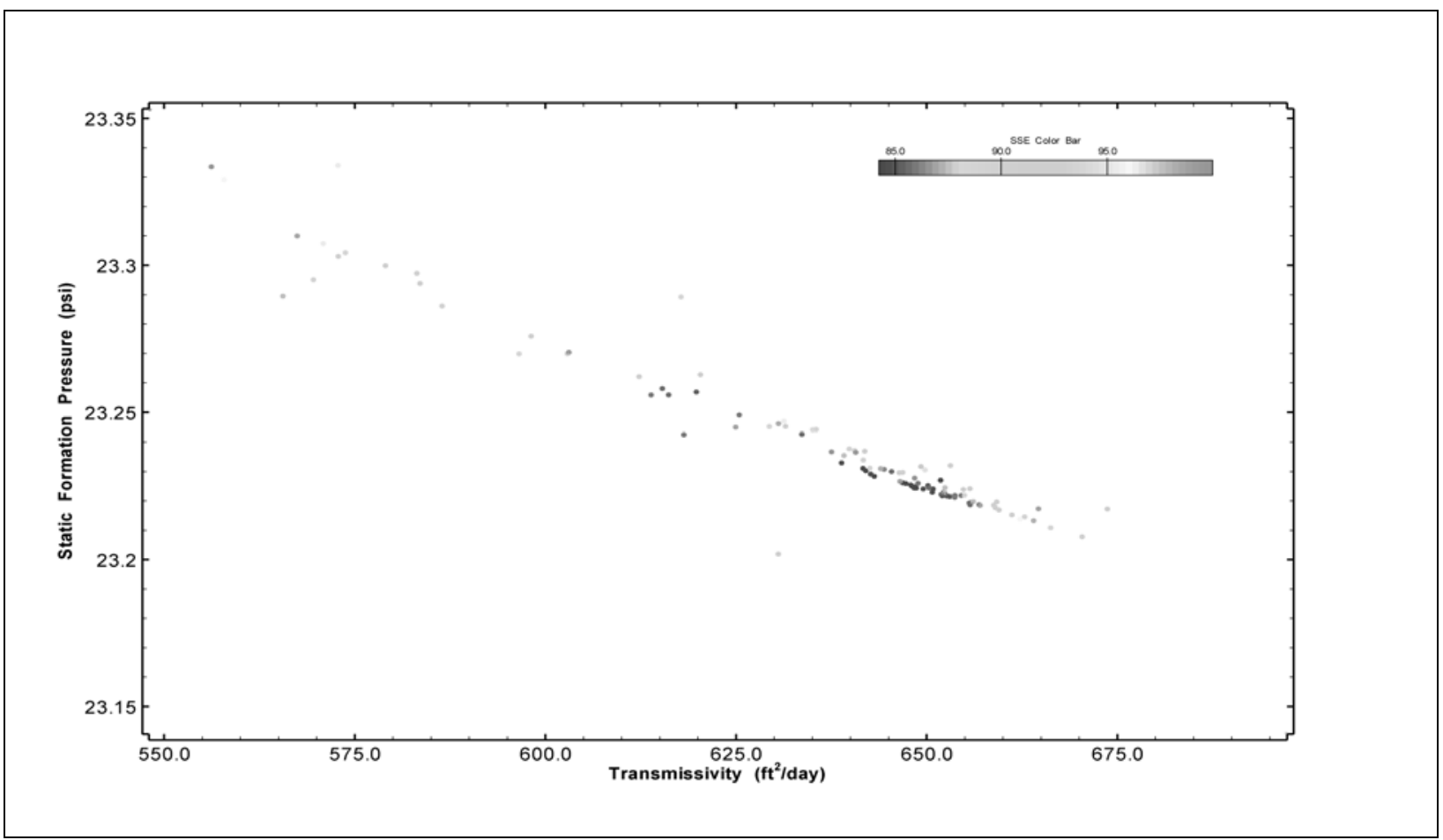

Figure 3-11

Sum of Squared Errors for Static Formation Pressure Versus Transmissivity

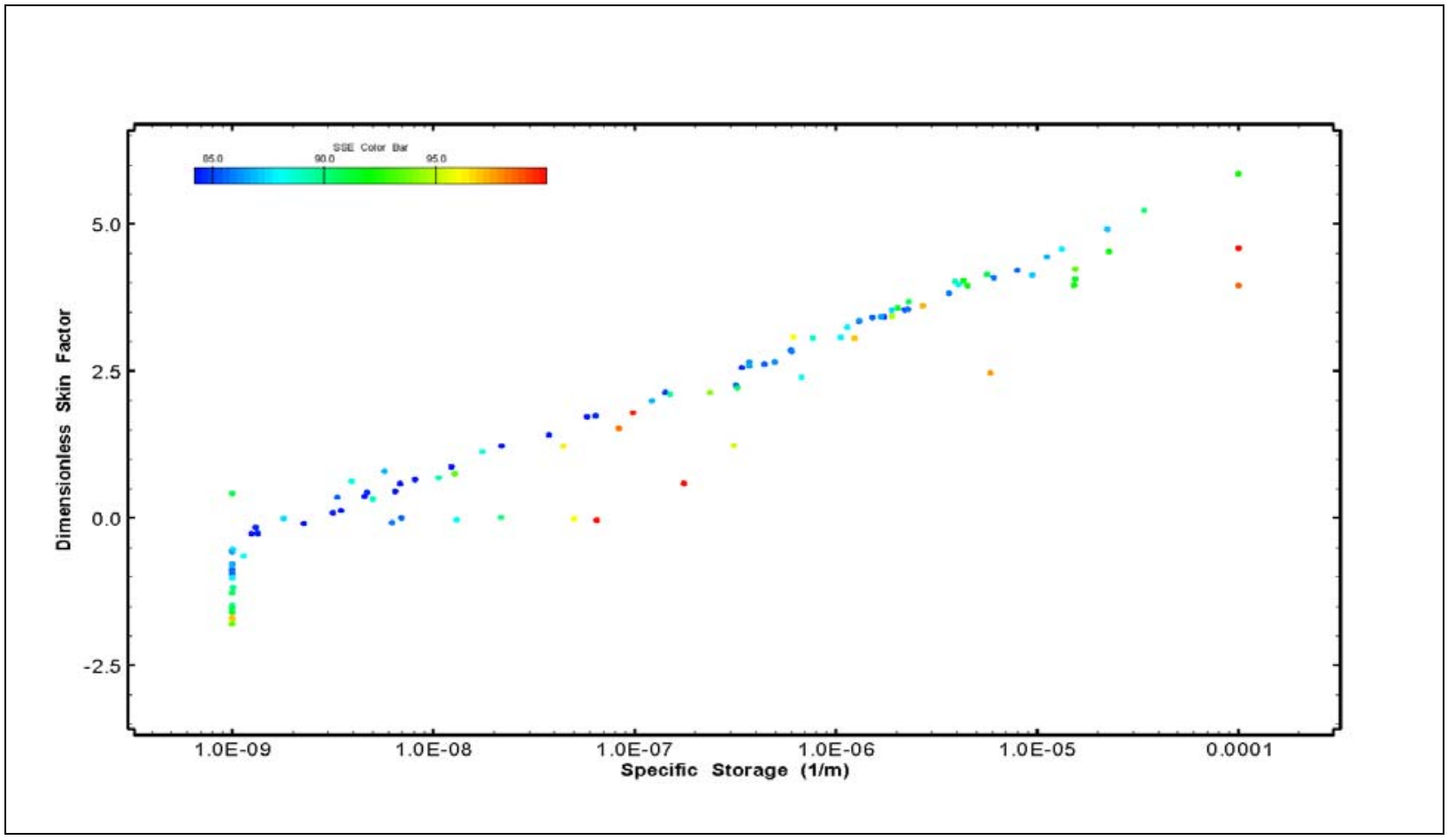

Figure 3-12

Sum of Squared Errors for Skin Versus Specific Storage 


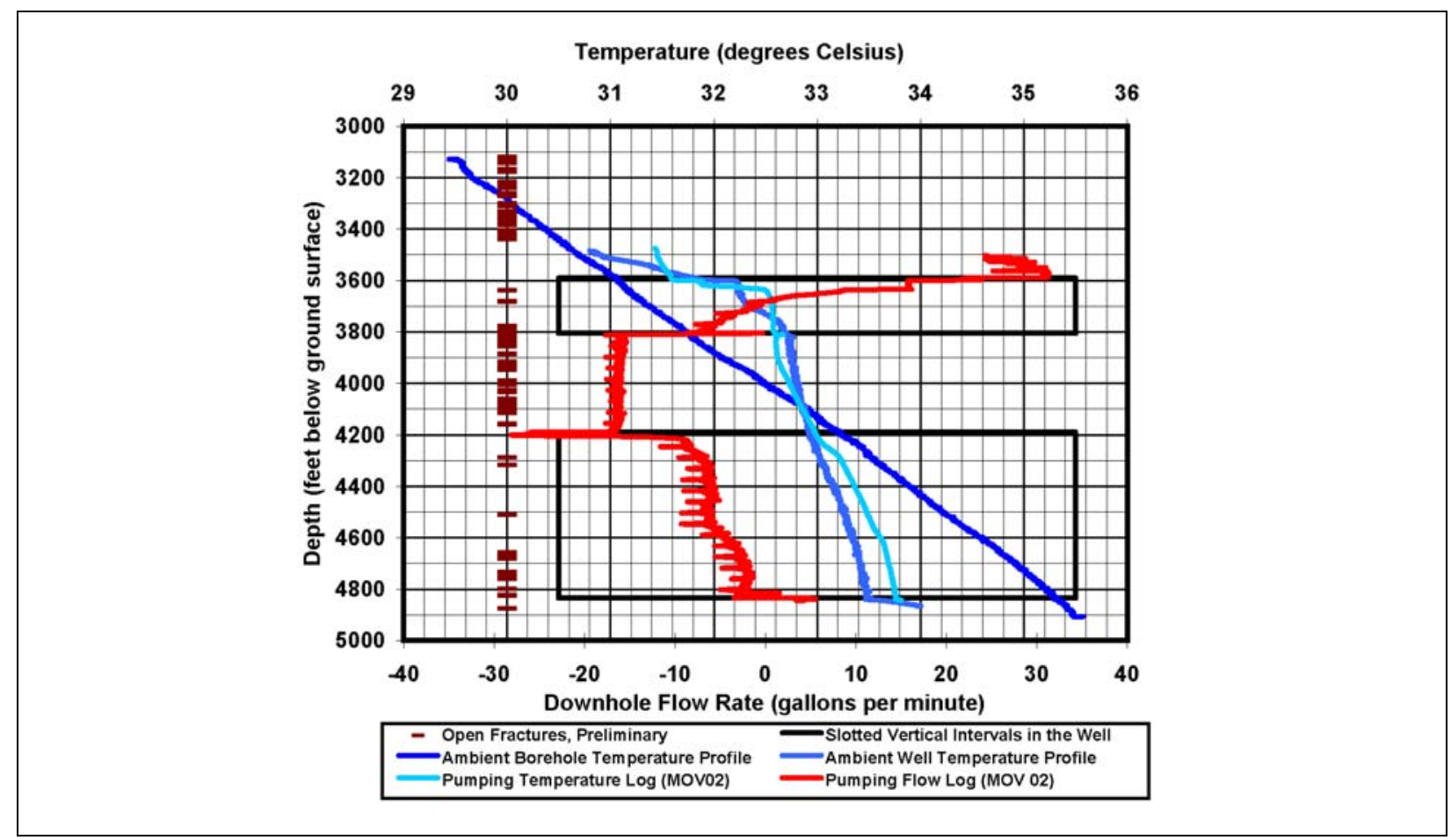

Figure 3-13

Pumping Temperature and Flow Profiles for ER-12-3

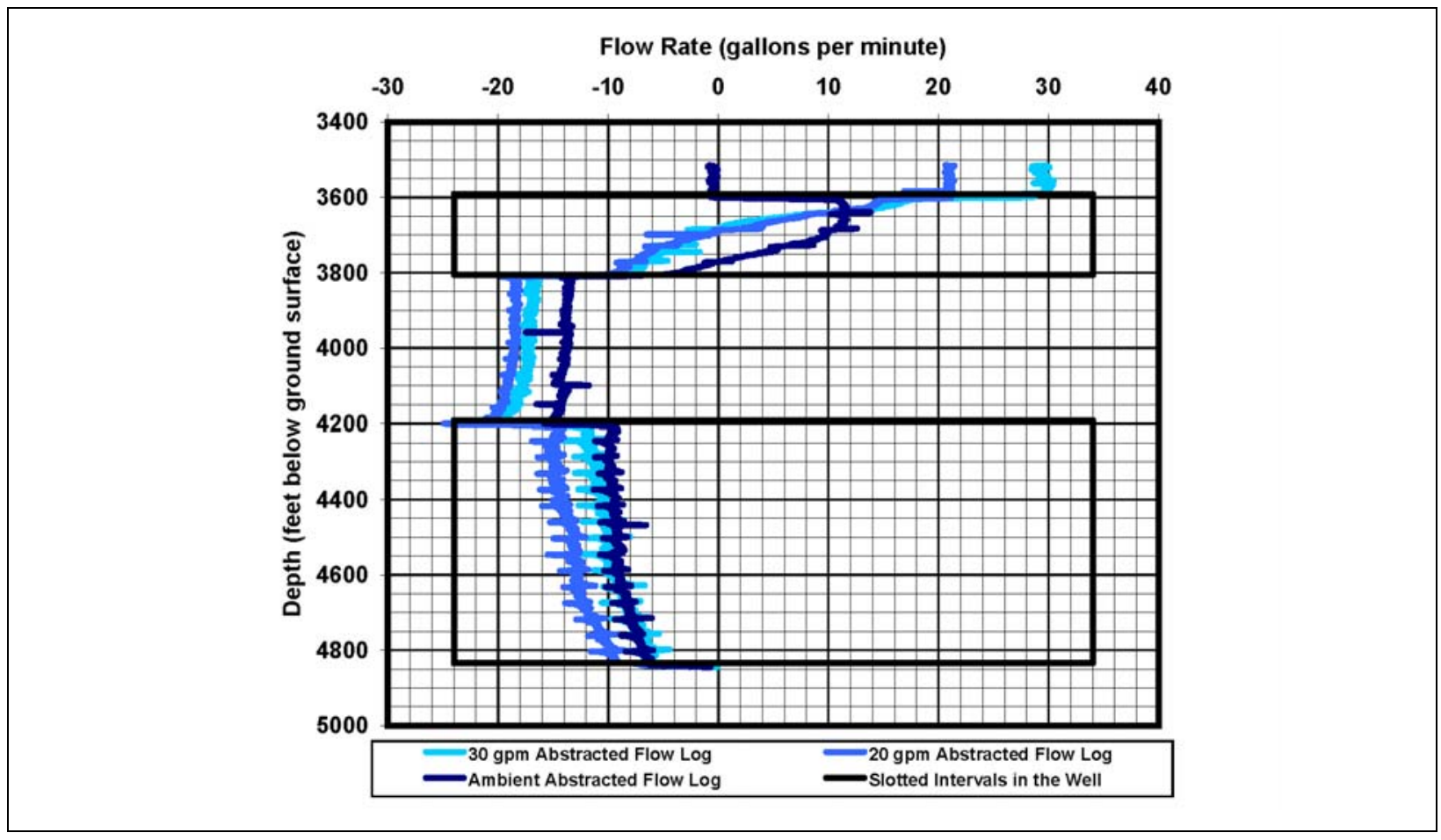

Figure 3-14

Abstracted Flow Profiles for ER-12-3 


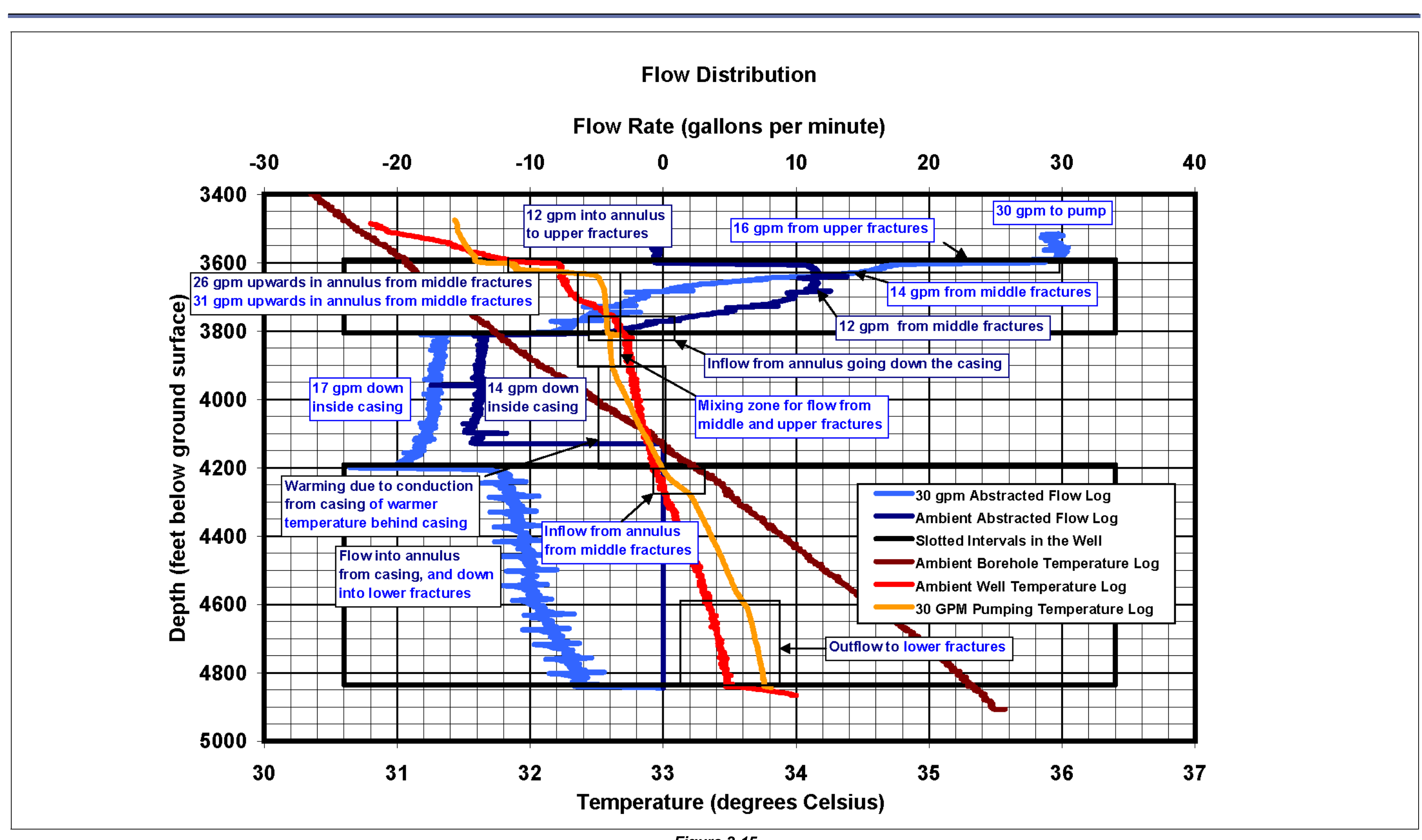

Figure 3-15

Schematic of Flow and Temperature Regimes in ER-12-3 


\subsection{Groundwater Chemistry}

This section presents an evaluation of the analytical results of the groundwater characterization samples collected during the well development and hydraulic testing activities at ER-12-3. Both depth-discrete bailed samples and well composite samples from the pumping discharge were collected at this site. The purpose of a discrete bailer is to collect groundwater samples that represent the groundwater quality of a depth-specific subsection of the formation supplying water to the well. The discrete samples are collected at a specific depth under pumping conditions and, therefore, represent groundwater produced at or below that depth. The composite groundwater sample is generally considered to be representative of all water-producing zones that contribute to the well. The groundwater chemistry data are used to determine whether ER-12-3 was sufficiently developed to restore the natural groundwater quality to that of the formation around the well. The data obtained from the depth-discrete and composite samples are compared to determine whether differences in water quality exist between the depth-specific zone and the combination of producing zones represented by the composite sample. The groundwater chemistry data are then evaluated to determine relative similarities between these groundwaters, groundwaters sampled from other wells in the area, and other wells that sample the same HSU.

\subsection{ER-12-3 Groundwater Characterization Sample Results}

On June 17, 2005, unfiltered (123-061705-2) and filtered (123-061705-2F) depth-discrete bailed samples were obtained from a depth of 3,810 ft bgs while the pump was operating at a pumping rate of $30 \mathrm{gpm}$. At the time of sample collection, approximately 183,000 gallons of groundwater had been pumped from the well. The sample was obtained using a DRI wireline logging truck, a boom truck, and a remotely-controlled discrete bailer.

On July 6, 2005, composite groundwater characterization samples (123-070605-1 and -1F) and field duplicate quality control samples (12-3-070605-2 and -2F) were collected from the wellhead sampling port after approximately 618,000 gallons of groundwater had been pumped from the well 
during development and testing activities. The production rate at the time of sampling was 30 gpm. The analytical results of these samples are presented in Table 4-1. Note that the analysis results for filtered (123-070605-1F and -2F) and unfiltered samples (123-070605-1 and -2) are listed as the dissolved and total concentrations, respectively. In addition, samples were collected for analyses by LLNL, the USGS, DRI, and LANL; the analytical results associated with these samples are presented in Table 4-2.

\subsubsection{Major, Minor, and Trace Constituents and Physical Parameters}

The data in Table 4-1 indicate that the wellhead composite groundwater characterization samples have very similar analytical results when compared to each other and when compared to the depth-discrete samples. Good agreement between laboratories is also observed (Table 4-2). Bicarbonate (98.5 to 100 milligrams per liter $[\mathrm{mg} / \mathrm{L}]$ as calcium carbonate $\left[\mathrm{CaCO}_{3}\right]$ and $120 \mathrm{mg} / \mathrm{L}$ as bicarbonate) is the predominant anion in the ER-12-3 samples. Note that two anomalous values were reported for alkalinity, 52 and $401 \mathrm{mg} / \mathrm{L}$ as $\mathrm{CaCO}_{3}$ (Tables 4-1 and 4-2), that result in charge balances of 22 and 50 percent, respectively. The large charge balances for these analyses indicate possible analytical error, and therefore these results will not be included in further evaluations.

Sodium (28.2 to $30.7 \mathrm{mg} / \mathrm{L}$ ) and calcium (13.8 to $18.1 \mathrm{mg} / \mathrm{L})$ are the predominate cations for both samples (Tables 4-1 and 4-2). A “J” qualifier, indicating an estimated value, is associated with the sodium measurements for the composite samples because a quality control measure (serial dilution) suggested a possible matrix effect for the analysis. The sodium measurements were quite similar between all laboratories and the charge balances ( 0.1 to 2.4 percent) for the samples were quite low, indicating adequate analysis results.

The ER-12-3 samples are relatively dilute with total dissolved solids values ranging from 169 to 190 $\mathrm{mg} / \mathrm{L}$. Sulfate (24.6 to $27.7 \mathrm{mg} / \mathrm{L}$ ), silicon (10 to $11 \mathrm{mg} / \mathrm{L}$ ), potassium (2.20 to $2.28 \mathrm{mg} / \mathrm{L}$ ), and chloride (5.69 to $5.8 \mathrm{mg} / \mathrm{L}$ ) are present in moderately low concentrations. The samples also have similar slightly basic $\mathrm{pH}$ values $(\mathrm{pH}=7.96$ to 8.2$)$. The "J" qualifier associated with the $\mathrm{pH}$ measurement for the depth-discrete sample indicates that the analysis was performed outside of the 48-hour holding time. The field-measured $\mathrm{pH}$ values were 8.07 to 8.13 and 8.17 to 8.20 for samples collected on June 17 and July 6, 2005, respectively. 
Table 4-1

Analytical Results for Groundwater Characterization Samples at ER-12-3

(Page 1 of 2)

\begin{tabular}{|c|c|c|c|c|c|c|c|c|}
\hline Analyte & $\begin{array}{l}\text { Reporting } \\
\text { Limit }^{\mathrm{a}}\end{array}$ & Laboratory & \multicolumn{2}{|c|}{\begin{tabular}{|c|} 
Depth-Discrete Sample \\
from $3,810 \mathrm{ft}$ bgs \\
$123-061705-2$ \\
$123-061705-2 F$
\end{tabular}} & \multicolumn{2}{|c|}{$\begin{array}{c}\text { Wellhead Composite } \\
\text { Sample } \\
\text { 123-070605-1 } \\
123-070605-1 F\end{array}$} & \multicolumn{2}{|c|}{$\begin{array}{c}\text { Duplicate Wellhead } \\
\text { Composite Sample } \\
\text { 123-070605-2 } \\
123-070605-2 F\end{array}$} \\
\hline \multicolumn{9}{|c|}{ Metals (mg/L) } \\
\hline & & & Total & Dissolved & Total & Dissolved & Total & Dissolved \\
\hline Aluminum & 0.2 & EMAX & $0.07 \mathrm{~J}^{\mathrm{b}}$ & $<0.2$ & $<0.2$ & $<0.2$ & $<0.2$ & $<0.2$ \\
\hline Arsenic & 0.01 & EMAX & $0.0051 \mathrm{~J}$ & 0.0105 & $0.0057 \mathrm{~J}$ & $0.0054 \mathrm{~J}$ & $<0.01$ & $0.0068 \mathrm{~J}$ \\
\hline Barium & 0.1 & EMAX & $0.03 \mathrm{~J}$ & $0.03 \mathrm{~J}$ & $0.02 \mathrm{~J}$ & $0.02 \mathrm{~J}$ & $0.05 \mathrm{~J}$ & $0.02 \mathrm{~J}$ \\
\hline Cadmium & 0.005 & EMAX & $<0.005$ & $<0.005$ & $<0.005$ & $<0.005$ & $<0.005$ & $<0.005$ \\
\hline Calcium & 1 & EMAX & 17.7 & 17.4 & 18.1 & 17.9 & 17.9 & 17.7 \\
\hline Chromium & 0.01 & EMAX & $<0.01$ & $<0.01$ & $<0.01$ & $<0.01$ & $<0.01$ & $<0.01$ \\
\hline Iron & 0.1 & EMAX & 0.512 & $0.049 \mathrm{~J}$ & 0.328 & 0.256 & 0.329 & 0.253 \\
\hline Lead & 0.003 & EMAX & $<0.003$ & $<0.003$ & $<0.003$ & $<0.003$ & $<0.003$ & $<0.003$ \\
\hline Lithium & 0.01 & EMAX & 0.0332 & 0.0335 & 0.0273 & 0.0268 & 0.0269 & 0.0267 \\
\hline Magnesium & 1 & EMAX & 7.72 & 7.89 & 8.71 & 8.59 & 8.58 & 8.54 \\
\hline Manganese & 0.01 & EMAX & 0.0151 & 0.0121 & 0.0288 & 0.0294 & 0.0282 & 0.0288 \\
\hline Potassium & 1 & EMAX & 2.14 & 2.22 & 2.28 & 2.26 & 2.28 & 2.24 \\
\hline Selenium & 0.005 & EMAX & $<0.005$ & $<0.005$ & $<0.005$ & $<0.005$ & $<0.005$ & $<0.005$ \\
\hline Silicon & 0.05 & EMAX & 10 & 10 & 11 & 11 & 11 & 11 \\
\hline Silver & 0.01 & EMAX & $<0.01$ & $<0.01$ & $<0.01$ & $<0.01$ & $<0.01$ & $<0.01$ \\
\hline Sodium & 1 & EMAX & 28.2 & 28.5 & $29.9 \mathrm{~J}$ & $29.6 \mathrm{~J}$ & $29.8 \mathrm{~J}$ & $29.4 \mathrm{~J}$ \\
\hline Strontium & 0.01 & EMAX & 0.151 & 0.136 & 0.112 & 0.111 & 0.112 & 0.109 \\
\hline Uranium & 0.1 & EMAX & $<0.1$ & $<0.1$ & $<0.1$ & $<0.1$ & $<0.1$ & $<0.1$ \\
\hline Mercury & 0.0002 & EMAX & $<0.0002$ & $<0.0002$ & $<0.0002$ & $<0.0002$ & $<0.0002$ & $<0.0002$ \\
\hline \multicolumn{9}{|c|}{ Inorganics (mg/L) } \\
\hline Chloride & $0.25,0.25,1.25$ & EMAX & N/A & 5.82 & N/A & 5.8 & N/A & 5.69 \\
\hline Fluoride & 0.25 & EMAX & N/A & 1.72 & N/A & 1.61 & N/A & 1.6 \\
\hline Bromide & 0.5 & EMAX & N/A & $<0.5$ & N/A & $<0.5$ & N/A & $<0.5$ \\
\hline Sulfate & $1,1,5$ & EMAX & N/A & 27.1 & N/A & 27.7 & N/A & 25 \\
\hline $\mathrm{pH}(\mathrm{SU})$ & 0.1 & EMAX & $7.94 \mathrm{~J}$ & $\mathrm{~N} / \mathrm{A}$ & 7.96 & $\mathrm{~N} / \mathrm{A}$ & 7.99 & $\mathrm{~N} / \mathrm{A}$ \\
\hline Total Dissolved Solids & 10 & EMAX & 190 & $\mathrm{~N} / \mathrm{A}$ & 176 & $\mathrm{~N} / \mathrm{A}$ & 186 & $\mathrm{~N} / \mathrm{A}$ \\
\hline Specific Conductivity ( $\mu \mathrm{S} / \mathrm{cm})$ & 1 & EMAX & 280 & N/A & 284 & N/A & 279 & N/A \\
\hline Carbonate as $\mathrm{CaCO}_{3}$ & 5 & EMAX & $<5$ & N/A & $<5$ & N/A & $<5$ & N/A \\
\hline Bicarbonate as $\mathrm{CaCO}_{3}$ & 5 & EMAX & 98.5 & $\mathrm{~N} / \mathrm{A}$ & 100 & $\mathrm{~N} / \mathrm{A}$ & 401 & N/A \\
\hline
\end{tabular}


Table 4-1

Analytical Results for Groundwater Characterization Samples at ER-12-3

(Page 2 of 2)

\begin{tabular}{|c|c|c|c|c|c|c|c|c|}
\hline \multirow[t]{3}{*}{ Analyte } & \multirow[t]{3}{*}{$\begin{array}{l}\text { Reporting } \\
\text { Limit }^{\mathrm{a}}\end{array}$} & \multirow[t]{3}{*}{ Laboratory } & \multicolumn{2}{|c|}{\begin{tabular}{|c} 
Depth-Discrete Sample \\
from $3,810 \mathrm{ft}$ bgs \\
$123-061705-2$ \\
$123-061705-2 F$
\end{tabular}} & \multicolumn{2}{|c|}{$\begin{array}{l}\text { Wellhead Composite } \\
\text { Sample } \\
\text { 123-070605-1 } \\
123-070605-1 \mathrm{~F}\end{array}$} & \multicolumn{2}{|c|}{$\begin{array}{c}\text { Duplicate Wellhead } \\
\text { Composite Sample } \\
\text { 123-070605-2 } \\
123-070605-2 F\end{array}$} \\
\hline & & & \multicolumn{6}{|c|}{ rganics (mg/L) } \\
\hline & & & Total & Dissolved & Total & Dissolved & Total & Dissolved \\
\hline Total Organic Carbon & 1 & EMAX & 2.05 & N/A & $<1$ & $\mathrm{~N} / \mathrm{A}$ & $<1$ & $\mathrm{~N} / \mathrm{A}$ \\
\hline \multicolumn{9}{|c|}{ Redox Parameter (mg/L) } \\
\hline & & & Total & Dissolved & Total & Dissolved & Total & Dissolved \\
\hline Total Sulfide & 1 & EMAX & $<1$ & N/A & $<1$ & $\mathrm{~N} / \mathrm{A}$ & $<1$ & N/A \\
\hline \multicolumn{9}{|c|}{ Radiological Indicator Parameters-Level I (pCi/L) } \\
\hline & & & Result & Error & Result & Error & Result & Error \\
\hline Tritium & $270,350,350$ & PAI & $<270$ & N/A & $<350$ & $N / A$ & $<350$ & N/A \\
\hline Gamma Spectroscopy & Varies by Nuclide & PAI & ND & $\begin{array}{l}\text { Varies by } \\
\text { Nuclide }\end{array}$ & ND & $\begin{array}{c}\text { Varies by } \\
\text { Nuclide }\end{array}$ & ND & $\begin{array}{c}\text { Varies by } \\
\text { Nuclide }\end{array}$ \\
\hline \multicolumn{9}{|c|}{ Radiological Indicator Parameters-Level II (pCi/L) } \\
\hline & & & Result & Error & Result & Error & Result & Error \\
\hline Gross Alpha & $0.99,1.5,1.43$ & PAI & 2.05 & 0.88 & $<1.5$ & $N / A$ & $<1.45(\mathrm{~J})$ & $N / A$ \\
\hline Gross Beta & $2.2,2.8,3.1$ & PAI & $<2.8(\mathrm{~J})$ & N/A & $<3.9(\mathrm{~J})$ & N/A & $<3.1(\mathrm{~J})$ & N/A \\
\hline Carbon-14 & $210,450,450$ & PAI & $<210$ & $\mathrm{~N} / \mathrm{A}$ & $<450$ & $\mathrm{~N} / \mathrm{A}$ & $<450$ & $\mathrm{~N} / \mathrm{A}$ \\
\hline Plutonium-238 & $0.017,0.026,0.039$ & PAI & $<0.017$ & $\mathrm{~N} / \mathrm{A}$ & $<0.026$ & $\mathrm{~N} / \mathrm{A}$ & $<0.039$ & $\mathrm{~N} / \mathrm{A}$ \\
\hline Plutonium-239 & $0.04,0.026,0.031$ & PAI & $<0.04$ & $\mathrm{~N} / \mathrm{A}$ & $<0.026$ & $N / A$ & $<0.031$ & $\mathrm{~N} / \mathrm{A}$ \\
\hline Strontium-90 & $0.34,0.28$ & PAI & N/A & $\mathrm{N} / \mathrm{A}$ & $<0.28$ & $\mathrm{~N} / \mathrm{A}$ & $<0.28$ & N/A \\
\hline lodine-129 & $2.7,3.2$ & PAI & N/A & $\mathrm{N} / \mathrm{A}$ & $<3.2(\mathrm{~J})$ & $\mathrm{N} / \mathrm{A}$ & $<3.2$ & N/A \\
\hline Technetium-99 & $5.9,6.5$ & PAI & N/A & N/A & $<6.5$ & $\mathrm{~N} / \mathrm{A}$ & $<6.5$ & N/A \\
\hline
\end{tabular}

a Where three reporting limits are given, the first corresponds with sample numbers 123-061705-2 and -2F, the second corresponds with sample numbers 123-070605-1 and 1F, and the third corresponds with sample numbers 123-070605-2 and 2F. Where two reporting limits are given, the first corresponds with sample numbers 123-070605-1 and -1F, and the second corresponds with sample numbers 12-3-070605-2 and -2F.

bThose values that are above the method detection limit but less than the reporting limit are given a "J" qualifier.

EMAX = EMAX Laboratories, Inc.

$\mathrm{ft}$ bgs $=$ Feet below ground surface

$\mathrm{J}=$ Indicates an estimated value

$\mathrm{mg} / \mathrm{L}=$ Milligrams per liter

N/A = Not applicable

$\mathrm{ND}=$ No gamma spectroscopy nuclides detected above detection limit

$\mathrm{PAI}=$ Paragon Analytics, Inc.

$\mathrm{pCi} / \mathrm{L}=$ Picocuries per liter

$\mathrm{SU}=$ Standard unit

$\mu \mathrm{S} / \mathrm{cm}=$ MicroSiemens per centimeter 


\section{Table 4-2 \\ Additional Analyses Results for ER-12-3 Wellhead Composite Samples (Page 1 of 3 )}

\begin{tabular}{|c|c|c|c|}
\hline Analyte & $\begin{array}{c}\text { Laboratory } \\
\text { Detection Limit }\end{array}$ & Laboratory & $\begin{array}{l}\text { Results of Wellhead Composite } \\
\text { (Sample date - 07/06/05) }\end{array}$ \\
\hline \multicolumn{4}{|c|}{ Water Chemistry } \\
\hline Alkalinity, $\mathrm{HCO}_{3}$ as $\mathrm{CaCO}_{3}$, Field $(\mathrm{mg} / \mathrm{L})$ & Not Provided & DRI & 52 \\
\hline Alkalinity, Total as $\mathrm{CaCO}_{3}$, Field (mg/L) & Not Provided & $\overline{\mathrm{DRI}}$ & 52 \\
\hline Aluminum (ppb) & Not Provided & DRI & 1.06 \\
\hline Antimony $(\mu \mathrm{g} / \mathrm{L})$ & 1 & USGS & $<1 \mid<1$ \\
\hline Arsenic $(\mu \mathrm{g} / \mathrm{L})$ & 3.0 & USGS & $7.0 \mid 7.1$ \\
\hline Barium $(\mu \mathrm{g} / \mathrm{L})$ & 15 & USGS & $23 \mid 23$ \\
\hline Beryllium $(\mu \mathrm{g} / \mathrm{L})$ & 1 & USGS & $<1 \mid<1$ \\
\hline Bicarbonate, Laboratory (mg/L) & 1 & DRI & 120 \\
\hline Boron $(\mu \mathrm{g} / \mathrm{L})$ & 50 & USGS & $60 \mid 60$ \\
\hline Cadmium $(\mu \mathrm{g} / \mathrm{L})$ & 1 & USGS & $<1 \mid<1$ \\
\hline Calcium (mg/L) & Not Provided & LLNL & 13.8 \\
\hline Calcium (mg/L) & 0.2 & $\overline{\mathrm{DRI}}$ & 17.4 \\
\hline Chloride (mg/L) & Not Provided & LLNL & 5.7 \\
\hline Chloride (mg/L) & 0.02 & DRI & 6.0 \\
\hline Chromium ( $\mu \mathrm{g} / \mathrm{L})$ & 4.5 & USGS & $<4.5 \mid<4.5$ \\
\hline Cobalt $(\mu \mathrm{g} / \mathrm{L})$ & 1.3 & USGS & $<1.3 \mid<1.3$ \\
\hline Copper $(\mu \mathrm{g} / \mathrm{L})$ & 2.5 & USGS & $<2.5 \mid<2.5$ \\
\hline Dissolved Inorganic Carbon (mg/L as $\mathrm{HCO}_{3}$ ) & Not Provided & LLNL & 125 \\
\hline Fluoride (mg/L) & Not Provided & LLNL & 1.5 \\
\hline Fluoride (mg/L) & 0.1 & $\overline{\mathrm{DRI}}$ & 1.6 \\
\hline Iron (ppb) & Not Provided & DRI & 155 \\
\hline Lead $(\mu \mathrm{g} / \mathrm{L})$ & 0.9 & USGS & $<0.9 \mid<0.9$ \\
\hline Lithium $(\mu \mathrm{g} / \mathrm{L})$ & 2.5 & USGS & $24 \mid 24$ \\
\hline Magnesium (mg/L) & Not Provided & LLNL & 7.9 \\
\hline Magnesium (mg/L) & 0.1 & DRI & 8.03 \\
\hline Manganese $(\mu \mathrm{g} / \mathrm{L})$ & 0.8 & USGS & $27 \mid 27$ \\
\hline Molybdenum $(\mu \mathrm{g} / \mathrm{L})$ & 0.5 & USGS & $6.3 \mid 6.3$ \\
\hline Nickel $(\mu \mathrm{g} / \mathrm{L})$ & 15 & USGS & $<15 \mid<15$ \\
\hline Nitrate (mg/L) & Not Provided & LLNL & 0.8 \\
\hline Nitrate $(\mathrm{mg} / \mathrm{L})$ & 0.04 & $\overline{D R I}$ & 0.09 \\
\hline $\mathrm{pH}$ & Not Provided & LLNL & 8.2 \\
\hline $\mathrm{pH}, \mathrm{Lab}$ & 0.02 & DRI & 8.02 \\
\hline $\mathrm{pH}$, Field & 0.02 & DRI & 7.97 \\
\hline Potassium (mg/L) & Not Provided & LLNL & 2.2 \\
\hline Potassium (mg/L) & 0.1 & DRI & 2.76 \\
\hline Rubidium ( $\mu \mathrm{g} / \mathrm{L})$ & 0.5 & USGS & $7.2 \mid 7.3$ \\
\hline Selenium $(\mu \mathrm{g} / \mathrm{L})$ & 5 & USGS & $<5 \mid<5$ \\
\hline Silicon Dioxide (mg/L) & 0.5 & USGS & $25 \mid 25$ \\
\hline Silicon Dioxide (mg/L) & 0.2 & DRI & 25.3 \\
\hline Silver $(\mu \mathrm{g} / \mathrm{L})$ & 3.5 & USGS & $<3.5 \mid<3.5$ \\
\hline Sodium (mg/L) & Not Provided & LLNL & 30.7 \\
\hline Sodium (mg/L) & 0.2 & DRI & 29.8 \\
\hline Specific Conductivity $(\mu \mathrm{S} / \mathrm{cm})$ & Not Provided & LLNL & 306 \\
\hline
\end{tabular}


Table 4-2

Additional Analyses Results for ER-12-3 Wellhead Composite Samples (Page 2 of 3)

\begin{tabular}{|c|c|c|c|}
\hline Analyte & $\begin{array}{c}\text { Laboratory } \\
\text { Detection Limit }\end{array}$ & Laboratory & $\begin{array}{l}\text { Results of Wellhead Composite } \\
\text { (Sample date - 07/06/05) }\end{array}$ \\
\hline Specific Conductivity $(\mu \mathrm{S} / \mathrm{cm})$ & 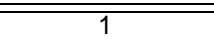 & $\overline{\mathrm{DRI}}$ & 288 \\
\hline Strontium $(\mu \mathrm{g} / \mathrm{L})$ & Not Provided & LLNL & 98 \\
\hline Strontium $(\mu \mathrm{g} / \mathrm{L})$ & 5 & USGS & $101 \mid 102$ \\
\hline Sulfate $(\mathrm{mg} / \mathrm{L})$ & Not Provided & LLNL & 24.6 \\
\hline Sulfate (mg/L) & 0.05 & DRI & 26.0 \\
\hline Thorium $(\mu \mathrm{g} / \mathrm{L})$ & 0.15 & USGS & $<0.15 \mid<0.15$ \\
\hline Total Dissolved Solids (mg/L) & Not Provided & DRI & 169 \\
\hline Uranium $(\mu \mathrm{g} / \mathrm{L})$ & Not Provided & LLNL & 1.83 \\
\hline Uranium $(\mu \mathrm{g} / \mathrm{L})$ & 0.15 & USGS & $1.96 \mid 1.92$ \\
\hline Vanadium $(\mu \mathrm{g} / \mathrm{L})$ & 1 & USGS & $2 \mid 2$ \\
\hline Water Temperature $\left({ }^{\circ} \mathrm{C}\right)$ & Not Provided & LLNL & 30.6 \\
\hline \multicolumn{4}{|c|}{ Environmental Isotopes } \\
\hline Argon-40 (atoms/g) & Not Provided & LLNL & $9.69 \times 10^{15}$ \\
\hline Carbon-14 (pmc) & Not Provided & LLNL & 2.9 \\
\hline Carbon-14 (years, uncorrected) ${ }^{b}$ & Not Provided & LLNL & 28,300 \\
\hline Chlorine-36 (atoms/L) & Not Provided & LLNL & $5.14 \times 10^{-7}$ \\
\hline Chlorine-36/Cl (ratio) & Not Provided & LLNL & $5.39 \times 10^{-13}$ \\
\hline Delta Carbon-13 (\%) & Not Provided & LLNL & -5.4 \\
\hline Delta Carbon-13 (\%) & Not Provided & $\overline{D R I}$ & -6.0 \\
\hline Delta Deuterium (\%) & Not Provided & LLNL & -106 \\
\hline Delta Deuterium (\%o) & Not Provided & $\overline{D R I}$ & -106 \\
\hline Delta Oxygen-18 (\%) & Not Provided & LLNL & -14.5 \\
\hline Delta Oxygen-18 (\%) & Not Provided & DRI & -14.5 \\
\hline Dissolved Organic Carbon-13 (\%) & Not Provided & $\overline{\mathrm{DRI}}$ & -40.5 \\
\hline Dissolved Organic Carbon-14 (pmc) & Not Provided & DRI & 53.7 \\
\hline Helium-3 (atoms/g) & Not Provided & LLNL & $3.24 \times 10^{6}$ \\
\hline Helium-3/4 (measured value) & Not Provided & LLNL & $1.8 \times 10^{-7}$ \\
\hline Helium-3/4, relative to air (ratio) & Not Provided & LLNL & 0.13 \\
\hline Helium-4 (atoms/g) & Not Provided & LLNL & $1.79 \times 10^{13}$ \\
\hline Krypton (atoms/g) & Not Provided & LLNL & $2.14 \times 10^{12}$ \\
\hline Neon-20 (atoms/g) & Not Provided & LLNL & $7.30 \times 10^{12}$ \\
\hline Strontium-87/86 (\%) & Not Provided & LLNL & 1.90 \\
\hline Strontium-87/86 (ratio) & Not Provided & LLNL & 0.71055 \\
\hline Strontium-87/86 (ratio) & Not Provided & USGS & 0.71034 \\
\hline Uranium-234/235 & Not Provided & LLNL & $1.58 \times 10^{-2}$ \\
\hline Uranium-234/238 & Not Provided & LLNL & $1.15 \times 10^{-4}$ \\
\hline Uranium-234/238 (activity ratio) & Not Provided & LLNL & 2.09 \\
\hline Uranium-234/238 (activity ratio) & Not Provided & USGS & 2.21 \\
\hline Uranium-235/238 & Not Provided & LLNL & $7.26 \times 10^{-3}$ \\
\hline Xenon-130 (atoms/g) & Not Provided & LLNL & $1.16 \times 10^{10}$ \\
\hline
\end{tabular}


Table 4-2

Additional Analyses Results for ER-12-3 Wellhead Composite Samples (Page 3 of 3 )

\begin{tabular}{||l|c|c|c|}
\hline \multicolumn{1}{|c|}{ Analyte } & $\begin{array}{c}\text { Laboratory } \\
\text { Detection Limit }\end{array}$ & Laboratory & $\begin{array}{c}\text { Results of Wellhead Composite } \\
\text { (Sample date - 07/06/05) }\end{array}$ \\
\hline \hline \multicolumn{3}{|c|}{ Radiochemistry } \\
\hline Chlorine-36 (pCi/L) & Not Provided & LLNL & $1.0 \times 10^{-4}$ \\
\hline Krypton-85 (pCi/L) & 0.5 & LANL & $<0.5$ \\
\hline Tritium (pCi/L) & $<0.5$ & LLNL & 0.5 \\
\hline Tritium (pCi/L) & 500 & LANL & $<500$ \\
\hline Uranium-234 (pCi/L) & Not Provided & LLNL & 1.30 \\
\hline Uranium-235 (pCi/L) & Not Provided & LLNL & 0.029 \\
\hline Uranium-238 $(\mathrm{pCi} / \mathrm{L})$ & Not Provided & LLNL & 0.612 \\
\hline
\end{tabular}

aDuplicate samples (123-070605-5 and -5F [a] and 123-070605-5 and -5F [b]) were analyzed by the USGS. The results for each sample are presented.

bThe reported carbon-14 age is not corrected for reactions along the flow path

$\begin{array}{ll}\text { atoms } / \mathrm{g}=\text { Atoms per gram } & \text { pmc }=\text { Percent modern carbon } \\ \mathrm{CaCO}_{3}=\text { Calcium carbonate } & \mathrm{ppb}=\text { Parts per billion } \\ \mathrm{HCO}_{3}=\text { Bicarbonate } & \%=\text { Per mil } \\ \mathrm{mg} / \mathrm{L}=\text { Milligrams per liter } & \mu \mathrm{S} / \mathrm{cm}=\text { MicroSiemens per centimeter } \\ \mathrm{pCi} / \mathrm{L}=\text { Picocuries per liter } & \mu \mathrm{g} / \mathrm{L}=\text { Micrograms per liter }\end{array}$

A significant number of the analytes in the "metals" section (minor and trace elements) of Table 4-1 were not detected above the method detection limit. Although the concentrations of most of the reduction/oxidation (redox) sensitive parameters (i.e., arsenic, chromium, iron, manganese, sulfate/sulfide, selenium, and uranium) are below the method detection limits, the detectable concentrations are relatively similar between all samples collected.

\subsubsection{Environmental Isotopes}

The measured values of delta deuterium $(\delta \mathrm{D})$ and delta oxygen-18 $\left(\delta^{18} \mathrm{O}\right)$ were identical for the LLNL and DRI analyses, -106 per mil (\%o) and -14.5\%o for $\delta \mathrm{D}$ and $\delta^{18} \mathrm{O}$, respectively. The delta carbon-13 $\left(\delta^{13} \mathrm{C}\right)$ of dissolved inorganic carbon ranged from -6.0 \%o (DRI) to -5.4 \%o (LLNL). The carbon-14 $\left({ }^{14} \mathrm{C}\right)$ was measured to be $2.9 \mathrm{pmc}$, which resulted in an uncorrected ${ }^{14} \mathrm{C}$ age of approximately 28,300 years. However, the low ${ }^{14} \mathrm{C}$ and the moderately heavy $\delta^{13} \mathrm{C}$ are indicative of groundwater interaction with the carbonate host rock causing the measured ${ }^{14} \mathrm{C}$ age to appear older than the actual age of the water (LLNL, 2006). The $\delta^{13} \mathrm{C}$ and ${ }^{14} \mathrm{C}$ associated with the dissolved organic carbon are $-40.5 \%$ and 53.7 pmc, respectively (Table 4-2). 
The helium-3/4 $\left({ }^{3} \mathrm{He} /{ }^{4} \mathrm{He}\right)$ ratio in the composite sample $\left(\mathrm{R}=1.8 \times 10^{-7}\right)$ is much lower than the natural atmospheric ratio $\left(\mathrm{R}_{\mathrm{a}}=1.38 \times 10^{-6}\right)$ and yields an $\mathrm{R} / \mathrm{R}_{\mathrm{a}}$ of 0.13 . These data reflect an excess of ${ }^{4} \mathrm{He}$ in the water, presumably from the decay of uranium and thorium in the aquifer, and suggest a groundwater residence time on the order of 13,000 years (LLNL, 2006).

The chlorine-36/ $\mathrm{Cl}\left({ }^{36} \mathrm{Cl} / \mathrm{Cl}\right)$ ratio reported by LLNL, $5.39 \times 10^{-13}$, is in the range of the modern atmospheric ratio for southern Nevada (Fabryka-Martin et al., 1993) but greater than that observed for groundwaters of the LCA3 in Yucca Flat (SNJV, 2006a). The strontium-87/86 $\left({ }^{87} \mathrm{Sr} /{ }^{86} \mathrm{Sr}\right)$ ratios of 0.71055 and 0.71034 are in general lower than observed in Yucca Flat LCA3/LCA groundwater (SNJV, 2006a). The elevated ${ }^{36} \mathrm{Cl} / \mathrm{Cl}$ and lower ${ }^{87} \mathrm{Sr} /{ }^{86} \mathrm{Sr}$ suggest mixing of groundwater of the LCA3 with that of the overlying volcanic aquifer (LLNL, 2006).

\subsubsection{Radionuclide Contaminants}

No detectable activity for any of the measured radionuclides was observed in the sample collected by SNJV and analyzed by Paragon Analytics, Inc. (Table 4-1). The concentration of dissolved uranium (1.8 to $1.9 \mu \mathrm{g} / \mathrm{L}$; Table 4-2) was reported to be within the expected range for waters of the LCA3. In addition, the uranium-234/238 $\left({ }^{234} \mathrm{U} / 238 \mathrm{U}\right)$ ratio (2.09 to 2.21$)$ indicates that the uranium is of natural origin (LLNL, 2006). The tritium activity $(0.5 \mathrm{pCi} / \mathrm{L})$ is significantly less than the activity in other wells on and near Rainier Mesa (LLNL, 2006).

\subsubsection{Colloids}

Table 4-3 presents the results for the colloid analysis, performed by LANL, of the composite samples collected from ER-12-3 on July 6, 2005. Duplicate analyses of two composite samples were performed. The colloid concentrations for each analysis, along with the average concentration, are reported in Table 4-3, which shows that the composite groundwater characterization sample had a total average colloid concentration of $1.88 \times 10^{8}$ particles per milliliter (particles/mL) for colloids in the size range of 50 to 1,000 nanometers (nm). Note that the colloid size reported in Table 4-3 is the equivalent spherical diameter (the amount of light scattered by a spherical particle of a given diameter). A decreasing trend is observed in the concentration of colloids as the size increased from 90 to $1,000 \mathrm{~nm}$. 
Table 4-3

Colloid Analyses for ER-12-3 Composite Wellhead Samples

\begin{tabular}{|c|c|c|c|c|c|}
\hline $\begin{array}{l}\text { Colloid Particle Size } \\
\qquad(\mathrm{nm})\end{array}$ & $\begin{array}{c}\text { 1230-05-150 (1) } \\
\text { Concentration } \\
\text { (particles } / \mathrm{mL} \text { ) }\end{array}$ & $\begin{array}{c}\text { 1230-05-150 (2) } \\
\text { Concentration } \\
\text { (particles } / \mathrm{mL} \text { ) }\end{array}$ & $\begin{array}{l}\text { 1230-05-160 (1) } \\
\text { Concentration } \\
\text { (particles } / \mathrm{mL} \text { ) }\end{array}$ & $\begin{array}{l}\text { 1230-05-160 (2) } \\
\text { Concentration } \\
\text { (particles } / \mathrm{mL} \text { ) }\end{array}$ & $\begin{array}{c}\text { Average } \\
\text { Concentration } \\
\text { (particles } / \mathrm{mL} \text { ) }\end{array}$ \\
\hline 50 & $1.81 \mathrm{E}+07$ & $1.92 \mathrm{E}+07$ & $3.23 \mathrm{E}+07$ & $3.43 \mathrm{E}+07$ & $2.60 \mathrm{E}+07$ \\
\hline 60 & $2.15 \mathrm{E}+07$ & $2.28 \mathrm{E}+07$ & $3.78 \mathrm{E}+07$ & $3.96 \mathrm{E}+07$ & $3.04 \mathrm{E}+07$ \\
\hline 70 & $2.02 \mathrm{E}+07$ & $2.20 \mathrm{E}+07$ & $3.46 \mathrm{E}+07$ & $3.91 \mathrm{E}+07$ & $2.90 \mathrm{E}+07$ \\
\hline 80 & $1.85 \mathrm{E}+07$ & $1.97 \mathrm{E}+07$ & $3.08 \mathrm{E}+07$ & $3.40 \mathrm{E}+07$ & $2.57 \mathrm{E}+07$ \\
\hline 90 & $2.40 \mathrm{E}+07$ & $2.63 \mathrm{E}+07$ & $4.25 \mathrm{E}+07$ & $4.57 \mathrm{E}+07$ & $3.46 \mathrm{E}+07$ \\
\hline 100 & $8.15 \mathrm{E}+06$ & $9.12 \mathrm{E}+06$ & $1.46 \mathrm{E}+07$ & $1.65 \mathrm{E}+07$ & $1.21 \mathrm{E}+07$ \\
\hline 110 & $5.59 \mathrm{E}+06$ & $5.89 \mathrm{E}+06$ & $1.03 \mathrm{E}+07$ & $1.10 \mathrm{E}+07$ & $8.20 \mathrm{E}+06$ \\
\hline 120 & $3.97 \mathrm{E}+06$ & $4.26 \mathrm{E}+06$ & $7.05 \mathrm{E}+06$ & $7.55 \mathrm{E}+06$ & $5.71 \mathrm{E}+06$ \\
\hline 130 & $2.80 \mathrm{E}+06$ & $3.03 \mathrm{E}+06$ & $5.17 \mathrm{E}+06$ & $5.52 \mathrm{E}+06$ & $4.13 \mathrm{E}+06$ \\
\hline 140 & $2.11 \mathrm{E}+06$ & $2.19 \mathrm{E}+06$ & $4.17 \mathrm{E}+06$ & $4.74 \mathrm{E}+06$ & $3.31 \mathrm{E}+06$ \\
\hline 150 & $1.60 \mathrm{E}+06$ & $1.65 \mathrm{E}+06$ & $3.33 \mathrm{E}+06$ & $3.30 \mathrm{E}+06$ & $2.47 \mathrm{E}+06$ \\
\hline 160 & $1.08 \mathrm{E}+06$ & $1.35 \mathrm{E}+06$ & $2.18 \mathrm{E}+06$ & $2.42 \mathrm{E}+06$ & $1.76 \mathrm{E}+06$ \\
\hline 170 & $8.42 \mathrm{E}+05$ & $9.03 \mathrm{E}+05$ & $1.75 \mathrm{E}+06$ & $2.05 \mathrm{E}+06$ & $1.38 \mathrm{E}+06$ \\
\hline 180 & $6.54 \mathrm{E}+05$ & $6.54 \mathrm{E}+05$ & $1.47 \mathrm{E}+06$ & $1.50 \mathrm{E}+06$ & $1.07 \mathrm{E}+06$ \\
\hline 190 & $4.33 \mathrm{E}+05$ & $4.66 \mathrm{E}+05$ & $1.11 \mathrm{E}+06$ & $1.01 \mathrm{E}+06$ & $7.55 \mathrm{E}+05$ \\
\hline 200 & $4.09 \mathrm{E}+05$ & $4.21 \mathrm{E}+05$ & $9.33 \mathrm{E}+05$ & $1.00 \mathrm{E}+06$ & $6.91 \mathrm{E}+05$ \\
\hline 220 & $1.18 \mathrm{E}+05$ & $1.28 \mathrm{E}+05$ & $2.90 \mathrm{E}+05$ & $3.16 \mathrm{E}+05$ & $2.13 \mathrm{E}+05$ \\
\hline 240 & $6.32 \mathrm{E}+04$ & $5.96 \mathrm{E}+04$ & $1.43 \mathrm{E}+05$ & $1.67 \mathrm{E}+05$ & $1.08 \mathrm{E}+05$ \\
\hline 260 & $2.88 \mathrm{E}+04$ & $3.12 \mathrm{E}+04$ & $7.36 \mathrm{E}+04$ & $7.48 \mathrm{E}+04$ & $5.21 \mathrm{E}+04$ \\
\hline 280 & $1.52 \mathrm{E}+04$ & $1.44 \mathrm{E}+04$ & $3.56 \mathrm{E}+04$ & $3.76 \mathrm{E}+04$ & $2.57 \mathrm{E}+04$ \\
\hline 300 & $2.60 \mathrm{E}+04$ & $2.80 \mathrm{E}+04$ & $7.32 \mathrm{E}+04$ & $7.80 \mathrm{E}+04$ & $5.13 \mathrm{E}+04$ \\
\hline 400 & $5.60 \mathrm{E}+03$ & $4.80 \mathrm{E}+03$ & $1.44 \mathrm{E}+04$ & $1.56 \mathrm{E}+04$ & $1.01 \mathrm{E}+04$ \\
\hline 500 & $5.20 \mathrm{E}+03$ & $6.00 \mathrm{E}+03$ & $1.76 \mathrm{E}+04$ & $1.68 \mathrm{E}+04$ & $1.14 \mathrm{E}+04$ \\
\hline 600 & $6.40 \mathrm{E}+03$ & $8.00 \mathrm{E}+03$ & $2.60 \mathrm{E}+04$ & $2.52 \mathrm{E}+04$ & $1.64 \mathrm{E}+04$ \\
\hline 800 & $2.80 \mathrm{E}+03$ & $2.40 \mathrm{E}+03$ & $8.00 \mathrm{E}+03$ & $8.40 \mathrm{E}+03$ & $5.40 \mathrm{E}+03$ \\
\hline 1,000 & $5.20 \mathrm{E}+03$ & $5.20 \mathrm{E}+03$ & $1.40 \mathrm{E}+04$ & $1.36 \mathrm{E}+04$ & $9.50 \mathrm{E}+03$ \\
\hline $\begin{array}{c}\text { Total Concentration } \\
(50-1,000 \mathrm{~nm})\end{array}$ & $1.30 \mathrm{E}+08$ & $1.40 \mathrm{E}+08$ & $2.31 \mathrm{E}+08$ & $2.50 \mathrm{E}+08$ & $1.88 E+08$ \\
\hline
\end{tabular}

\subsection{Comparison of ER-12-3 Groundwater Chemistry to Surrounding Wells}

Table 4-4 presents groundwater chemistry data for ER-12-3 and from selected wells and tunnel seeps in its vicinity (see Figure 1-2). These data were obtained from the Comprehensive Groundwater Chemistry Database, Geochem05.mdb (SNJV, 2005a). Table 4-4 shows the analytical results for selected major, minor, and trace constituents; physical parameters; environmental isotopes; and tritium (if available). The dissolved concentrations are reported for all parameters with the exception of bicarbonate, carbonate, the environmental isotopes, and tritium; the total concentrations were reported for these parameters. In general, the most recent samples that contain the most complete suite of key analytes were selected for this comparison. For those cases where multiple samples were collected on the same date and analyzed for the same parameters, the mean and the range of the 
Table 4-4

Groundwater Chemistry Data for ER-12-3 and Surrounding Area

(Page 1 of 2)

\begin{tabular}{|c|c|c|c|c|c|c|c|c|c|c|c|c|c|c|}
\hline & \multicolumn{2}{|c|}{ ER-12-3 } & \multirow{2}{*}{$\begin{array}{l}\text { ER-12-1 } \\
(1,641 \text { to } \\
1,846 \mathrm{ft}) \\
12 / 08 / 04 \\
\end{array}$} & \multirow{2}{*}{$\begin{array}{c}\text { TW-1 } \\
7 / 10 / 91 \\
\end{array}$} & \multirow{2}{*}{$\begin{array}{c}\text { U-12s } \\
7 / 13 / 93 \\
\end{array}$} & \multirow{2}{*}{$\begin{array}{c}\text { ER-12-2 } \\
4 / 01 / 03 \\
\end{array}$} & \multirow{2}{*}{$\begin{array}{c}\text { U12n.05 } \\
7 / 01 / 84 \\
\text { to } 8 / 16 / 86 \\
\end{array}$} & \multirow{2}{*}{$\begin{array}{l}\text { U12n.03 } \\
5 / 09 / 86 \\
\end{array}$} & \multirow{2}{*}{$\begin{array}{c}\text { U12t } \\
11 / 20 / 72\end{array}$} & \multirow{2}{*}{$\begin{array}{c}\text { UE-10j-1 } \\
3 / 17 / 97 \\
\end{array}$} & \multirow{2}{*}{$\begin{array}{r}\text { UE-10j-2 } \\
3 / 20 / 97 \\
\end{array}$} & \multirow{2}{*}{$\begin{array}{c}\text { UE-10j-3 } \\
3 / 24 / 97 \\
\end{array}$} & \multirow{2}{*}{$\begin{array}{c}\text { WW-2 } \\
2 / 08 / 05\end{array}$} & \multirow{2}{*}{$\begin{array}{c}\text { WW-8 } \\
11 / 04 / 97\end{array}$} \\
\hline & $\begin{array}{c}\text { Discrete Bailer } \\
6 / 17 / 105\end{array}$ & $\begin{array}{c}\text { Composite } \\
7 / 06 / 05\end{array}$ & & & & & & & & & & & & \\
\hline \multicolumn{15}{|c|}{ Physical Parameters } \\
\hline $\mathrm{pH}$ & 7.9 & $\begin{array}{c}8.1 \\
(8.0 / 8.2)\end{array}$ & $\begin{array}{c}7.6 \\
(7.4 / 8.0)\end{array}$ & $\begin{array}{c}8.9 \\
(8.7 / 9.2)\end{array}$ & 10.45 & $\begin{array}{c}8.1 \\
(7.6 / 8.3) \\
\end{array}$ & $\begin{array}{c}8.1 \\
(7.7 / 8.5)\end{array}$ & $\begin{array}{c}8.1 \\
(7.7 / 8.6) \\
\end{array}$ & $\begin{array}{c}7.6 \\
(7.0 / 8.21)\end{array}$ & $\begin{array}{c}6.6 \\
(6.4 / 6.7)\end{array}$ & 6.7 & $\begin{array}{c}7.1 \\
(7.0 / 7.2)\end{array}$ & 8.3 & $\begin{array}{c}7.5 \\
(7.4 / 7.6)\end{array}$ \\
\hline Specific Conductance & 280 & $\begin{array}{c}290 \\
(279 / 306)\end{array}$ & \begin{tabular}{|c|}
993 \\
$(976 / 1010)$
\end{tabular} & $\begin{array}{c}238 \\
(223 / 245)\end{array}$ & 632 & $\begin{array}{c}543 \\
(528 / 550)\end{array}$ & $\begin{array}{c}342 \\
(316 / 362)\end{array}$ & $\begin{array}{c}330 \\
(325 / 334)\end{array}$ & 291 & $\begin{array}{c}1079 \\
(1070 / 1087)\end{array}$ & 725 & $\begin{array}{c}625 \\
(589 / 661)\end{array}$ & 270 & $\begin{array}{c}198 \\
(193 / 201)\end{array}$ \\
\hline Water Temperature $\left({ }^{\circ} \mathrm{C}\right)$ & & 30.6 & 25.0 & $26.6^{b}$ & 26.1 & 35.2 & & & & 32.7 & 32.3 & 32.1 & 26 & $\begin{array}{c}24.2 \\
(23.4 / 24.7)\end{array}$ \\
\hline \multicolumn{15}{|c|}{ Major Constituents (mg/L) } \\
\hline Bicarbonate & 120 & $\begin{array}{c}121 \\
(120 / 122)\end{array}$ & $\begin{array}{c}221 \\
(209 / 238)\end{array}$ & $\begin{array}{c}110 \\
(87 / 123)\end{array}$ & 146 & $\begin{array}{c}298 \\
(286 / 305)\end{array}$ & $\begin{array}{c}200 \\
(187 / 212)\end{array}$ & 191 & 150 & $\begin{array}{c}552 \\
(504 / 600)\end{array}$ & 403 & \begin{tabular}{|c|}
322 \\
$(295 / 349)$
\end{tabular} & 144 & $\begin{array}{c}74.9 \\
(63.4 / 84.7)\end{array}$ \\
\hline Calcium & 17.4 & $\begin{array}{c}16.7 \\
(13.8 / 17.9)\end{array}$ & \begin{tabular}{|c|}
97.7 \\
$(88.4 / 102)$
\end{tabular} & $\begin{array}{c}4.6 \\
(2.0 / 5.9)\end{array}$ & 35.6 & $\begin{array}{c}5.8 \\
(5.5 / 6.5)\end{array}$ & $\begin{array}{c}12.2 \\
(10.8 / 13.0)\end{array}$ & $\begin{array}{c}5.7 \\
(5.5 / 5.8)\end{array}$ & 2.9 & $\begin{array}{c}107 \\
(101 / 113)\end{array}$ & 68 & $\begin{array}{c}60 \\
(56 / 64)\end{array}$ & 14 & $\begin{array}{c}7.9 \\
(7.4 / 8.62)\end{array}$ \\
\hline Carbonate & $<0.6$ & $\begin{array}{c}1 \\
(<0.6 / 1) \\
\end{array}$ & \begin{tabular}{c|}
$<0.3$ \\
$(<0.3 /<0.3)$
\end{tabular} & $\begin{array}{c}12.5 \\
(7.8 / 20.6) \\
\end{array}$ & & $\begin{array}{c}5.5 \\
(2.0 / 7.2) \\
\end{array}$ & $\begin{array}{c}5.6 \\
(4.8 / 6.3) \\
\end{array}$ & & & $\begin{array}{c}0.1 \\
(<6 / 0.1) \\
\end{array}$ & 0.1 & $\begin{array}{c}0.2 \\
(<6 / 0.2)\end{array}$ & $<0.3$ & \\
\hline Chloride & 5.8 & $\begin{array}{c}5.8 \\
(5.7 / 6.0) \\
\end{array}$ & \begin{tabular}{|c|}
17.2 \\
$(16.8 / 17.7)$ \\
\end{tabular} & $\begin{array}{c}3.7 \\
(3.4 / 3.8)\end{array}$ & 14 & $\begin{array}{c}6.9 \\
(6.9 / 7.0) \\
\end{array}$ & $\begin{array}{c}8.3 \\
(7.8 / 8.8) \\
\end{array}$ & $\begin{array}{c}6.7 \\
(6.6 / 7.1) \\
\end{array}$ & 13 & $\begin{array}{c}24 \\
(23.7 / 24) \\
\end{array}$ & 16 & $\begin{array}{c}12.8 \\
(12.5 / 13.1)\end{array}$ & 15.1 & $\begin{array}{c}7.3 \\
(7.0 / 7.7)\end{array}$ \\
\hline Magnesium & 7.9 & $\begin{array}{c}8.3 \\
(7.9 / 8.6) \\
\end{array}$ & \begin{tabular}{|c|}
64.9 \\
$(58.8 / 69.8)$ \\
\end{tabular} & $\begin{array}{c}0.3 \\
(0.2 / 0.4) \\
\end{array}$ & 0.13 & $\begin{array}{c}2.0 \\
(1.9 / 2.1) \\
\end{array}$ & $\begin{array}{c}2.7 \\
(0.6 / 4.8) \\
\end{array}$ & $\begin{array}{c}0.26 \\
(0.25 / 0.28) \\
\end{array}$ & 0.1 & $\begin{array}{c}44.7 \\
(42.3 / 47.1)\end{array}$ & 30 & $\begin{array}{c}26.8 \\
(25.4 / 28.1) \\
\end{array}$ & 8.6 & $\begin{array}{c}1.2 \\
(1.2 / 1.24)\end{array}$ \\
\hline Potassium & 2.2 & $\begin{array}{c}2.4 \\
(2.2 / 2.8) \\
\end{array}$ & $\begin{array}{c}3.2 \\
(3.0 / 3.4) \\
\end{array}$ & $\begin{array}{c}0.9 \\
(0.4 / 1.2)\end{array}$ & 5 & $\begin{array}{c}3.0 \\
(2.1 / 3.5) \\
\end{array}$ & $\begin{array}{c}8.0 \\
(7.7 / 8.4) \\
\end{array}$ & $\begin{array}{c}5.8 \\
(5.4 / 6.6) \\
\end{array}$ & 3.6 & $\begin{array}{c}13 \\
(12.3 / 14)\end{array}$ & 8.3 & $\begin{array}{c}7.3 \\
(6.9 / 7.7)\end{array}$ & 6.6 & $\begin{array}{c}3.32 \\
(3.23 / 3.49)\end{array}$ \\
\hline Sodium & 28.5 & $\begin{array}{c}29.9 \\
(29.4 / 30.7) \\
\end{array}$ & \begin{tabular}{|c|}
37.9 \\
$(36.4 / 38.6)$ \\
\end{tabular} & $\begin{array}{c}52 \\
(50.0 / 53.5) \\
\end{array}$ & 24 & $\begin{array}{c}112 \\
(110 / 117) \\
\end{array}$ & $\begin{array}{c}64.0 \\
(60.7 / 68.3)\end{array}$ & $\begin{array}{c}69.7 \\
(68.6 / 70.7)\end{array}$ & 68 & $\begin{array}{c}68 \\
(64 / 72.4) \\
\end{array}$ & 43 & $\begin{array}{c}37 \\
(35 / 38.6)\end{array}$ & 30.7 & $\begin{array}{c}31.1 \\
(30.8 / 31.5)\end{array}$ \\
\hline Sulfate & 27.1 & $\begin{array}{c}25.8 \\
(24.6 / 27.7)\end{array}$ & $\begin{array}{c}346 \\
(332 / 356)\end{array}$ & $\begin{array}{c}8.7 \\
(7.0 / 9.7)\end{array}$ & $<1$ & $\begin{array}{c}27.1 \\
(27.0 / 27.4)\end{array}$ & $\begin{array}{c}12.5 \\
(8.8 / 17.2)\end{array}$ & $\begin{array}{c}12.8 \\
(11.1 / 14.0)\end{array}$ & 18 & $\begin{array}{c}79 \\
(75.5 / 83)\end{array}$ & 67 & $\begin{array}{c}58.5 \\
(56.2 / 60.8)\end{array}$ & 8 & $\begin{array}{c}15 \\
(15 / 15)\end{array}$ \\
\hline \multicolumn{15}{|c|}{ Minor and Trace Constituents } \\
\hline Aluminum $(\mu \mathrm{g} / \mathrm{L})$ & $<60$ & $\begin{array}{c}1.1 \\
(<60 / 1.1)\end{array}$ & $\begin{array}{c}4.9 \\
(0.32 / 9.5) \\
\end{array}$ & $<60^{\mathrm{b}}$ & $<60$ & $<50$ & & & $<10$ & $<60$ & $<60$ & $<60$ & & $\begin{array}{c}3.4 \\
(2.1 / 5.9) \\
\end{array}$ \\
\hline Arsenic ( $\mu \mathrm{g} / \mathrm{L})$ & 11 & $\begin{array}{c}7 \\
(5 / 7)\end{array}$ & $\begin{array}{c}64 \\
(50 / 106)\end{array}$ & $<100^{\circ}$ & $<1$ & $\begin{array}{c}5 \\
(<20 / 5)\end{array}$ & & & & 30 & 18 & 16 & & $\begin{array}{c}2 \\
(2 / 2)\end{array}$ \\
\hline Boron (mg/L) & & $\begin{array}{c}0.06 \\
(0.06 / 0.06)\end{array}$ & \begin{tabular}{|c|}
0.07 \\
$(0.07 / 0.07)$ \\
\end{tabular} & $<0.06^{b}$ & 0.06 & $\begin{array}{c}0.22 \\
(0.11 / 0.45)\end{array}$ & & & & 0.55 & 0.33 & 0.25 & & \\
\hline Barium (mg/L) & 0.03 & $\begin{array}{c}0.02 \\
(0.02 / 0.02)\end{array}$ & \begin{tabular}{|c|}
0.03 \\
$(0.02 / 0.03)$ \\
\end{tabular} & $<0.01^{\mathrm{b}}$ & 0.166 & $\begin{array}{c}0.20 \\
(0.19 / 0.21)\end{array}$ & & & & 0.10 & 0.07 & 0.05 & & $\begin{array}{c}0.0001 \\
(0.0001 / 0.0001)\end{array}$ \\
\hline Chromium (mg/L) & $<0.003$ & $\begin{array}{c}<0.003 \\
(<0.003 /<0.005)\end{array}$ & $<0.005$ & & & $<0.005$ & & & & & & & & $\begin{array}{c}0.0002 \\
(0.0002 / 0.0002\end{array}$ \\
\hline Bromide (mg/L) & $<0.1$ & $\begin{array}{c}0.06 \\
(<0.1 / 0.06)\end{array}$ & \begin{tabular}{c|}
0.4 \\
$(<0.5 / 0.4)$
\end{tabular} & & & $\begin{array}{c}0.4 \\
(0.2 /<0.7)\end{array}$ & 0.035 & 0.045 & & 0.1 & & 0.1 & & $\begin{array}{c}0.05 \\
(0.05 / 0.06)\end{array}$ \\
\hline Fluoride (mg/L) & 1.7 & $\begin{array}{c}1.6 \\
(1.5 / 1.6) \\
\end{array}$ & $\begin{array}{c}0.2 \\
(<0.25 / 0.25) \\
\end{array}$ & & $<1$ & $\begin{array}{c}2.2 \\
(2.2 / 2.2) \\
\end{array}$ & & & 0.1 & $\begin{array}{c}0.3 \\
(<3 / 0.3) \\
\end{array}$ & 0.33 & $\begin{array}{c}0.3 \\
(0.3 / 0.4) \\
\end{array}$ & 0.3 & $\begin{array}{c}0.7 \\
(0.7 / 0.7) \\
\end{array}$ \\
\hline Iron (mg/L) & 0.05 & $\begin{array}{c}0.22 \\
(0.16 / 0.26) \\
\end{array}$ & \begin{tabular}{|c|}
3.41 \\
$(2.04 / 4.99)$ \\
\end{tabular} & $\begin{array}{c}0.15 \\
(0.04 / 0.23) \\
\end{array}$ & 0.2 & $\begin{array}{c}0.27 \\
(0.26 / 0.28) \\
\end{array}$ & & & 0.07 & 0.88 & 0.09 & 0.09 & & 0.01 \\
\hline Lithium (mg/L) & 0.034 & $\begin{array}{c}0.025 \\
(0.024 / 0.027) \\
\end{array}$ & \begin{tabular}{|c|}
0.27 \\
$(0.26 / 0.28)$ \\
\end{tabular} & $\begin{array}{c}0.059 \\
(0.04 / 0.13)\end{array}$ & 0.13 & $\begin{array}{c}0.23 \\
(0.19 / 0.24)\end{array}$ & 0.04 & 0.05 & 0.03 & 0.33 & 0.15 & 0.09 & & $\begin{array}{c}0.028 \\
(0.027 / 0.029)\end{array}$ \\
\hline Manganese (mg/L) & 0.012 & $\begin{array}{c}0.028 \\
(0.027 / 0.028)\end{array}$ & \begin{tabular}{|c|}
0.12 \\
$(0.11 / 0.14)$ \\
\end{tabular} & $<0.03^{b}$ & $<0.01$ & $\begin{array}{c}0.02 \\
(0.02 / 0.02)\end{array}$ & & & $<0.01$ & 0.08 & 0.10 & 0.07 & & $\begin{array}{c}0.0012 \\
(0.0011 / 0.0012 \\
\end{array}$ \\
\hline
\end{tabular}


Table 4-4

Groundwater Chemistry Data for ER-12-3 and Surrounding Area

(Page 2 of 2)

\begin{tabular}{|c|c|c|c|c|c|c|c|c|c|c|c|c|c|c|}
\hline & \multicolumn{2}{|c|}{ ER-12-3 } & \multirow{2}{*}{$\begin{array}{l}\text { ER-12-1 } \\
(1,641 \text { to } \\
1,846 \mathrm{ft}) \\
12 / 08 / 04 \\
\end{array}$} & \multirow{2}{*}{$\begin{array}{c}\text { TW-1 } \\
7 / 10 / 91\end{array}$} & \multirow{2}{*}{$\begin{array}{c}\text { U-12s } \\
7 / 13 / 93\end{array}$} & \multirow{2}{*}{$\begin{array}{c}\text { ER-12-2 } \\
4 / 01 / 03\end{array}$} & \multirow{2}{*}{$\begin{array}{c}\text { U12n.05 } \\
7 / 01 / 84 \\
\text { to } 8 / 16 / 86\end{array}$} & \multirow{2}{*}{$\begin{array}{l}\text { U12n.03 } \\
5 / 09 / 86\end{array}$} & \multirow{2}{*}{$\begin{array}{c}\text { U12t } \\
11 / 20 / 72\end{array}$} & \multirow{2}{*}{$\begin{array}{c}\text { UE-10j-1 } \\
3 / 17 / 97\end{array}$} & \multirow{2}{*}{$\begin{array}{c}\text { UE-10j-2 } \\
3 / 20 / 97\end{array}$} & \multirow{2}{*}{$\begin{array}{l}\text { UE-10j-3 } \\
3 / 24 / 97\end{array}$} & \multirow{2}{*}{$\begin{array}{l}\text { WW-2 } \\
2108 / 05\end{array}$} & \multirow{2}{*}{$\begin{array}{c}\text { WW-8 } \\
11 / 04 / 97\end{array}$} \\
\hline & $\begin{array}{c}\text { Discrete Bailer } \\
6 / 17 / 05\end{array}$ & $\begin{array}{c}\text { Composite } \\
7 / 06 / 05\end{array}$ & & & & & & & & & & & & \\
\hline Selenium (mg/L) & $<0.005$ & $<0.005$ & $<0.005$ & $<0.1^{\mathrm{b}}$ & $<0.007$ & $<0.005$ & & & & $<0.01$ & $<0.01$ & $<0.01$ & & $\begin{array}{c}0.0007 \\
(0.0007 / 0.0007)\end{array}$ \\
\hline Silicon dioxide $(\mathrm{mg} / \mathrm{L})$ & 21.4 & $\begin{array}{c}24 \\
(23.5 / 25)\end{array}$ & $\begin{array}{c}21.6 \\
(18.4 / 24)\end{array}$ & $\begin{array}{c}14.4 \\
(12.0 / 20.2)\end{array}$ & 22.0 & \begin{tabular}{|c|}
21.6 \\
$(14.8 / 25.5)$
\end{tabular} & $\begin{array}{c}52 \\
(51 / 54)\end{array}$ & $\begin{array}{c}46 \\
(44 / 48)\end{array}$ & 42 & $\begin{array}{c}40.7 \\
(38.7 / 42.8)\end{array}$ & 36.4 & \begin{tabular}{c|}
32 \\
$(29.7 / 34)$
\end{tabular} & 7.7 & 50 \\
\hline Strontium (mg/L) & 0.136 & $\begin{array}{c}0.104 \\
(0.098 / 0.111)\end{array}$ & \begin{tabular}{|c|}
0.21 \\
$(0.02 / 0.21)$ \\
\end{tabular} & $\begin{array}{c}0.02 \\
(0.01 / 0.03)\end{array}$ & 2.06 & \begin{tabular}{|c|}
0.33 \\
$(0.32 / 0.34)$
\end{tabular} & & & $<0.01$ & 0.47 & 0.32 & 0.27 & & $\begin{array}{c}0.005 \\
(0.005 / 0.006)\end{array}$ \\
\hline Uranium $(\mu \mathrm{g} / \mathrm{L})$ & $<50$ & $\begin{array}{c}1.9 \\
(<50 / 2.0)\end{array}$ & \begin{tabular}{|c|}
1.6 \\
$(<100 / 1.7)$
\end{tabular} & $<0.6^{\mathrm{b}}$ & ND & & & & & 5 & 3 & 3 & & $\begin{array}{c}0.37 \\
(0.35 / 0.39)\end{array}$ \\
\hline \multicolumn{15}{|c|}{ Environmental Isotopes and Tritium } \\
\hline$\delta^{13} \mathrm{C}(\%)$ & & $\begin{array}{c}-5.7 \\
(-6.0 /-5.4)\end{array}$ & \begin{tabular}{c|}
-10.8 \\
$(-10.8 /-10.7)$
\end{tabular} & -10.2 & & \begin{tabular}{|c|}
-5.6 \\
$(-6.2 /-4.9)$
\end{tabular} & & & & $\begin{array}{c}-3.6 \\
(-4.6 /-2.7)\end{array}$ & $\begin{array}{c}-5.7 \\
(-6.4 /-5.1)\end{array}$ & $\begin{array}{c}-7.7 \\
(-7.9 /-7.4)\end{array}$ & & $\begin{array}{c}-12 \\
(-12 /-11)\end{array}$ \\
\hline${ }^{14} \mathrm{C} \mathrm{pmc}$ & & 2.9 & 11.0 & 30 & 100 & 1.5 & & & & 7.5 & 11.4 & 12.6 & & 25 \\
\hline${ }^{36} \mathrm{C} / / \mathrm{Cl}$ & & $5.39 \mathrm{E}-13$ & $7.80 \mathrm{E}-13$ & $9.68 \mathrm{E}-13$ & $3.35 \mathrm{E}-13$ & $6.90 \mathrm{E}-13$ & & & & $2.41 \mathrm{E}-13$ & $3.91 \mathrm{E}-13$ & 4.45E-13 & & \\
\hline$\delta \mathrm{D}(\%)$ & & $\begin{array}{c}-106 \\
(-106 /-106)\end{array}$ & \begin{tabular}{c|}
-94 \\
$(-94.5 /-94)$
\end{tabular} & $\begin{array}{c}-111 \\
(-112 /-111)\end{array}$ & -94 & \begin{tabular}{c|}
-101 \\
$(-101 /-101)$
\end{tabular} & $\begin{array}{c}-94.4 \\
(-97 /-90)\end{array}$ & \begin{tabular}{c|}
-97 \\
$(-101 /-90)$
\end{tabular} & & $\begin{array}{c}-104 \\
(-107 /-101)\end{array}$ & $\begin{array}{c}-102 \\
(-105 /-98)\end{array}$ & $\begin{array}{c}-100 \\
(-103 /-97)\end{array}$ & \begin{tabular}{|c|}
$-103^{\mathrm{a}}$ \\
$(-104 /-102)$
\end{tabular} & -103 \\
\hline$\delta^{18} \mathrm{O}(\%)$ & & $\begin{array}{c}-14.5 \\
(-14.5 /-14.5)\end{array}$ & $\begin{array}{c}-12.6 \\
(-12.6 /-12.6)\end{array}$ & $\begin{array}{c}-14.9 \\
(-15 /-14.8)\end{array}$ & -12.6 & \begin{tabular}{c|}
-13.7 \\
$(-13.8 /-13.5)$
\end{tabular} & $\begin{array}{c}-13.0 \\
(-13.4 /-11.9)\end{array}$ & \begin{tabular}{|c|}
-13.4 \\
$(-14.2 /-12.4)$
\end{tabular} & & $\begin{array}{c}-13.6 \\
(-13.6 /-13.5)\end{array}$ & $\begin{array}{c}-13.2 \\
(-13.2 /-13.1)\end{array}$ & $\begin{array}{c}-12.8 \\
(-12.9 /-12.8)\end{array}$ & \begin{tabular}{|c|}
$-13.5^{\mathrm{a}}$ \\
$(-14.2 /-13.0)$
\end{tabular} & -13.5 \\
\hline${ }^{87} \mathrm{~S} /{ }^{86} \mathrm{Sr}$ & & $\begin{array}{c}0.71045 \\
(0.71034 / 0.71055)\end{array}$ & $\begin{array}{l}0.71234 \\
(0.71234 / \\
0.71235)\end{array}$ & 0.70893 & 0.70555 & $\begin{array}{l}0.71662 \\
(0.71659 / \\
0.71664)\end{array}$ & & & & 0.71464 & 0.71352 & 0.71261 & & 0.71025 \\
\hline${ }^{234} \mathrm{U} / 238 \mathrm{U}$, Activity & & $\begin{array}{c}2.1 \\
(2.1 / 2.2)\end{array}$ & $\begin{array}{c}5.3 \\
(1.6 / 7.2)\end{array}$ & & & $\begin{array}{c}5.3 \\
(3.3 / 6.3)\end{array}$ & & & & 5.05 & 4.98 & 4.96 & & 2.9 \\
\hline Tritium (pCi/L) & $<270$ & $\begin{array}{c}0.5 \\
(<350 / 0.5)\end{array}$ & \begin{tabular}{|c|}
3.2 \\
$(<360 / 3.2)$
\end{tabular} & $\begin{array}{c}57 \\
(54 / 60)\end{array}$ & & \begin{tabular}{|c|}
4.3 \\
$(<500 / 4.3)$
\end{tabular} & & & & 38.5 & & 61.9 & $10^{\mathrm{a}}$ & \\
\hline
\end{tabular}

Note: A single value is reported when multiple measurements were not performed for a specific parameter. When multiple measurements were made for a specific parameter, the average is reported along with the minimum and maximum value (in parentheses). A blank indicates that no measurement was performed for the given parameter. Values reported as below the detection limit were not included when calculating the average. This is so that concentrations are not biased high due to measurements made by laboratories with large relative detections limits. This is particularly important for reporting tritium activities where detection limits often vary by two to three orders of magnitude depending on the analytical procedure.

a The $\delta D$ and $\delta^{18} O$ values for WW-2 are an average from samples collected on 6/02/82, 9/11/89, and 4/16/90.

b Selected parameters for TW-1 are from a sample collected on 8/13/92 by LLNL. 
results are presented in Table 4-4. Samples collected on different dates were combined in some cases so that a more complete suite of parameters were available for the evaluation.

The groundwater sampling locations in the vicinity of ER-12-3 are shown in Figure 1-2. Three sampling locations shown in Figure 1-2 are not presented in Table 4-4, nor are they included in this comparison. These wells are identified below and a brief explanation for their exclusion is provided.

- Hagestad \#1 produces groundwater from the lower tuff confining unit (LTCU). Samples from this well were collected in 1958 and analyzed for physical parameters, major constituents, and a few minor constituents. No environmental isotope data are available. A high $\mathrm{pH}$ of the groundwater (10.3 to 11.1) indicates poor well development and contamination from cement during well construction.

- Well ER-19-1 also produces groundwater from the LTCU. A high $\mathrm{pH}$ of the groundwater (10.7) indicates poor well development and contamination from cement during well construction.

- Well UE-2ce produces groundwater from the LCA3 near the NASH test cavity in Yucca Flat. Groundwaters of this well have been impacted by the NASH test; tritium activities as high as $35,000,000 \mathrm{pCi} / \mathrm{L}$ have been measured in this well.

A brief description of the well and tunnel seep samples included in this comparison (see Figure 1-2) is provided below.

- Well ER-12-1 is located in the Rainier Mesa/Shoshone Mountain CAU. Groundwater samples are collected from the uppermost zone of this well that produces groundwater from the LCA3 HSU.

- Well U-12s produces groundwater from the Mesozoic granite confining unit (MGCU). Only one sample has been collected from this well, and some of the analytical results are somewhat anomalous (for instance, the ${ }^{14} \mathrm{C}$ was reported to be 100 percent modern).

- Well TW-1 produces water from the BRA. Although samples were collected from different depths within this well $(1,470,1,510,1,553,1,740$, and $1,930 \mathrm{ft}$ bgs), similar chemistry is observed. This is apparent from the narrow ranges in concentrations shown in Table 4-4. For this reason, the average groundwater composition from all depths was used for the evaluation.

- U12n.05 and U12n.03 samples were collected from the N-Tunnel. These data are described in detail by Russell (1987). Several samples were collected between July 1984 and August 1986. The mean of all samples, along with the range of values, are reported in Table 4-4. These samples represent perched waters of the volcanic confining unit. 
- U12t samples were collected from the main drift of the T-Tunnel. Samples were collected by the USGS in 1972 and analyzed for physical parameters, major constituents, and only a few minor constituents. No environmental isotope data are available. These samples represent perched waters of the volcanic confining unit.

- Well ER-12-2 is located in Yucca Flat and is completed in the UCCU. Measured ${ }^{14} \mathrm{C},{ }^{36} \mathrm{Cl} / \mathrm{Cl}$, ${ }^{87} \mathrm{Sr} /{ }^{86} \mathrm{Sr}$, and ${ }^{3} \mathrm{He} /{ }^{4} \mathrm{He}$ of these groundwaters are consistent with a groundwater residence time between 10,000 and 60,000 years; however, a component of local recharge could not be ruled out based on the $\delta \mathrm{D}$ and $\delta^{18} \mathrm{O}$ (LLNL, 2003).

- Well UE-10j is located in northern Yucca Flat and is constructed such that three zones within the well are sampled. Although all three zones are completed in the LCA3, a recent geochemical study conducted for the Yucca Flat/Climax Mine CAU (SNJV, 2006a) indicated that the shallowest zone (UE-10j-3) was dominated by a local recharge component (70 to 87 percent) mixed with a much smaller percentage of groundwater inflow through the LCA3 that was represented by groundwater of the deepest zone of the same well (UE-10j-1).

- Well WW-2 is located in Yucca Flat southwest of UE-10j. Geochemical models presented in SNJV (2006a) suggested that the groundwaters of WW-2 can be derived from a mixture of groundwater from TW-1, UE-10j-3, and Oak Spring, and that groundwater at WW-2 is primarily derived from mixing of volcanic and perched water sources in northern Yucca Flat. The geochemical models indicated that only 4 percent or less of the groundwater at WW-2 is derived by inflow through the LCA.

- Well WW-8 produces water from the BRA HSU. Samples were collected by multiple organizations (DRI, LLNL, and USGS) on November 4, 1997, to obtain a full suite of analytical parameters to support a geochemical evaluation of flow paths within Pahute Mesa Oasis Valley (Rose et al., 2002). The mean values for these samples were therefore used for the evaluation described herein.

The data in Table 4-4 were used to construct the trilinear diagram shown in Figure 4-1. Trilinear diagrams are used to identify trends or similarities in groundwater chemistry based on the relative abundance of major ions in groundwater samples. The concentrations along the axes are expressed in percent milliequivalents per liter. The two triangles in the lower left and right corners represent the cations and anions, respectively. The diamond-shaped field in the center combines the information from the adjacent cation and anion triangles and is used to illustrate similarities in groundwater chemistry (i.e., water types) and any relationships that may exist between different water types.

The samples from ER-12-3 are identical to each other with respect to the trilinear diagram (Figure 4-1). These samples represent a calcium-magnesium-sodium-bicarbonate water type, suggesting that the groundwater of ER-12-3 is a mixture of volcanic and carbonate type 


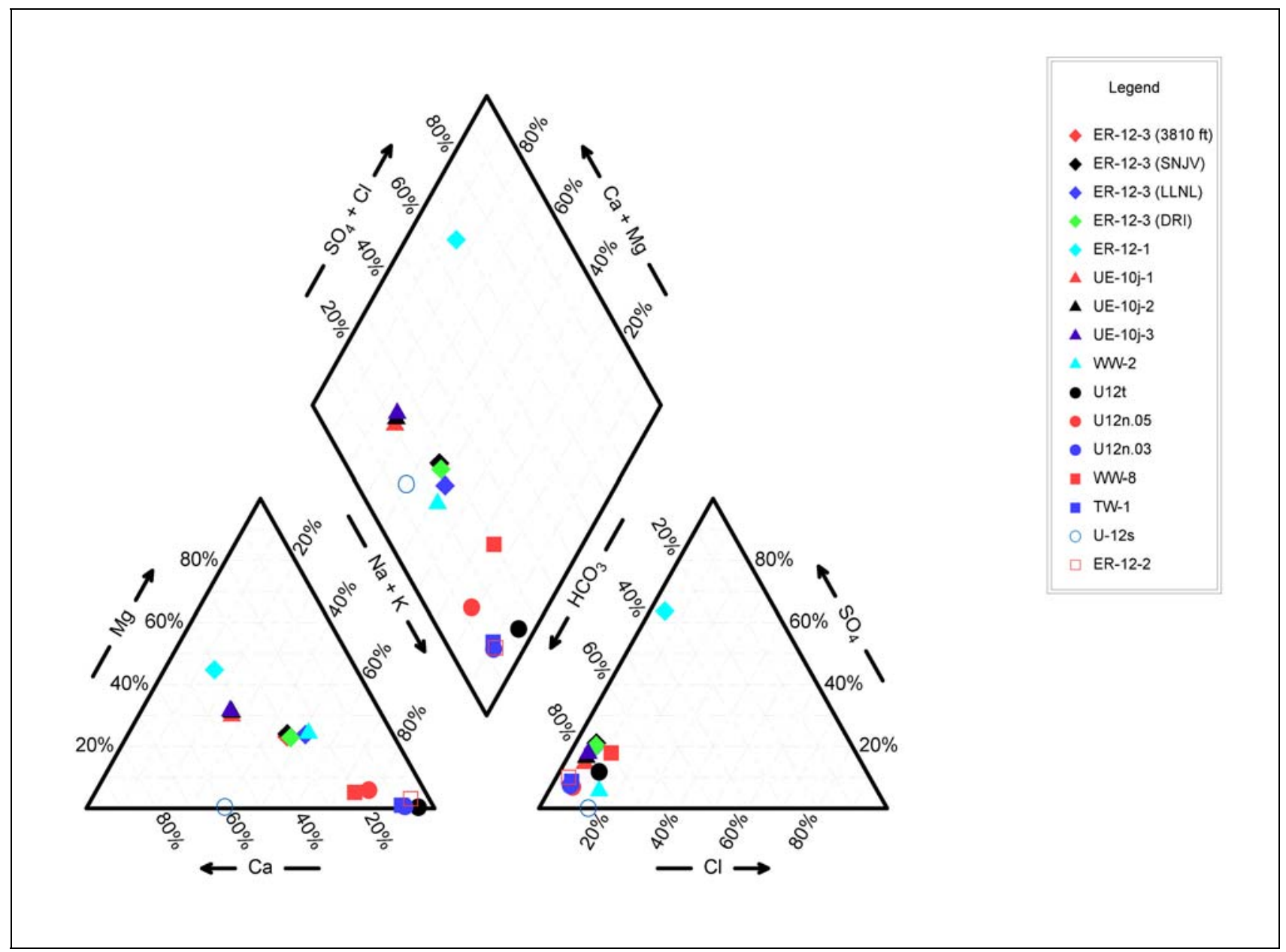

\section{Piper Diagram Showing Relative Major lon Percentages for Groundwater from ER-12-3 and Vicinity}

Note: LCA3 samples are represented using diamonds, LCA samples are represented using trpiangles, tunnel samples are represented using filled circles, BRA samples are represented using filled squares, MGCU samples are represented using open circles, and UCCU samples are represented using an open square.

groundwaters. The groundwater samples plot between those of UE-10j and those of the tunnel seeps and volcanic rock aquifers and confining units. Well ER-12-3 groundwaters are chemically distinct from those of ER-12-1 and are more similar to those of WW-2. As previously mentioned, groundwaters of WW-2 are thought to be a mixture of volcanic and perched water sources in northern Yucca Flat with little contribution from inflow through the LCA.

Figure 4-2 shows the $\delta \mathrm{D}$ and $\delta^{18} \mathrm{O}$ composition of groundwater for ER-12-3 and selected wells and tunnel seeps in its vicinity. The global meteoric water line (Craig, 1961) and the local meteoric water line (Ingraham et al., 1990), are also shown in Figure 4-2. Figure 4-2 shows that ER-12-3 


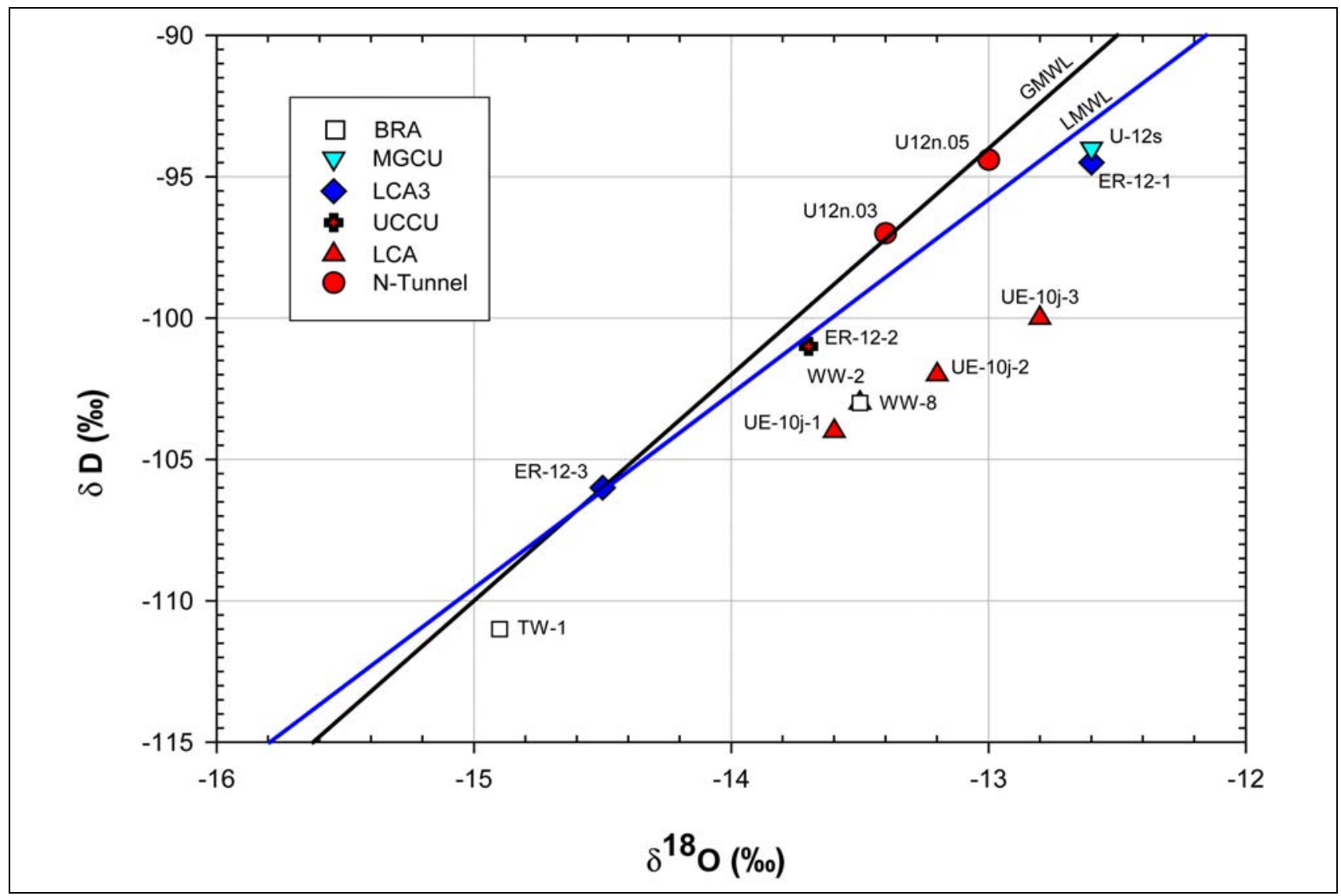

Figure 4-2

Stable Isotope Composition for ER-12-3 and Vicinity

groundwater plots on the local and global meteoric water lines. This suggests that no significant secondary fractionation of these isotopes has occurred. The $\delta^{18} \mathrm{O}(-14.5 \%)$ and $\delta \mathrm{D}(-106 \%$ \% are isotopically lighter (more negative $\delta$-values) than the Yucca Flat LCA/LCA3 samples. It was suggested by LLNL (2006) that this isotopically lighter composition may result from mixing with a combination of overlying volcanic aquifer waters and Rainier Mesa tunnel waters. In addition, these results suggest that theLCA3 groundwater underlying the ER-12-3 well location may be in poor communication with the northern Yucca Flat LCA3 (LLNL, 2006).

\subsection{Restoration of Natural Groundwater Quality}

A primary purpose for well development is to restore the natural groundwater quality of the completion interval so that groundwater samples would accurately represent the water quality of the producing formation. During drilling operations for ER-12-3, the makeup water was tagged with a 
lithium bromide ( $\mathrm{LiBr}$ ) tracer (approximately 10 to 50+ mg/L) to help determine groundwater influx in the borehole and the respective water production rate during drilling, and for use in evaluation of progress and completeness of development. The relatively high concentration of bromide ( $\left.\mathrm{Br}^{-}\right)$ions injected into the wellbore provides a potential means to ascertain the effectiveness of the well development. Table 4-2 shows that the dissolved concentration of $\mathrm{Br}^{-}$was less than $0.5 \mathrm{mg} / \mathrm{L}$ for both the depth-discrete bailer and the composite groundwater samples. This value is substantially lower than the concentration of $\mathrm{Br}^{-}$used during drilling, and likely indicates that the well was sufficiently developed to restore groundwater quality back to its natural condition. This conclusion pertains only to the formation(s) producing water during pumping.

\subsection{Source Formation(s) of Groundwater Samples}

Section 3.3 discussed the production distribution of water during pumping, and Section 2.2.3 discussed the flow in the well under ambient conditions. During pumping, groundwater is produced from two fracture intervals, the upper fracture interval above about 3,440 ft bgs and the middle fracture interval between 3,800 and 4,100 ft bgs in approximately equal proportions. Both of these intervals are in the LCA3, indicating that the LCA3 is the source of produced water. The static water level in the well is below the top of the LCA3, suggesting that the formation above the upper fracturing interval is not continuously saturated up to the overlying volcanic formation. This would appear to preclude any other substantial source of water from the overlying volcanic formation, either through the wellbore or by saturated vertical flow to the LCA3. However, there is some evidence that the higher "perched" head in the overlying volcanic formation is possibly connected to the middle fracture interval, perhaps through high-angle fractures, so there may possibly be a pathway for contribution to produced water from the overlying volcanic formation by way of the LCA3.

\subsection{Representativeness of Water Chemistry Results}

Although both completion intervals for this well are within the LCA3, a general agreement between all chemical indicators (major ions, stable isotopes, ${ }^{36} \mathrm{Cl} / \mathrm{Cl}$, and ${ }^{87} \mathrm{Sr} /{ }^{86} \mathrm{Sr}$ ) suggests that the groundwater is not typical of the LCA/LCA3. The ER-12-3 samples instead appear to be a mixture of LCA3 groundwaters and groundwaters of a volcanic rock aquifer. It can not be determined whether these groundwaters are representative of LCA3 groundwaters of the Rainier Mesa/Shoshone Mountain CAU because of a lack of wells completed in the LCA3 within this area and the lack of 
geochemical similarity between the ER-12-3 and most groundwaters of the LCA/LCA3. Though there is a low likelihood, it should be noted that the presence of makeup water from WW-8 may be the cause of the volcanic rock aquifer signature of the ER-12-3 groundwaters. Again, the absence of $\mathrm{Br}^{-}$ in the groundwaters indicates that this is probably not the case.

\subsection{Use of ER-12-3 for Future Monitoring}

Well ER-12-3 is located within 1 mile of 30 nuclear tests (DOE/NV, 2000). However, all of these tests are well above the regional water table. The local direction of groundwater flow is not known, and the productive intervals in this well are a considerable depth below any HSU impacted by nuclear testing. This well may not be appropriate for monitoring radionuclide transport from the tests.

Sampling groundwater from the ER-12-3 piezometer may be more appropriate for monitoring radionuclide transport from the tests in Rainier Mesa. This is provided that the piezometer could be adequately purged, ensuring that formation water of the TCU is sampled. 


\subsection{Review of the Testing Program and analysis}

This section contains comments on the well design, the test design and implementation, and the interpretation and analysis of the testing data. Recommendations for changes are provided.

\subsection{Comments on Well Design}

The design of this well presented significant difficulties for the collection of representative flow and temperature logs, and for the analysis of groundwater production distribution in the formation. Two features of the well design caused problems: 1 ) the arrangement of two discrete intervals of continuous slotted casing with long intervals of unslotted casing shielding the remainder of the formation, and 2) the lack of a filter pack in the annulus of the completion. The flow and temperature logs reflected the flow pattern resulting from the discrete slotted intervals, making it difficult to determine the actual flow in the annulus between the completion casing and the borehole, and the distribution of production from the formation. The intervals of slotted casing are not coincident with the fracturing in the well and with the production from the formations such that almost all groundwater production occurs behind unslotted casing. Flow logging observed flow inside the casing string, which does not directly reflect production from the formation. In addition, the lack of filter pack in the annulus appears to have allowed significant vertical circulation in the annulus outside the slotted casing, which affected the flow logs through the slotted intervals by allowing eddying, introducing additional uncertainty in the flow logs. Typically, discrete completion intervals would have been separated by an annular seal so that they could not interact behind the unslotted casing. The lack of an annular seal between slotted intervals also precludes measurement of head differences for the different fracturing intervals.

Future well designs should consider installation of continuous slotted casing or alternating slotted and unslotted casing to provide continuous access to the formation, at least at a coarse scale. This design would allow the flow pattern for the formation to be observed directly rather than having to infer the pattern. The alternating design would not require more slotted casing than was used to construct this 
well, and would provide superior information. Inclusion of filter material in the annulus generally appears to restrict vertical circulation in the annulus such that flow observed in the well casing can be more simply interpreted as a reflection of flow from or into the formation.

The slotted intervals in the well construction appear to correspond with the intervals of greatest water production observed during drilling, which may have been one of the factors considered in selecting those intervals. The observed production distribution in the formation, however, indicates that in this instance, such production may not necessarily be a good guide. There are several factors involved in water production during drilling that modify the surface production relative to the productivity of the formation at the drilling face that must be considered to properly use such data. The fracturing information is probably a better guide to production capability and distribution because the fracturing density (frequency and open character of the fractures) generally reflects the hydraulic conductivity of the formation.

\subsection{Comments on Well Testing Program}

Several aspects of the records collected during the testing program were problematic, as described in the following sections. While the testing program was conducted mostly according to the testing plan, the schedule for the testing program did not provide sufficient time to collect optimal records because the well was slow to recover from stresses. Future testing program schedules should be determined to the extent possible to provide improved information according to the recommendations provided below.

\subsubsection{Pre-Test and Post-Test Monitoring Records}

The processing of the water-level monitoring record to determine the drawdown response would be greatly improved with the collection of sufficiently long pre-test and recovery records to support accurate characterization of background trends. The scheduled pre-development monitoring for this well and the pre-constant-rate-test monitoring were not long enough to allow the well to recover from development, and to provide a sufficient record to determine any background-water-level trend. This situation overlaps with the discussion in the next subsection. In general, the pre-test record should be at least equal to the length of the test. The post-test record should continue until the well has fully recovered and temperature has equilibrated. The latter situation can be determined by a 
comprehensive and detailed look at the monitoring records to evaluate the situation with respect to background trends. Schedules need to be flexible enough to accommodate slow equilibration.

Also, the BE analysis was hampered by the short records collected and by the fact that these records were collected when the well was still equilibrating from previous pumping. The lack of a record incorporating the response to a significant barometric pressure change precluded determining the $\mathrm{BE}$ accurately.

\subsubsection{Background Well Monitoring Record}

A substantial improvement in the processing of the drawdown monitoring record to determine the actual drawdown response can be provided by the use of a contemporaneous record from a background well to remove background-water-level trends, earth tides, and other non-specific noise in the testing drawdown record. However, background records recorded in nearby wells during testing of this well are insufficient because they do not cover the entire period of testing, including pre- and post-test monitoring. Monitoring of a background well during testing should be considered for future testing programs to improve the test analysis quality. The background well should be selected with particular attention to the appropriate location, completion, and representativeness of the formation response for application to the well to be tested. The record should start well before testing activities begin and extend past the completion of recovery monitoring for the test(s).

\subsubsection{Recovery Monitoring after the Constant-Rate Test}

This well did not recover head quickly from any of the production stresses, including the initial drilling, and the various tests were begun before recovery from previous testing was complete. This was particularly true of the constant-rate test, which was started from a recovery curve following well development. Within the development program, the step-drawdown tests were started in the middle of recoveries. This situation requires that the previous stress history be included in the analyses, which significantly complicated the overall analysis and introduced additional uncertainty. In the case of ER-12-3, the ambient head is not known as of this report because the well has never been in apparent equilibrium following drilling. 


\subsection{Further Testing}

The testing program produced results that are not definitive, but indicate that the separate fracturing intervals in the LCA3 have considerably different hydraulic characteristics, and that there may be significant differences in hydraulic head between the overlying volcanic formation and within the LCA3. This may have implications for contaminant transport from the overlying tunnels to the regional carbonate aquifer worth investigation. Additional testing of ER-12-3 would provide information useful in further characterizing the hydrology. Pumping the well at several rates greater than those used for the testing program, with associated water-level monitoring and flow/temperature logging, would provide data to characterize the situation more completely.

\subsection{Use of ER-12-3 for Monitoring}

The ER-12-3 completion is well connected to the formation and provides good water-level-monitoring capability for the LCA3. However, as discussed in Section 3.3.2, the different fracture intervals within the LCA3 appear to have substantially different heads, and the heads cannot be determined independently but only inferred from analysis of the hydraulic responses. The measured head is a transmissivity-weighted composite of the heads for the three intervals and must be interpreted in this context. The ER-12-3 piezometer also provides water-level-monitoring capability for the volcanic formation above the LCA3.

Based on the flow interpretation in Sections 2.2 and 3.3, there are two widely separated depth intervals from which groundwater is produced with the installed pump for water-quality determination. However, due to the well construction, these two intervals cannot be sampled separately. The water produced into the completion casing during pumping is a composite of the two different intervals. The water from the middle fracture interval could be sampled separately downhole using a discrete bailer at a depth, based on inference from the flow and temperature logs, below the inflow from the upper fracture interval. This well should provide suitable monitoring capability for LCA3 water quality in this location as well as water-level trends in the LCA3. There is no evidence that the formation in the well completion is not representative of the LCA3 in this area nor that the groundwater quality of the samples is not representative. 
However, as noted, there is substantial flow in this well from the middle fracturing interval to the upper fracturing interval under the natural gradient, so groundwater derived from the upper fracturing interval in the future would probably mostly reflect the water quality of the middle fracturing interval. There is no apparent way of sampling water from the lower fracturing interval, which is receiving water from the middle fracturing interval continuously, even during pumping.

\subsection{Summary}

This document presents the analysis of data for ER-12-3. The water levels measured during the testing program served to define the formation pressure used for analysis of the constant-rate test but are not indicative of a stable, representative head. The hydraulic test analysis provides an interpretation of the transmissivity of the well completion interval for the LCA3. However, an average value for K over the completion interval of LCA3 is left for the user to determine to suit the particular requirements for use of the $\mathrm{K}$ value due to the complicated production situation in the well. Values of $\mathrm{K}$ representative of the different production intervals identified in the completion interval, which would reflect the higher $\mathrm{K}$ values of the fractured intervals, could be roughly determined based on estimates of the head distribution in the borehole and the flow rates for the different intervals. 


\subsection{REFERENCES}

ASME, see American Society of Mechanical Engineers.

American Society of Mechanical Engineers. 1990. Quality Assurance Requirements of Computer Software for Nuclear Facility Applications, ASME NQA-2a-1990 addenda, Part 2.7. New York, NY.

Bredehoeft, J.D., and S.S. Papadopulos. 1980. "A Method for Determining the Hydraulic Properties of Tight Formations.” In Water Resources Research, v. 16(1): 233-238.

Cooper, H.H., Jr., J.D. Bredehoeft, and S.S. Papadopulos. 1967. "Response of a Finite-Diameter Well to an Instantaneous Charge of Water." In Water Resources Research, v. 3(1): 263-269.

Craig, H. 1961. “Isotopic Variations in Meteoric Waters.” In Science, v. 133: 1702-1703. Washington, DC: American Association for the Advancement of Science.

DOE/NV, see U.S. Department of Energy, Nevada Operations Office.

Fabryka-Martin, J., S.J. Wightman, W.J. Murphy, M.P. Wickham, M.W. Caffee, G.J. Nimz, J.R. Southon, and P. Sharma. 1993. Distribution of Chlorine-36 in the Unsaturated Zone at Yucca Mountain: An Indicator of Fast Transport Paths. Paper presented at FOCUS '93 Site Characterization and Model Validation. Las Vegas, NV.

Horne, R.N. 1995. Modern Well Test Analysis. Palo Alto, CA: Petroway, Inc.

Ingraham, N.L., R.L. Jacobson, B.F. Lyles, and J.W. Hess. 1990. Stable Isotopic Study of Precipitation and Spring Discharge on the Nevada Test Site, Publication No. 45078; DOE/NV/10845-03. Las Vegas, NV: Desert Research Institute.

LLNL, see Lawrence Livermore National Laboratory.

Lawrence Livermore National Laboratory. 2003. Letter Report to Robert Bangerter: "Isotopic Analyses: Environmental Monitoring Well ER-12-2,” 28 September.

Lawrence Livermore National Laboratory. 2006. Letter Report to Bill Wilborn: "Isotopic Analyses: Environmental Monitoring Well ER-12-3,” 28 September. 
Leavitt, A. 2005. Formation Image Interpretation Report, Bechtel Nevada, Well: ER-12-3, Nevada Test Site, Nye County, Nevada.

Lohman, S.W. 1972. Ground-Water Hydraulics, Professional Paper 708. U.S. Geological Survey.

NNSA/NSO, see National Nuclear Security Administration Nevada Site Office.

Oberlander, P.L., and C.E. Russell. 2005. Borehole Flow and Horizontal Hydraulic Conductivity with Depth at Well ER-12-3, DOE/NV13609-LTR2005-00228. Las Vegas, NV.

Pickens, J.F., G.E. Grisak, J.D. Avis, D.W. Belanger, and M. Thury. 1987. “Analysis and Interpretation of Borehole Hydraulic Tests in Deep Boreholes: Principles, Model Development, and Applications.” In Water Resource Research, v. 23(7): 1341-1375. Washington, DC: American Geophysical Union.

Roberts, R.M., R.L. Beauheim, and P.S. Domski. 1999. Hydraulic Testing of Salado Formation Evaporites at the Waste Isolation Pilot Plant Site: Final Report, SAND98-2537. Albuquerque, NM: Sandia National Laboratories.

Rose, T.P., F.C. Benedict, Jr., J.M. Thomas, W.S. Sicke, R.L. Hershey, J.B. Paces, I.M. Farnham, and Z.E. Peterman. 2002. Written communication. Subject: Geochemical Data Analysis and Interpretation of the Pahute Mesa-Oasis Valley Groundwater Flow System, Nye County, Nevada. Livermore, CA: Lawrence Livermore National Laboratory. Reno, NV: Desert Research Institute and HSI GeoTrans. Denver, CO: U.S. Geological Survey. Las Vegas, NV: Harry Reid Center for Environmental Studies, University of Nevada.

Russell, C.E. 1987. Hydrogeologic Investigations of Flow in Fractured Tuffs, Rainier Mesa, Nevada Test Site. Masters Thesis. Las Vegas, NV: Department of Geoscience, University of Nevada Las Vegas.

SNJV, see Stoller-Navarro Joint Venture.

Stoller-Navarro Joint Venture. 2005a. Geochem05.mdb and a User's Guide to the Comprehensive Water Quality Database for Groundwater in the Vicinity of the Nevada Test Site, S-N/99205--059. Las Vegas, NV.

Stoller-Navarro Joint Venture. 2005b. Rainier Mesa-Shoshone Mountain Hydrogeologic Investigation Wells Drilling and Completion Criteria, S-N/99205--038. Las Vegas, NV.

Stoller-Navarro Joint Venture. 2005c. Written communication. Subject: Rainier Mesa ER-12-3 Well Data Report. Las Vegas, NV.

Stoller-Navarro Joint Venture. 2006a. Geochemical and Isotopic Evaluation of Groundwater Movement in Corrective Action Unit 97: Yucca Flat/Climax Mine, Nevada Test Site, Nevada, Rev. 0, S-N/99205--070. Las Vegas, NV. 
Stoller-Navarro Joint Venture. 2006b. Written communication. Subject: Rainier Mesa Well ER-12-3 Data Report for Well Development and Hydraulic Testing. Las Vegas, NV.

Theis, C.V. 1935. “The Relation Between the Lowering of the Piezometric Surface and the Rate and Duration of Discharge of a Well Using Groundwater Storage.” In Trans Amer. Geophys. Union, v. 2: 519-524.

USGS, see U.S. Geological Survey.

USGS/DOE, see U.S. Geological Survey and U.S. Department of Energy.

U.S. Department of Energy, Nevada Operations Office. 2000. United States Nuclear Tests, July 1945 through September 1992, DOE/NV--209, Rev. 15. Las Vegas, NV.

U.S. Department of Energy, National Nuclear Security Administration Nevada Site Office. 2006. Completion Report for Well ER-12-3 Corrective Action Unit 99: Rainier Mesa - Shoshone Mountain, DOE/NV/11718--1182. Las Vegas, NV.

U.S. Geological Survey and U.S. Department of Energy. 2006. Download of ER-12-3 main, ER-12-3 piezometer, and ER-12-1 (1,641-1,846 ft) water-level monitoring data and graphs. As accessed at http://nevada.usgs.gov/doe_nv/sitepage_temp.cfm?site_id=371142116125102 (ER-12-3 main), http://nevada.usgs.gov/doe_nv/sitepage_temp.cfm?site_id=371142116125101 (ER-12-3 piezometer), and http://nevada.usgs.gov/doe_nv/sitepage_temp.cfm?site_id=371106116110401 (ER-12-1), on 6 April. 
Appendix A

EMI Logs Containing Deviation Information for ER-12-3 


\section{A.1.0 Wellbore Deviation Surveys}

A specific wellbore deviation survey has not been run in this well; however, the EMI logs contain some information on deviation. The EMI logs include a drift-angle measurement at each depth station for the depth range of the log. These logs start at a depth of 2,400 ft bgs and continue to TD. Consequently, there is no information on borehole deviation above 2,400 ft bgs. Both logs indicate low deviation from vertical at 2,400 ft bgs, which steadily increases to about 21 degrees at TD. This represents substantial deviation, and the correction for true vertical depth and bottom-hole location at TD would be significant. At the static water level, about 3,113 ft bgs measured depth, the deviation is about 5.5 degrees. A correction for true vertical depth from 2,400 ft bgs to 3,113 ft, based on the deviation measurements in the file EMI-2_CA6-3_GR-8.las, is about $1.05 \mathrm{ft}$, which is greater than the criteria of $0.5 \mathrm{ft}$ used by the USGS for inclusion in the reported depth to water.

Table A.1-1 shows electronic files of two EMI logs, which have been included on the CD in text format.

Table A.1-1

EMI Logs with Borehole Deviation Information

\begin{tabular}{||c|c|c||}
\hline File Name & $\begin{array}{c}\text { Depth Range } \\
\text { (ft amsl) }\end{array}$ & $\begin{array}{c}\text { Deviation Range } \\
\text { (Degrees from north) }\end{array}$ \\
\hline \hline EMI-2_CA6-3_GR-8.las & $2,400-4,918$ & $0.0253-21.2032$ \\
\hline EMI-3_CA6-4_GR-14.las & $2,400-4,920$ & $0.6232-18.4081$ \\
\hline
\end{tabular}




\section{DISTRIBUTION}

Bill R. Wilborn

Environmental Restoration Project

U.S. Department of Energy

National Nuclear Security Administration

Nevada Site Office

P.O. Box 98518, MS/505

Las Vegas, NV 89193-8518

Alicia Tauber

Environmental Management Records

U.S. Department of Energy

National Nuclear Security Administration

Nevada Site Office

P.O. Box 98518, MS/505

Las Vegas, NV 89193-8518

U.S. Department of Energy

National Nuclear Security Administration

Nevada Site Office

Technical Library

P.O. Box 98518, M/S 505

Las Vegas, NV 89193-8518

U.S. Department of Energy

Office of Scientific and Technical Information

P.O. Box 62

Oak Ridge, TN 37831-0062

Southern Nevada Public Reading Facility

c/o Nuclear Testing Archive

P.O. Box 98521, M/S 400

Las Vegas, NV 89193-8521

Manager, Northern Nevada FFACO

Public Reading Facility

c/o Nevada State Library \& Archives

100 N Stewart Street

Carson City, NV 89701-4285
$2 \mathrm{HC} / 2 \mathrm{CD}$

$1 \mathrm{HC} / 1 \mathrm{CD}$
$1 \mathrm{CD}$

$2 \mathrm{HC} / 2 \mathrm{CD}$

$1 \mathrm{HC} / 1 \mathrm{CD}$ 
Naomi Becker

$1 \mathrm{CD}$

Los Alamos National Laboratory, M/S F665

Bikini Atoll Rd., SM30

Los Alamos, NM 87545

P. W. Reimus

$1 \mathrm{CD}$

Los Alamos National Laboratory, M/S J534

Bikini Atoll Rd., SM30

Los Alamos, NM 87545

Gayle Pawloski

$1 \mathrm{CD}$

Lawrence Livermore National Laboratory

7000 East Avenue, L-221

Livermore, CA 94550-9234

Mavrik Zavarin

$1 \mathrm{CD}$

Lawrence Livermore National Laboratory

7000 East Avenue, L-221

Livermore, CA 94550-9234

R. M. Maxwell

$1 \mathrm{CD}$

Lawrence Livermore National Laboratory

7000 East Avenue, L-208

Livermore, CA 94550-9234

Bonnie Thompson

$1 \mathrm{CD}$

U. S. Geological Survey

160 North Stephanie Street

Henderson, NV 89074

R. P. Graves

$1 \mathrm{CD}$

U. S. Geological Survey

160 North Stephanie Street

Henderson, NV 89074

Chuck E. Russell

$1 \mathrm{CD}$

Desert Research Institute

755 E. Flamingo

Las Vegas, NV 89119

Ken Ortego

$1 \mathrm{CD}$

Bechtel Nevada

P.O. Box 98521, M/S NLV 082

Las Vegas, NV 89193-8521 
Sig Drellack

$1 \mathrm{CD}$

Bechtel Nevada

P. O. Box 98521, M/S NLV 082

Las Vegas, NV 89193-8521

John P. McCord

$1 \mathrm{CD}$

Stoller-Navarro Joint Venture

7710 W. Cheyenne, Bldg. 3

Las Vegas, NV 89129

Greg Ruskauff

$1 \mathrm{CD}$

Stoller-Navarro Joint Venture

7710 W. Cheyenne, Bldg. 3

Las Vegas, NV 89129

Jeff Wurtz

$1 \mathrm{CD}$

Stoller-Navarro Joint Venture

7710 W. Cheyenne, Bldg. 3

Las Vegas, NV 89129

Irene Farnham

$1 \mathrm{CD}$

Stoller-Navarro Joint Venture

7710 W. Cheyenne, Bldg. 3

Las Vegas, NV 89129

Bill Fryer

$1 \mathrm{CD}$

Stoller-Navarro Joint Venture

990 S. Public, Suite A

Lafeyette, CO 80026

Stoller-Navarro Joint Venture

$1 \mathrm{HC} / 1 \mathrm{CD}$

Central Files

7710 W. Cheyenne, Bldg. 3

Las Vegas, NV 89129

Public Reading Facility Coordinator

$1 \mathrm{HC} / 1 \mathrm{CD}$

Stoller-Navarro Joint Venture

7710 W. Cheyenne, Bldg. 3

Las Vegas, NV 89129 